UNIVERSIDAD NACIONAL DEL CENTRO DEL PERÚ ESCUELA DE POSGRADO FACULTAD DE EDUCACIÓN

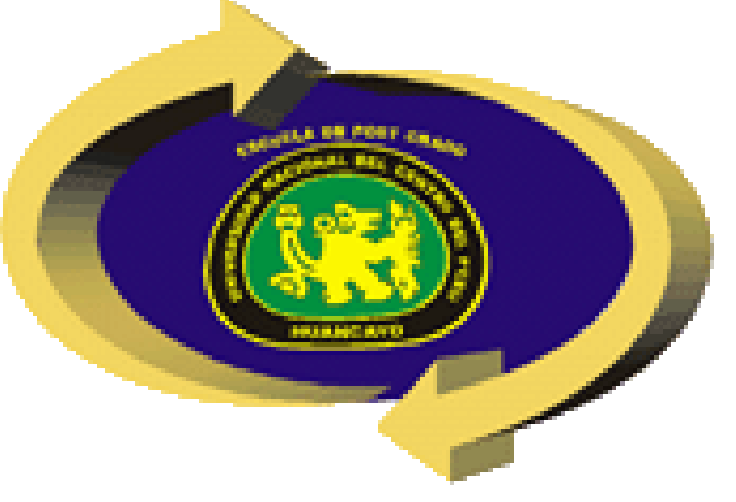

\title{
RÚBRICA Y DESEMPEÑO DOCENTE EN LA PROVINCIA DE HUANCAYO
}

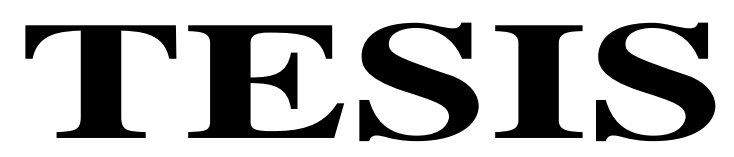

PRESENTADA POR:

JUAN CARLOS CÁRDENAS VALVERDE

PARA OPTAR EL GRADO ACADÉMICO DE:

DOCTOR EN EDUCACIÓN

MENCIÓN: CIENCIAS DE LA EDUCACIÓN

HUANCAYO - PERÚ

2015 


\title{
UNIVERSIDAD NACIONAL DEL CENTRO DEL PERÚ ESCUELA DE POS GRADO DE LA FACULTAD DE EDUCACIÓN
}

\author{
TESIS \\ PRESENTADA POR: \\ JUAN CARLOS CÁRDENAS VALVERDE
}

PARA OPTAR EL GRADO DE DOCTOR

SUSTENTADA ANTE EL SIGUIENTE JURADO:

Dr. Moya Rojas, Nicanor

Dr. Victor Hugo Martel Vidal Jurado
Dr. Amador G. Vilcatoma Sánchez Jurado
Dr. Luis Orlando Huaytalla Torres Jurado
Dr. Jesús Tello Yance Jurado 


\section{ASESOR:}

Doctor Nicanor Moya Rojas 
A Giovanna, por su entrega inconmensurable a la familia.

A Jean y Kimberly, por iniciar sus sueños profesionales.

A Carolina y Edgar, dignos representantes de esfuerzo y vehemencia.

A los investigadores y científicos; por su inconmensurable y vehemente aporte al conocimiento.

Juan Carlos. 


\section{AGRADECIMIENTO}

A Juan e Isidora, por darme la vida e iniciarme en este sueño.

A Giovanna, Jean y Kimberly por tolerar mis ausencias paternas y compartir este sueño.

A Nicolás, Arturo, Antonio y Alfonso, por incentivar, establecer y perfeccionar las estrategias para soñar.

A la Congregación Salesiana, por permitir que este sueño, no solo sea un deseo, sino una orden hermosa de desarrollo humano inspirado por el corazón de Don Bosco.

A los docentes de la IEP Salesiano Santa Rosa de Huancayo, por su motivación en la consecución de muchos sueños que comienzan a diario; desde sus aulas.

A los señores catedráticos del Doctorado en Ciencias de la Educación de la Facultad de Educación de la Unidad de Post Grado de la Universidad Nacional del Centro del Perú: por sus valiosas enseñanzas y dilucidar la epistemología del sueño.

A todos los que sueñan para transformar el mundo.

Juan Carlos. 


\section{ÍNDICE}

Portada.

Hoja de sustentación

Asesor.

Dedicatoria.

iv

Agradecimiento.

Índice del documento.

Índice de cuadros.

Índice de tablas.

Índice de gráficos.

Resumen.

Abstract. $\mathrm{XV}$

Sintesi. $x v i$

Introducción.

$x v i i$

\section{CAPÍTULO I \\ FUNDAMENTOS TEÓRICOS}

1.1. Antecedentes de la investigación.

1.1.1. A nivel internacional.

1.1.2. A Nivel nacional. 22

1.1.3. A nivel local. 23

1.2. Bases teóricas que fundamentan la investigación. 23

1.2.1. Requisitos de la evaluación. 24

1.2.2. Condiciones de una evaluación. 24 
1.2.3. El agente evaluador.

1.2.4. Clasificación de los instrumentos de evaluación. 25

1.2.5. Evaluación alternativa en la sociedad del conocimiento. 25

1.3. Bases conceptuales. 25

1.3.1. La rúbrica. $\quad 25$

1.3.1.1. Etimología. $\quad 25$

1.3.1.2. Definición. $\quad 26$

1.3.1.3. Importancia de las rúbricas. $\quad 28$

1.3.1.4. Características de las rúbricas. 28

1.3.1.5. Partes de una rúbrica. 28

1.3.1.6. Categorías de calificación de una rúbrica $\quad 29$

1.3.1.7. Funciones de la rúbrica. $\quad 30$

1.3.1.8. Ventajas del uso de las rúbricas. $\quad 30$

1.3.1.9. Desventajas del uso de las rúbricas. 31

1.3.1.10. Clases de rúbricas. 32

a) Comprehensiva, global u holística 32

b) Comprehensiva analítica 32

1.3.1.11. ¿Cómo hacer una rúbrica? 33

1.3.1.12. Criterios para perfeccionar una rúbrica. 34

1.3.2. Desempeño docente. 34

1.3.2.1. Definición. 34

1.3.2.2. La docencia y la escuela que queremos. 35

1.3.2.3. ¿Qué debe saber el buen docente? 35

1.3.2.4. ¿Cómo debe actuar el buen docente? 36

1.3.2.5. ¿Para qué evaluar el desempeño docente? 36

1.3.2.6. Funciones de la evaluación del desempeño docente. 37

1.3.2.7. Desafíos en la formación docente. 37

1.3.2.8. ¿Cómo entender la evaluación docente? 37

1.3.2.9. ¿Qué resultados debe lograr el buen 37

docente en su práctica profesional? 38

1.3.2.10. Dimensiones de la docencia propuestos por del MBDD. 38

a) Dimensión pedagógica. 38 
b) Dimensión cultural 38

c) Dimensión política. 38

1.3.2.11. Propósitos de la docencia propuestos por el MBDD 39

1.3.2.12. Los dominios que propone el MBDD. 39

1.3.2.13. Las 9 competencias que propone el MBDD 40

1.3.2.14. Los desempeños que propone el MBDD. 41

1.3.2.15. Dimensiones del desempeño docente en el aula 42

1.3.2.16. Indicadores del desempeño docente en el aula.

a) Planificación. $\quad 42$

b) Metodología. $\quad 42$

c) Evaluación. 42

d) Clima para el aprendizaje. 42

e) Tiempo en el aula. 42

f) Recursos y materiales. 42

1.3.2.17. Procedimientos de evaluación del desempeño docente.

\section{CAPÍTULO II HIPÓTESIS}

2.1. Hipótesis de investigación. 43

2.1.1 Hipótesis general. 43

2.1.2. Hipótesis específicas. 43

2.2. Variables e indicadores. 44

2.2.1. Variables. $\quad 44$

a) Variable Independiente. 44

b) Variable Dependiente.

C) Intervinientes. 44

2.2.2. Operacionalización de las variables $\quad 44$

a) Variable Independiente: Rúbrica. 44

b) Variable Dependiente: Desempeño 
docente en la provincia de Huancayo.

2.2.3. Escala de medición.

\section{CAPÍTULO III \\ METODOLOGÍA}

3.1. Tipo de investigación. $\quad 47$

3.2. Nivel de investigación. 47

3.3. Métodos de investigación. $\quad 47$

3.3.1. Método General. $\quad 47$

3.3.2. Métodos particulares. $\quad 48$

3.4. Diseño de investigación. 48

3.5. Población y muestra. $\quad 49$

3.5.1. Población. $\quad 49$

3.5.2. Muestra. $\quad 50$

a) Determinación del tamaño de muestra. 50

3.5.3. Tipo demuestra. 52

3.6. Técnicas e instrumentos de recolección de datos 52

3.6.1. Técnicas. 52

3.6.2. Instrumentos. $\quad 52$

3.6.3. Validación y confiabilidad del instrumento. 52

I. Evaluación de la validez 52

1.1. Validez subjetiva $\quad 55$

1.2. Validez objetiva. $\quad 57$

II. Evaluación de la confiabilidad 58

3.7. Procedimientos de recolección de datos. 59

3.8. Técnicas de procesamiento y análisis de resultados. 59

\section{CAPÍTULO IV \\ PRESENTACIÓN Y ANÁLISIS DE RESULTADOS}

4.1. Presentación, análisis e interpretación de los datos. 62

4.1.1. Desempeño docente de los profesores 62

4.1.1.1. Desempeño docente de los profesores, 75 
por sexo

4.1.1.2. Desempeño docente de los profesores, por edad

4.1.1.3. Desempeño docente de los profesores, por nivel.

4.2. Contrastación estadística de la hipótesis de investigación

4.2.1. Contrastación estadística del Desempeño docente de los profesores.

4.2.2. Contrastación estadística de las dimensiones del desempeño docente de los profesores.

\section{CAPÍTULO V DISCUSIÓN}

5.3. Discusión de resultados.

5.2. Aportes teóricos o metodológicos.

5.3. Aportes institucionales o adopción de decisiones.

CONCLUSIONES.

SUGERENCIAS.

REFERENCIA BIBLIOGRÁFICA.

\section{ANEXOS.}

- Matriz de consistencia de la Investigación

- Validación por juicio de expertos de la rúbrica de autoevaluación del monitoreo, acompañamiento y supervisión de la sesión de clase.

- Rúbrica de autoevaluación del monitoreo, acompañamiento y supervisión de la sesión de clase.

- Programa de aplicación de la rúbrica en el desarrollo del desempeño docente.

- Fotografías de la aplicación. 


\section{ÍNDICE DE CUADROS}

Cuadro $N^{\circ} 01$. Validez subjetiva de los ítems por juicio de expertos con la t de Student

Cuadro $\mathrm{N}^{\circ}$ 02. Correlaciones $r$ de Pearson corregidas ítem-test (30 ítems)

Cuadro $\mathrm{N}^{\circ}$ 03. Estadísticos de Fiabilidad

Cuadro $N^{\circ} 04$. Valoración de los ítems del cuestionario de desempeño docente $(n=751)$

Cuadro $N^{\circ} 05$. Estadísticos del desempeño docente de los profesores $(n=751)$

Cuadro $N^{\circ} 06$. Nivel del desempeño docente de los profesores $(n=751)$

Cuadro $N^{\circ} 07$. Estadísticos del desempeño docente de los profesores, por sexo

Cuadro $N^{\circ} 08$. Nivel del desempeño docente de los profesores, por sexo

Cuadro $N^{\circ} 09$. Estadísticos del desempeño docente de los profesores, por edad

Cuadro $N^{\circ} 10$. Nivel del desempeño docente de los profesores, por edad

Cuadro $N^{\circ} 11$. Estadísticos del desempeño docente de los profesores, por nivel Índice de tablas

Cuadro $N^{\circ} 12$. Nivel del desempeño docente de los profesores, por nivel

Cuadro No 13. Chi cuadrado del Desempeño Docente

Cuadro No 14. Estadísticos de Contraste - Desempeño Docente

Cuadro $N^{\circ} 15$. Evaluación de la significación estadística de las medias de las dimensiones del desempeño docente

Cuadro $\mathrm{N}^{\circ} 16$. Prueba chi cuadrada para la igualdad de proporciones - Planificación

Cuadro $N^{\circ} 17$. Estadísticos de contraste - Planificación

Cuadro № 18. Evaluación de la significación estadística de las proporciones de las dimensiones del desempeño 


\section{ÍNDICE DE TABLAS}

Tabla Nº 01. Taxonomía cognitiva de Louis D’hainaut 24

Tabla $\mathrm{N}^{\circ} 02$. Ventajas del uso de las rúbricas 30

Tabla $N^{\circ}$ 03. Matriz de consistencia de la variable independiente Índice de gráficos $\quad 45$

Tabla $N^{\circ}$ 04. Matriz de consistencia de la variable dependiente 45

Tabla № 06. Resumen de las características de la muestra 50

\section{ÍNDICE DE GRÁFICOS}

Gráfico N 01. Clasificación de los instrumentos de evaluación 25

Gráfico No 02. Esquema general de una rúbrica 29

Gráfico №3. Modelo de rúbrica holística para evaluar la planificación de la sesión de clases

Gráfico № 04. Modelo de rúbrica analítica para evaluar un trabajo Colaborativo 33

Gráfico N 05. Dominios del Marco de Buen Desempeño Docente 39

Gráfico Nº6. Región de rechazo y aceptación de Ho 54

Gráfico № 07. Valoración de los ítems del cuestionario de desempeño docente $(n=751) \quad 64$

Gráfico $N^{\circ}$ 08. Desempeño docente de Planificación 66

Gráfico Nº9. Desempeño docente de Metodología 66

Gráfico N 10. Desempeño docente de Evaluación 67

Gráfico No 11. Desempeño docente de Clima para el Aprendizaje 67

Gráfico № 12. Desempeño docente de Tiempo en el aula 68

Gráfico No 13. Desempeño docente de Recursos y Materiales 68

Gráfico No 14. Resultados del Desempeño docente 69

Gráfico №15. Medias teóricas y reales de las dimensiones del desempeño docente 69

Gráfico № 16. Nivel de desempeño en: Planificación. 71

Gráfico № 17. Nivel de desempeño en: Metodología. 72 
Gráfico N 18. Nivel de desempeño en: Evaluación. 72

Gráfico № 19. Nivel de desempeño en: Clima para el Aprendizaje. 73

Gráfico № 20. Nivel de desempeño en: Recursos y Materiales. 73

Gráfico № 21. Nivel de desempeño en general. 74

Gráfico $N^{\circ}$ 22. Media del Desempeño Docente de los profesores, por sexo $\quad 75$

Gráfico $N^{\circ}$ 23. Medias de las Dimensiones del desempeño docente, por sexo $\quad 76$

Gráfico № 24. Nivel de desempeño docente de los profesores, por sexo

Gráfico №25. Media del desempeño docente de los profesores, por edad 80

Gráfico $N^{\circ} 26$. Medias de las dimensiones del desempeño docente por edad

Gráfico № 27. Nivel de desempeño docente delos profesores, por nivel

Gráfico № 28. Medias de las dimensiones del desempeño docente, por nivel

Gráfico $N^{\circ} 29$. Nivel de desempeño docente de los profesores, por nivel

Gráfico $N^{\circ}$ 30. Nivel de desempeño docente de los profesores, por nivel

Gráfico No 31. Prueba Z de Gauss para una media Desempeño Docente

Gráfico $N^{\circ}$ 32. Prueba $Z$ de Gauss para una media Planificación 


\section{RÚBRICA Y DESEMPEÑO DOCENTE EN LA PROVINCIA DE HUANCAYO}

\section{RESUMEN}

La investigación comenzó con la interrogante: ¿Cuál es la influencia de la rúbrica en el desarrollo del desempeño docente de los profesores de la provincia de Huancayo? El objetivo fue: Determinar la influencia de la rúbrica en el desarrollo del desempeño docente de los profesores de la provincia de Huancayo. La hipótesis fue: La aplicación de la rúbrica tiene influencia positiva en el desarrollo del desempeño docente de los profesores de la provincia de Huancayo. La investigación fue de tipo aplicativa, ya que se aplicó la rúbrica para el desarrollo del desempeño docente. Los métodos fueron: científico, descriptivo, experimental y estadístico. El diseño de investigación fue de un solo grupo solo después. La población estuvo conformada por los docentes de las instituciones educativas de la provincia de Huancayo y la muestra, por algunos docentes de dichas instituciones. Las técnicas de recopilación de datos empleadas fueron: observación, encuesta y fichaje. En las técnicas de procesamiento y análisis de datos se utilizó: la estadística descriptiva e inferencial. La conclusión es: La aplicación de la rúbrica tiene influencia positiva en el desarrollo del desempeño docente de los profesores de la provincia de Huancayo.

\section{Palabras clave:}

Rúbrica, Desempeño Docente, Provincia de Huancayo. 


\section{RUBRIC AND TEACHER PERFORMANCE IN THE PROVINCE OF HUANCAYO}

\section{ABSTRACT}

The research began with the question: What is the influence of the rubric in the development of teaching performance of teachers in the province of Huancayo? The objective was: To determine the influence of the rubric in the development of teaching performance of teachers in the province of Huancayo. The hypothesis was: The application of the rubric has positive influence on the development of teaching performance of teachers in the province of Huancayo. The research was applicative type since rubric for the development of teacher performance was applied. The methods were: scientific, descriptive, experimental and statistical. The research design was a single group only later. The population consisted of teachers in the educational institutions of the province of Huancayo and displays by some teachers of these institutions. The data collection techniques used were: observation, survey and signing. In processing techniques and data analysis were used: descriptive and inferential statistics. The conclusion is: The application of the rubric has positive influence on the development of teaching performance of teachers in the province of Huancayo.

\section{Keywords:}

Rubric, Teacher Performance, Province of Huancayo. 


\section{RUBRICA E RENDIMENTO DEGLI INSEGNANTI NELLA PROVINCIA DI HUANCAYO}

\section{SINTESI}

La ricerca è iniziata con la domanda: Qual è l'influenza della rubrica dell'insegnamento delle prestazioni degli insegnanti in provincia di Huancayo? L'obiettivo era quello di determinare l'influenza della rubrica dell'insegnamento delle prestazioni degli insegnanti, in provincia di Huancayo. L'ipotesi era: L'applicazione della rubrica ha influenza positiva di insegnare prestazioni docenti nella provincia di Huancayo. La ricerca è stata di tipo applicativo in quanto rubrica delle prestazioni degli insegnanti è stato applicato. I metodi sono: scientifico, descrittiva, sperimentale e statistico. II progetto di ricerca è stato un singolo gruppo solo più tardi. La popolazione era costituita da insegnanti delle istituzioni scolastiche della provincia di Huancayo e mostra da alcuni insegnanti di queste istituzioni. Le tecniche di raccolta dei dati utilizzati sono stati: l'osservazione, l'indagine e la firma. In tecniche di elaborazione e analisi dei dati sono stati utilizzati: statistica descrittiva e inferenziale. La conclusione è: L'applicazione della sezione ha influenza positiva rubrica di insegnare le prestazioni degli insegnanti, in provincia di Huancayo.

\section{Parole chiave:}

Rubrica, rendimento degli insegnanti, Provincia di Huancayo. 


\section{INTRODUCCIÓN}

Señor Presidente, señores miembros del jurado examinador.

Presento a vuestra consideración y alto espíritu académico, el trabajo de investigación, en la modalidad de Tesis, titulada: Rúbrica y desempeño docente en la provincia de Huancayo, que se realizó con la finalidad de optar el grado académico de Doctor en educación: Mención: Ciencias de la educación.

Cardó, A. (2010) manifiesta que el fracaso o el éxito de todo sistema educativo depende fundamentalmente de la calidad del desempeño de sus docentes; esa calidad que debe demostrar en el desarrollo de su clase y en el desarrollo de las capacidades, destrezas y habilidades de sus alumnos.

De la misma manera el desempeño docente, a decir de OREALCUNESCO (2007) es un conjunto de características, competencias y conductas de los docentes, que permiten a los estudiantes alcanzar los resultados deseados, que pueden incluir el logro de objetivos de aprendizajes específicos, además de objetivos más amplios como la capacidad de resolver problemas, pensar críticamente, trabajar colaborativamente y transformarse en ciudadanos efectivos. En ese sentido, el desempeño docente es el conjunto de pensamientos, valores, actitudes, emociones, cultura, teorías implícitas que se traducen en actuaciones y relaciones con los otros y el entorno; que se lleva a cabo en el marco de su responsabilidad y contrato social.

Por otro lado Hernández, C. (2009) afirma que el docente debe conocer el contenido de lo que enseñanza y el modo cómo ese contenido puede tener sentido para sus alumnos, saber hablar en un lenguaje comprensible y promover el diálogo con los estudiantes, que implica saber comunicar y generar comunicación, mostrar y entregar lo que tiene y quiere plantear estableciendo 
reglas claras en su relación con los estudiantes y estar dispuesto a discutir esas reglas. La relación docente - estudiante, es una relación dialógica, de entendimiento. De ahí la necesidad de ser un buen comunicador. Ha de tener también una base de conocimientos interdisciplinarios, un soporte socio afectivo y un inquebrantable compromiso ético que le permitan comprender y reconocer los sentidos y significados de su actuación.

Aylwin, M. (2001) manifiesta que la diversidad de capacidades que requiere un docente no se limita a un mero desafío cognitivo. Es deseable una vocación y un compromiso afectivo con una tarea que es social y política, que tiene que ver con la formación de personas. Es un desafío contar con ciertas capacidades de manera convergente, como condición asociada al buen desempeño. Es decir, tan importantes como los conocimientos y las habilidades son las actitudes y las motivaciones. En el aula, su buen desempeño tiene que ver tanto con el diseño cuidadoso, la conducción responsable y la evaluación profunda de los procesos de aprendizaje, así como con la relación comunicativa y afectiva que establece con todos y cada uno de sus estudiantes.

Como vemos, el desempeño docente viene siendo un tema trabajado actualmente por el Ministerio de Educación. Sin embargo, no aporta con certidumbre a todas las variables que debe evaluarse. Quizás porque, no hay instrumentos que puedan evaluar realmente cada indicador del desempeño docente. Sin embargo la Rúbrica de evaluación, nos permitirá evaluar cada indicador del mismo.

El trabajo posee fundamentación teórica, pues la revisión bibliográfica que se presenta en la investigación permitirá a investigadores sobre el tema Rúbrica y Desempeño docente; a utilizar la información que presentamos. 0 sea, servirá de antecedente teórico a otras investigaciones y ayudará a comprender con mayor fortuna la inserción de la rúbrica a la educación, en especial a la autoevaluación desempeño docente.

Cabe mencionar que su fundamentación científica, recae en que la investigación, cuando se socialice, será marco teórico a nuestros pares, alumnos de pre y pos grado sobre este tema y radica su importancia en ello pues es necesario un cambio consiente de todos los agentes educativos (sociedad de entorno, padres de familia, alumnado, personal docente, 
administrativo y directivos) y su fundamentación epistémica dará las nociones preliminares de lo que vendrá a ser el marco teórico que permitirá conocer los pormenores de la rúbrica en nuestro idioma. No nos olvidemos que la fundamentación metodológica que trae consigo la rúbrica permite a los directores de la provincia de Huancayo de los colegios participantes, adecuar su trabajo de Gestión Docente al entrenamiento constante. Este entrenamiento permitió renovar lazos de amistad y familiaridad profesional entre los miembros de la comunidad docente de su centro educativo utilizando la rúbrica de autoevaluación del monitoreo, acompañamiento y supervisión de la sesión de clase.

Por lo mencionado, el trabajo responde a la interrogante: ¿Cuál es la influencia de la rúbrica en el desarrollo del desempeño docente de los profesores de la provincia de Huancayo? El objetivo logrado fue: Determinar la influencia de la rúbrica en el desarrollo del desempeño docente de los profesores de la provincia de Huancayo. La hipótesis fue: La aplicación de la rúbrica tiene influencia positiva en el desarrollo del desempeño docente de los profesores de la provincia de Huancayo.

La investigación fue de tipo aplicativa, debido a que se aplicó la rúbrica para el desarrollo del desempeño docente. Los métodos fueron: científico, descriptivo, experimental y estadístico. El diseño de investigación fue de un solo grupo solo después. La población estuvo conformada por los docentes de las instituciones educativas de la provincia de Huancayo y la muestra, por algunos docentes de dichas instituciones. Las técnicas fueron: observación, encuesta y fichaje. En las técnicas de procesamiento y análisis de datos se utilizó: la estadística descriptiva e inferencial.

Para una correcta lectura y entendimiento pertinente, el trabajo de investigación ha sido estructurado en cinco capítulos:

El capítulo I, se refiere al planteamiento del problema; en el que se aborda con detalle la caracterización del problema, formulación del problema, objetivos de la investigación, justificación e importancia, limitaciones de la investigación. El capítulo II, trata sobre el marco teórico; en el cual se dan a conocer los antecedentes de investigación: a nivel internacional, nacional y local, las bases teóricas que fundamentan la investigación, bases conceptuales, hipótesis y variables de investigación. El capítulo III, hace 
referencia a la metodología de la investigación, que aborda el tipo, nivel, métodos y diseño de investigación, población y muestra, técnicas, instrumentos y procedimientos de recolección de datos y técnicas de procesamiento de análisis de datos. El capítulo IV, trata sobre el análisis e interpretación de resultados, en el que se incluye la presentación y análisis de los datos, interpretación de los resultados, proceso de la prueba de hipótesis y discusión de resultados. El capítulo V, abarcan los aportes de la investigación, considerando aportes teóricos o metodológicos y aportes institucionales 0 adopción de decisiones.

Finalmente se presentan las conclusiones, sugerencias, referencia bibliográfica y los anexos respectivos.

Agradezco al Doctor Nicanor Moya Rojas (Asesor del trabajo), por sus constantes orientaciones para la culminación de la presente investigación, en las arduas sesiones interminables de trabajo de lectura crítica, acopio de información, revisión y consolidación de propuestas, como las que se presentan.

Juan Carlos Cárdenas Valverde 


\section{CAPÍTULO I FUNDAMENTOS TEÓRICOS}

\subsection{ANTECEDENTES DE LA INVESTIGACIÓN.}

\subsubsection{A nivel internacional.}

Torres, J. (2010) En la tesis de la Universidad de Sevilla-España podemos encontrar que la rúbrica supone -para el docente que la utiliza- una nueva forma de entender y de llevar a cabo los procesos de evaluación, a la vez que un mayor acercamiento por parte del estudiante a la función tutorial que éste desempeña.

Domínguez, M; Sánchez, L. y Aguilar, M, (2010) manifiestan en su tesis para la Universidad de del Estado de Morelos-México que: Se presenta una rúbrica para evaluar mapas conceptuales cuyo propósito es guiar la interpretación del docente en la evaluación de mapas conceptuales elaborados por alumnos universitarios a partir de la lectura de texto.

Flores, F. (2009) En la Tesis doctoral de la Universidad Complutense de Madrid-España manifiesta que: Las competencias que los profesores de educación básica movilizan en su desempeño profesional docente. Concluye: En el estudio desarrollado se considera como primer criterio el referido al dominio de los contenidos de las disciplinas y el marco curricular nacional, este se desglosó en seis descriptores que describen las competencias profesionales que el profesor pone en acción; las consideradas por el 60\% y más de la muestra que siempre la ponen en acción están: a) La consideración de los principios y conceptos de las disciplina que se enseña.

Cedeño, I. y otro (2008) mencionan que su trabajo de tesis, estuvo orientada a determinar el coaching como herramienta gerencial para optimizar 
el desempeño laboral del docente de la UNEFA, Núcleo Barquisimeto. Venezuela Este estudio se enmarcó en una investigación de campo, de modalidad descriptiva, cuyo objetivo se basó en determinar la situación actual del desempeño de los docentes y su conocimiento sobre las estrategias del coaching que pueden ser aplicables en el ámbito educativo.

Martínez, J. (2008) en la tesis de la Universidad Nacional de Colombia menciona que las rúbricas como instrumento de evaluación son perfectibles en tanto que las mismas constituyen una herramienta que se puede ir ajustando con la práctica hasta encontrar el valor justo de las metas de la evaluación a las cuales se espera llegar o se quiere que los estudiantes lleguen. También se puede afirmar que una rúbrica es una descripción de los criterios empleados para valorar o emitir un juicio sobre la ejecutoria de un estudiante en algún trabajo o proyecto.

\subsubsection{A Nivel nacional.}

Alan, A. (2014) en la tesis: Desarrollo de un sistema de gestión de evaluaciones basadas en rúbricas en cursos de proyectos universitarios de una carrera acreditada. Facultad de Ciencias e Ingeniería de la Pontificia Universidad Católica del Perú.

Romero, A. (2014) en la tesis: Evaluación del desempeño docente en una red de colegios particulares de Lima. Escuela de Posgrado de la Pontificia Universidad Católica del Perú, concluye: 1) En todas las Sub - variables, tanto los directores como los alumnos expresaron que el desempeño de sus docentes es "Alto" (superior a 89).

Flores, L. (2009) en la tesis: Rubrica para la evaluación de proyectos de tesis en Ingeniería Informática. Pontificia Universidad Católica del Perú. Facultad de Ciencias e Ingeniería. Especialidad de Ingeniería Informática. Concluye: La rúbrica abarca dos partes: la evaluación del informe escrito por el estudiante y su defensa oral del contenido del mismo ante un jurado designado.

Mendoza, R. (2009) en la tesis: El coaching y su aplicación en la Institución Educativa № 14344 Silahua-Frias-Ayabaca-Piura. Concluye que: a) Las organizaciones e instituciones educativas necesitan gente que pueda pensar por sí misma, que sea responsable de todo lo que ocurre en su centro educativo porque así lo sienten, porque así lo desean. 
Adriano, A. (2007) en la investigación "Clima organizacional y satisfacción laboral en las instituciones educativas del distrito de Satipo", concluye que: a) El clima organizacional y la satisfacción laboral en las instituciones educativas privadas es estable y persistente en las actividades y acciones que realizan los docentes en coordinación con los directivos a diferencia de las Instituciones Educativas públicas, el clima organizacional y la satisfacción es parcialmente estable.

\subsubsection{A nivel local.}

Cárdenas, J. (2011) en la tesis: Coaching y desempeño docente en la Provincia de Huancayo, de la Unidad de posgrado de la Facultad de Educación de la Universidad Nacional del Centro del Perú. Concluye: 1) La aplicación del coaching tiene influencia positiva en el desarrollo del desempeño docente de los profesores de la Provincia de Huancayo

Montalvo, M. (2008) en la tesis: Motivación y Desempeño Docente. Manifiesta que la motivación es el factor más importante del desempeño docente; lo que significa que el docente debe estar motivado psicológica, moral, económica, política, social y anímicamente para demostrar un desempeño docente pertinente y adecuado; esto se demuestra a partir de la experiencia de mejora de salarios de los docentes pertenecientes a la carrera pública magisterial.

\subsection{BASES TEÓRICAS QUE FUNDAMENTAN LA INVESTIGACIÓN.}

La evaluación educativa ha sido definida como el proceso a través del cual se recoge, analiza y emite juicios de valor sobre los aprendizajes logrados por los aprendices, con el propósito de tomar decisiones conducentes a la mejora de la calidad de esos aprendizajes.

Damián, L. (2007) sostiene que evaluar es una capacidad que consiste en valorar la interrelación entre el producto, el objetivo y el proceso. Como capacidad implica el desarrollo de ciertas destrezas concretas como diagnosticar, verificar, criticar y valorar entre otras. Diagnosticar, a su vez, supone poner en juego habilidades tales como examinar, apreciar, valorar, estimar, juzgar, etc. Se evalúa lo que se planifica y lo que se aprende y enseña. 
En ese sentido, la taxonomía cognitiva de Louis D’hainaut, que presentamos a continuación.

TABLA N 01

Taxonomía cognitiva de Louis D'hainaut

\begin{tabular}{|c|c|}
\hline CAPACIDAD & HABILIDADES \\
\hline 1. Reproducción & $\begin{array}{l}\text { Reproduce, cuenta, expresa, indica, nombra, } \\
\text { registra, cita, describe, relata, enumera, defina, } \\
\text { anota, lee, señala, enuncia, formula. }\end{array}$ \\
\hline 2. Conceptualización & $\begin{array}{l}\text { Localiza, relata, define, resume, clasifica, compara, } \\
\text { diferencia, describe, asocia, completa, informa, } \\
\text { ubica, explica, selecciona, ejemplifica, discute, } \\
\text { indica }\end{array}$ \\
\hline 3. Aplicación & $\begin{array}{l}\text { Agrupa, emplea, organiza, calcula, transforma, } \\
\text { relaciona, desarrolla, experimenta, grafica, resuelve, } \\
\text { usa diagrama. }\end{array}$ \\
\hline 4. Exploración & $\begin{array}{l}\text { Diferencia, descompone, relaciona, selecciona, } \\
\text { explica, separa, calcula, investiga, indaga, planifica, } \\
\text { revisa }\end{array}$ \\
\hline 5. Movilización & $\begin{array}{l}\text { Construye, integra, resume, compone, propone, } \\
\text { combina, desarrolla, organiza, formula, crea, diseña, } \\
\text { produce, inventa. }\end{array}$ \\
\hline $\begin{array}{l}\text { 6. Resolución de } \\
\text { Problemas }\end{array}$ & $\begin{array}{l}\text { Critica, sustenta, determina, categoriza, interpreta, } \\
\text { resuelve, califica. }\end{array}$ \\
\hline
\end{tabular}

Fuente: Luis Damián Casas (2007: 69).

\subsubsection{Requisitos de la evaluación.}

Capote, S. y Sosa A. (2006) manifiestan que la evaluación tiene los siguientes requisitos: validez, continuidad, acumulatividad, integralidad, objetividad, clarificidad, cooperatividad y diferenciación, relevania y oportunidad.

\subsubsection{Condiciones de una evaluación.}

Stufflebeam, D. y Shinkfield, A. (1995) Las evaluaciones tienen condiciones establecidas: Ser útil, factible, ética y exacta.

\subsubsection{El agente evaluador.}

Conteras, W. (2008) manifiesta que por el agente evaluador se distinguen tres tipos: autoevaluación, coevaluación y heteroevaluación. 
1.2.4. Clasificación de los instrumentos de evaluación.

Contreras, W. (2001) resumen la clasificación de los instrumentos de evaluación mediante el siguiente gráfico.

\section{Gráfico $N^{\circ} 01$}

Clasificación de los instrumentos de evaluación

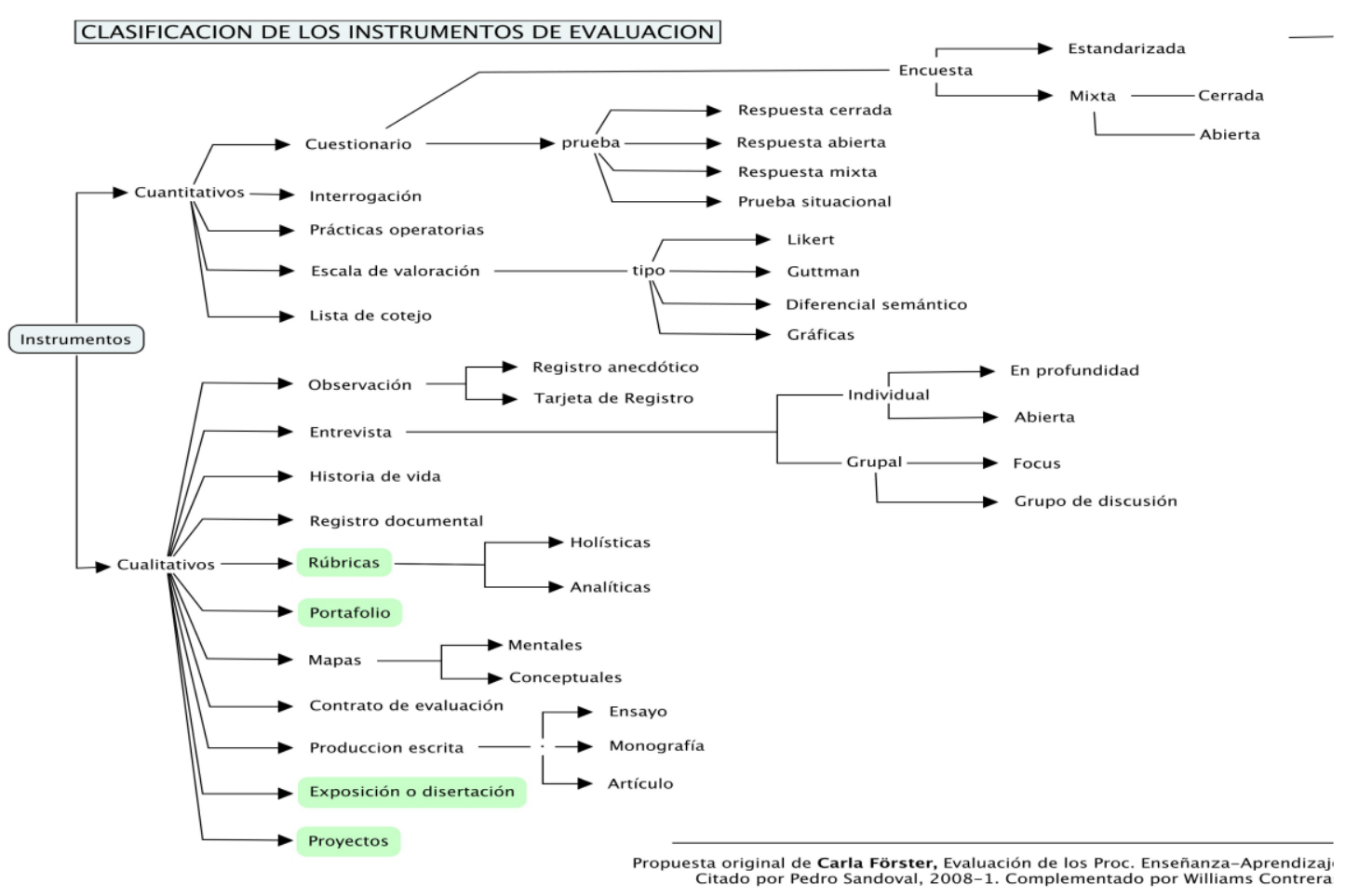

\subsubsection{Evaluación alternativa en la sociedad del conocimiento.}

López, B. e Hinojosa, E. (2000) manifiestan que aun cuando no existe una sola definición de lo que es la evaluación alternativa, lo que ésta pretende, esencialmente, es recoger evidencias acerca de cómo los estudiantes procesan, completan tareas y desarrollan capacidades sobre un tema particular.

\subsection{BASES CONCEPTUALES.}

\subsubsection{LA RÚBRICA.}

\subsubsection{Etimología.}

Díaz, F. y De la Cruz, G. (2011) La palabra rúbrica procede del latín ruber y significa rojo, debido a que se refiere a las indicaciones en color rojo que consistían en las reglas y prescripciones de la autoridad incluidas en los textos litúrgicos medievales. Su introducción en el ámbito académico se refería 
a las notas en color rojo que el profesor escribiría en un ensayo o documento elaborado por el estudiante cuando lo corregía y calificaba; actualmente, ha derivado en una herramienta de calificación del desempeño.

\subsubsection{Definición.}

Stevens, D. y Levi, A. (2012) Una rúbrica es una herramienta de puntuación que divide una misión en sus partes componentes y objetivos, y proporciona una descripción detallada de lo que constituye niveles de rendimiento para cada parte aceptables e inaceptables. Las rúbricas se pueden utilizar para cualquier grado de asignación o tarea: investigación papeles, reseñas de libros, participación en debates, trabajo de laboratorio, portafolios, presentaciones orales, trabajos en grupo, y más.

Díaz, F. y De la Cruz, G. (2011) Las rúbricas o matrices de valoración son guías o escalas de evaluación donde se establecen niveles progresivos de dominio o pericia relativos al desempeño que una persona muestra un amplio rango de criterios que cualifican el modo progresivo el tránsito de un desempeño incipiente o novato al grado del experto. Son escalas ordinales que destacan una evaluación del desempeño centrada en aspectos cualitativos, aunque es posible el establecimiento de puntuaciones numéricas.

Rowe, A. (2010) afirma que las rúbricas son una vinculación entre la evaluación y el proceso de enseñanza aprendizaje. Estas operacionalizan la calidad en nuestras mentes de manera que podamos enseñar más efectivamente y guiar a nuestros alumnos.

Goodrich, H. (2008) define una rúbrica como una herramienta de evaluación que identifica ciertos criterios para un trabajo. Generalmente, las rúbricas especifican el nivel de desarrollo esperado para obtener diferentes niveles de calidad. Estos pueden estar expresados en términos de una escala (Excelente, Bueno, Necesita mejorar) o en términos numéricos $(4,3,2,1)$, que al final se suman para determinar un resultado al que se le asigna una nota $(A$, B, C, o usando la escala vigesimal; es decir, de 0 a 20).

Martínez, J. (2008) Una rúbrica es una matriz que puede explicarse como un listado del conjunto de criterios específicos y fundamentales que permiten valorar el aprendizaje, los conocimientos o las competencias logrados por el estudiante en un trabajo o materia particular. 
Blanco, A. (2008) Las rúbricas son guías de puntuación usadas en la evaluación del desempeño de los estudiantes que describen las características específicas de un producto, proyecto o tarea en varios niveles del rendimiento, con el fin de clarificar lo que se espera del trabajo del alumno, de valorar su ejecución y de facilitar la proporción del feedback,

Vera, L. (2008) Las rúbricas son instrumentos de medición en los cuales se establecen criterios y estándares por niveles, mediante la disposición de escalas, que permiten determinar la calidad de la ejecución de los estudiantes en unas tareas específicas.

Rimari, W. (2008) manifiesta que la rúbrica es: a) Una herramienta de evaluación para evaluar el trabajo de los educandos y que ayuda a mejorar el aprendizaje y la enseñanza.

López, M. (2007) La rúbrica o matriz de valoración es una estrategia de evaluación alternativa a través de un listado (por medio de una matriz), de un conjunto de criterios específicos y fundamentales que permiten valorar el aprendizaje, los conocimientos y/o competencias, logrados por el estudiante en un trabajo o materia particular.

Jonsson, A., y Svingby, G. (2007) Una rúbrica es un instrumento de calificación que contiene los criterios de evaluación de una actividad y que se compone de tres partes: los criterios de calidad, un gradiente de la calidad del trabajo en referencia a los criterios y la descripción breve de un qué consiste el estándar para esa categoría.

Andrade, H. (2005) Las rúbricas son guías de puntuación usadas en la evaluación del desempeño de los estudiantes que describen las características específicas de un producto, proyecto o tarea en varios niveles de rendimiento, con el fin de clarificar lo que se espera del trabajo del alumno, de valorar su ejecución y de facilitar la proporción de feedback.

Wikipedia (s/a) Una rúbrica es una herramienta de calificación utilizada para realizar evaluaciones de calidad. Es un conjunto de criterios y estándares ligados a los objetivos de aprendizaje usados para evaluar la actuación de alumnos en la creación de artículos, proyectos, ensayos y otras tareas.

Simon, M. y Forgette, R. (2001) Las rubricas se definen como "un descriptor cualitativo que establece la naturaleza de un desempeño". 


\subsubsection{Importancia de las rúbricas.}

Zazueta, M. y Herrera, L (2008) manifiestan que la rúbrica es importante porque:

- En toda tarea que se les asigne a los alumnos deben de establecerse de forma clara y precisa los criterios que fundamentan los objetivos de enseñanza.

- Asegura de forma precisa el nivel de aprendizaje que se desee de los alumnos.

- Los maestros pueden mejorar la calidad de su enseñanza al enfatizar y precisar los detalles particulares que consideren más pertinentes para garantizar trabajos de excelencia por sus alumnos.

- Permite a los maestros obtener una medida más precisa tanto del producto como del proceso de la ejecución de los estudiantes en diferentes tipos de tareas.

- Los estudiantes tienen una guía de forma explícita para realizar sus tareas de acuerdo a las expectativas de sus maestros.

- Facilita a que los estudiantes desarrollen mejor los conceptos y destrezas que requieren las tareas asignadas.

\subsubsection{Características de las rúbricas.}

Rodríguez, B (2008) manifiesta que la rúbrica tiene las siguientes características:

- Sirve como un proceso de auto-evaluación en donde el estudiante puede apreciar su propio desempeño.

- Proporciona información para las distintas etapas del aprendizaje del alumno.

- Se supeditan a una serie de criterios dados por el profesor o en acuerdo profesor-alumno.

- Hace más fácil el proceso de evaluación.

\subsubsection{Partes de una rúbrica.}

Toda rúbrica posee los siguientes elementos:

a) Dimensiones. Son los componentes que constituyen, por agregación el marco de la evaluación del producto/desempeño del estudiante. Pueden 
representar subcomponentes de la tarea, aspectos particulares de la misma, atributos genéricos, etc., formalmente suelen disponerse en la primera columna.

b) Niveles de desempeño. Categorías que, dispuestos como un gradiente, definen la calidad del trabajo del estudiante. Pueden estar expresados tanto con etiquetas cualitativas (excelente, satisfactorio, etc.) como con un sistema numérico, o con ambos elementos.

c) Descriptores. Vienen a ser una breve explicación de la evidencia que permite juzgar el trabajo particular de un estudiante a lo largo de las distintas dimensiones. Se disponen en las celdas que definen la intersección de cada criterio con cada nivel de desempeño.

\section{Gráfico $\mathrm{N}^{\circ} 02$}

Esquema general de una rúbrica

\begin{tabular}{|c|c|}
\hline & $\begin{array}{c}\text { ESCALA DE CALIFICACIÓN } \\
\text { (Niveles de desempeño) }\end{array}$ \\
\hline $\begin{array}{c}\text { (Dimensiones) } \\
\text { Aspectos a } \\
\text { evaluar }\end{array}$ & Descriptores \\
\hline
\end{tabular}

\subsubsection{Categorías de calificación de una rúbrica}

Zazueta, M. y Herrera, L. (2008) mencionan que las rúbricas pueden utilizar diferentes tipos de escalas para describir el desempeño de los estudiantes. Por ejemplo, se puede utilizar una lista de revisión de comportamientos para establecer su presencia o ausencia; también se puede utilizar una escala numérica, que establezca rangos para diferenciar los diferentes tipos de desempeños del 1 al 10.

Para la presente investigación, se eligieron 5 escalas que ayudarán a evaluar cada uno de las rúbricas: Muy Satisfactorio (5), Satisfactorio (4), Regular (3), Deficiente (2), Muy deficiente (1). 


\subsubsection{Funciones de la rúbrica.}

Goodrich, H. (2008) manifiesta que la rúbrica tiene las siguientes funciones que beneficiarán, tanto a docentes como a los alumnos:

- Es hacer más simple y transparente la calificación a través de la aplicación de criterios específicos estandarizados.

- Son una poderosa herramienta para el maestro que le permite evaluar de una manera más objetiva, pues los criterios de la medición están explícitos y son conocidos de antemano por todos, no se los puede cambiar arbitrariamente y con ellos se hace la medición a todos los casos sobre los cuales se ofrezca emitir juicios.

- Promueven expectativas sanas de aprendizaje en los estudiantes pues clarifican cuáles son los objetivos del maestro respecto de un determinado tema o aspecto y de qué manera pueden alcanzarlos los estudiantes.

- Enfocan al profesor para que determine de manera específica los criterios con los cuales va a medir y documentar el progreso del estudiante.

- Permiten al maestro describir cualitativamente los distintos niveles de logro que el estudiante debe alcanzar.

- Permiten que los estudiantes conozcan los criterios de calificación con que serán evaluados, previamente al momento mismo de la evaluación.

- Aclaran al estudiante cuáles son los criterios que debe utilizar al evaluar su trabajo y el de sus compañeros.

- Permiten que el estudiante evalúe y haga una revisión final a sus trabajos, antes de entregarlos al profesor.

\subsubsection{Ventajas del uso de las rúbricas.}

Bujan, K., Rekalde, I., y Aramendi, P. (2011) mencionan que las ventajas que tienen las rúbricas, tanto para docentes como para alumnos son las siguientes:

Tabla $\mathrm{N}^{\circ} 02$

Ventajas del uso de las rúbricas

\begin{tabular}{|l|l|}
\hline \multicolumn{1}{|c|}{ Para el docente } & \multicolumn{1}{c|}{ Para el alumno } \\
\hline $\begin{array}{l}\text { a) Es una herramienta poderosa para } \\
\text { evaluar }\end{array}$ & a) $\begin{array}{l}\text { Reduce la subjetividad en la } \\
\text { evaluación. }\end{array}$ \\
\hline $\begin{array}{l}\text { b) Promueve expectativas sanas de } \\
\text { aprendizaje pues clarifica cuáles son } \\
\text { los objetivos del docente y de qué }\end{array}$ & b) $\begin{array}{l}\text { Permite que evalúe y haga una } \\
\text { revisión final a su trabajo, antes de } \\
\text { entregar al docente. }\end{array}$ \\
\hline
\end{tabular}


manera pueden alcanzarlos los estudiantes.

c) Enfoca al maestro para que determine de manera específica los criterios con los cuáles va a medir y documentar los progresos del estudiante.

d) Permite al docente describir cualitativamente los distintos niveles de logro que el estudiante debe alcanzar.

e) Provee información de retorno sobre la efectividad del proceso de enseñanza que se está utilizando.

f) Ayuda a mantener el o los logros del objetivo de aprendizaje centrado en los estándares de desempeño establecido y en el trabajo del estudiante.

g) Proporciona criterios específicos para medir y documentar el progreso del estudiante.

c) Proporciona a los estudiantes retroalimentación sobre sus fortalezas y debilidades en las áreas que deben mejorar.

d) Permite que conozcan los criterios de calificación con que serán evaluados.

e) Promueve la responsabilidad y es fácil de utilizar y de explicar.

f) Proporciona criterios específicos para medir y documentar su progreso.

g) Mejora la calidad de sus aprendizajes, pues clarifica cuáles son los objetivos del docente y de qué manera pueden alcanzarlos.

h) Es fácil de utilizar y de explicar. $\quad$ h) Aclara cuáles son los criterios que deben utilizar al evaluar su trabajo y el de sus compañeros.

i) Les permite describir cualitativamente los niveles de logro que debe alcanzar

i) Indica con claridad las áreas en las que tiene falencias y con éste el estudiante. conocimiento planear con el profesor los correctivos a aplicar.

\subsubsection{Desventajas del uso de las rúbricas.}

Bujan, K., Rekalde, I., y Aramendi, P. (2011) mencionan que las desventajas que tienen las son:

- Su práctica incorrecta no logra el desarrollo de la atención, indagación, reflejo, afirmación y disciplina en el participante.

- No limita al participante la cantidad de sesiones de trabajo que se deben efectuar.

- Establece un tiempo de atención específico al participante logrando en éste, la mecanización de su tiempo.

- Requiere mucho tiempo para su elaboración.

- Se eliminan los detalles de la observación.

- Puede emplearse tiempo extra para los observadores.

- Se tiende a incluir comportamientos que no pueden observarse directamente o que constituyen categorías ambiguas. 


\subsubsection{Clases de rúbricas.}

Zazueta, M. y Herrera, L. (2008) manifiestan que existen dos clases de rúbricas: Rúbrica comprehensiva, global u holística y Rúbrica analítica.

a) La rúbrica comprehensiva, global u holística es aquella que permite hacer una valoración de conjunto del desempeño del estudiante sin determinar o definir los aspectos fundamentales que corresponden al proceso o tema evaluado. Como su nombre lo indica, permite hacer una valoración general o de conjunto de un determinado aspecto.

\section{Gráfico $N^{\circ} 03$ \\ Modelo de rúbrica holística para evaluar la planificación de la sesión de clases}

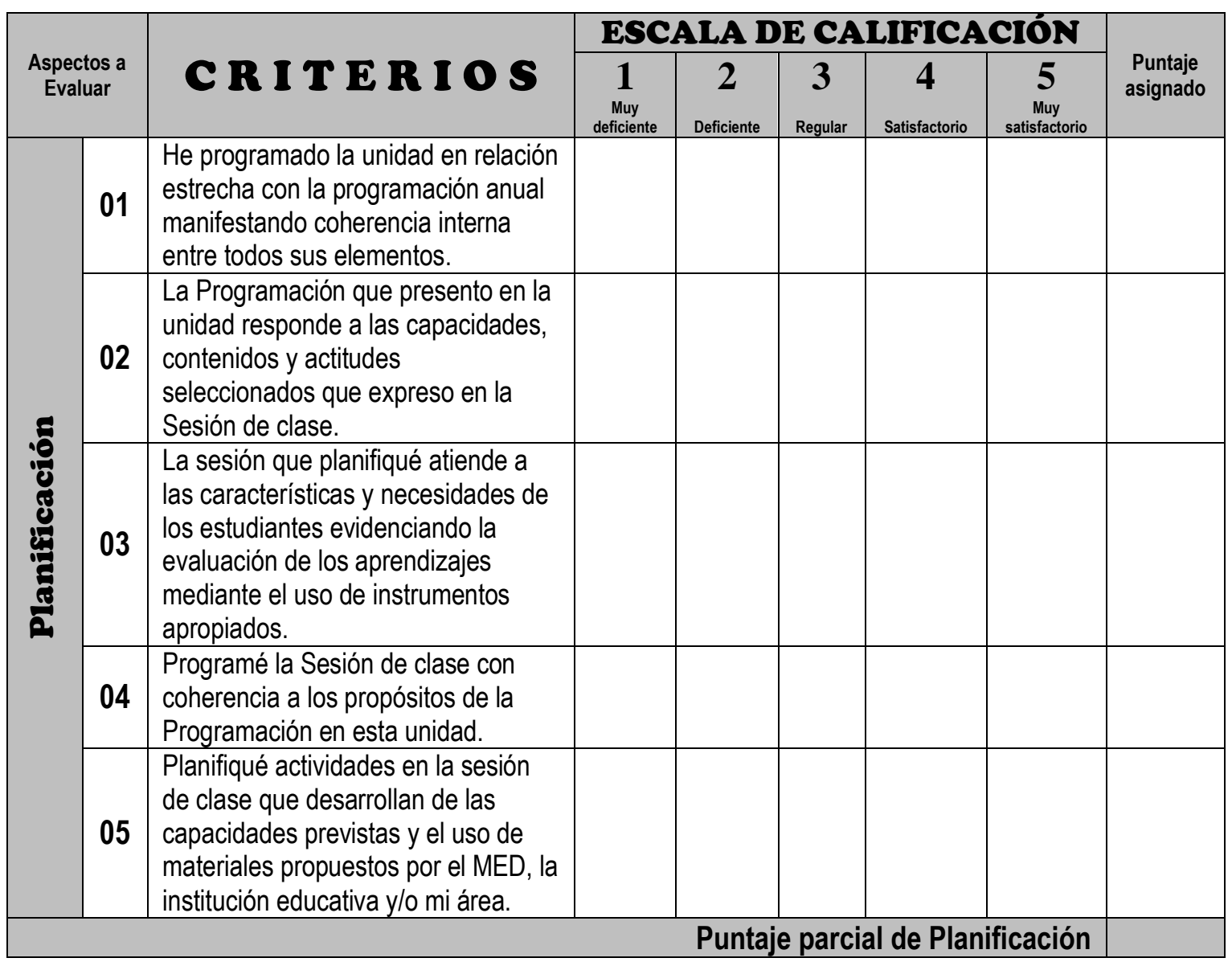

b) La rúbrica analítica es mucho más compleja, amplia y definitiva para la evaluación. Todas ellas pueden establecer diferentes niveles de manifestación de las habilidades y comportamientos a partir del desempeño de los alumnos, mediante una escala de al menos cuatro posibilidades, que nos indiquen diversos niveles de ejecución. 
Gráfico $N^{\circ} 04$

Modelo de rúbrica analítica para evaluar un trabajo colaborativo

\begin{tabular}{|c|c|c|c|c|}
\hline CATEGORÍA & EXCELENTE & BUENO & REGULAR & $\begin{array}{l}\text { NECESITA } \\
\text { AYUDA }\end{array}$ \\
\hline $\begin{array}{l}\text { Uso de la } \\
\text { Internet }\end{array}$ & $\begin{array}{l}\text { Usa con éxito } \\
\text { enlaces } \\
\text { sugeridos de la } \\
\text { Internet para } \\
\text { encontrar } \\
\text { información y } \\
\text { navega a través } \\
\text { de los sitios } \\
\text { fácilmente y sin } \\
\text { asistencia. }\end{array}$ & $\begin{array}{l}\text { Puede usar } \\
\text { enlaces } \\
\text { sugeridos de la } \\
\text { Internet para } \\
\text { encontrar } \\
\text { información y } \\
\text { navega a través } \\
\text { de los sitios } \\
\text { fácilmente y sin } \\
\text { asistencia. }\end{array}$ & $\begin{array}{l}\text { Puede usar } \\
\text { ocasionalmente } \\
\text { enlaces } \\
\text { sugeridos de la } \\
\text { Internet para } \\
\text { encontrar } \\
\text { información y } \\
\text { navega a través } \\
\text { de los sitios } \\
\text { fácilmente y sin } \\
\text { asistencia. }\end{array}$ & $\begin{array}{l}\text { Necesita } \\
\text { asistencia o } \\
\text { supervisión } \\
\text { para usar los } \\
\text { enlaces } \\
\text { sugeridos de la } \\
\text { Internet y/o } \\
\text { navegar a } \\
\text { través de los } \\
\text { sitios. }\end{array}$ \\
\hline Organización & $\begin{array}{l}\text { La información } \\
\text { está muy bien } \\
\text { organizada con } \\
\text { párrafos bien } \\
\text { redactados y con } \\
\text { subtítulos. }\end{array}$ & $\begin{array}{l}\text { La información } \\
\text { está organizada } \\
\text { con párrafos } \\
\text { bien } \\
\text { redactados. }\end{array}$ & $\begin{array}{l}\text { La información } \\
\text { está organizada, } \\
\text { pero los párrafos } \\
\text { no están bien } \\
\text { redactados. }\end{array}$ & $\begin{array}{l}\text { La información } \\
\text { proporcionada } \\
\text { no parece } \\
\text { estar } \\
\text { organizada. }\end{array}$ \\
\hline $\begin{array}{l}\text { Imágenes y } \\
\text { fotografías }\end{array}$ & $\begin{array}{l}\text { Las imágenes y } \\
\text { fotografías son } \\
\text { ordenados, } \\
\text { precisos y } \\
\text { añaden al } \\
\text { entendimiento } \\
\text { del tema. }\end{array}$ & $\begin{array}{l}\text { Las imágenes y } \\
\text { fotografías son } \\
\text { precisos y } \\
\text { añaden al } \\
\text { entendimiento } \\
\text { del tema. }\end{array}$ & $\begin{array}{l}\text { Las imágenes y } \\
\text { fotografías son } \\
\text { ordenados y } \\
\text { precisos y } \\
\text { algunas veces } \\
\text { añaden al } \\
\text { entendimiento } \\
\text { del tema. }\end{array}$ & $\begin{array}{l}\text { Las imágenes } \\
\text { y fotografías } \\
\text { no son } \\
\text { precisos o no } \\
\text { añaden al } \\
\text { entendimiento } \\
\text { del tema. }\end{array}$ \\
\hline Argumento & $\begin{array}{l}\text { El argumento del } \\
\text { tríptico impacta } \\
\text { es convincente e } \\
\text { invita a la acción } \\
\text { de los lectores }\end{array}$ & $\begin{array}{l}\text { El argumento } \\
\text { del tríptico es } \\
\text { convincente e } \\
\text { invita a la } \\
\text { acción de los } \\
\text { lectores }\end{array}$ & $\begin{array}{l}\text { El argumento del } \\
\text { tríptico es } \\
\text { convincente pero } \\
\text { no invita a la } \\
\text { acción de los } \\
\text { lectores }\end{array}$ & $\begin{array}{l}\text { El argumento y } \\
\text { del tríptico no } \\
\text { es convincente } \\
\text {, no invita a la } \\
\text { acción de los } \\
\text { lectores }\end{array}$ \\
\hline
\end{tabular}

\subsubsection{1. ¿Cómo hacer una rúbrica?}

Frola, P. y Velasquez, J. (2011) Para elaborar una rúbrica se debe tener en cuenta:

- El eje horizontal donde se ubican os indicadores.

- El eje vertical que definen a los niveles de desempeño.

- En el cruce de cada indicador con un nivel de desempeño se elabora un elemento llamado descriptor, que se define con la mayor precisión al desempeño esperado por cada indicador. 


\subsubsection{Criterios para perfeccionar una rúbrica.}

Zazueta, M. y Herrera, L. (2008) manifiestan que una rúbrica sea muy buena en su elaboración, ésta debe tener:

1. Continuidad: el cambio entre un nivel y otro debe guardar el mismo grado de dificultad; esto es, la diferencia que se establezca entre el nivel de desempeño más alto y el inmediato anterior, debe mantenerse en toda la rúbrica, para marcar la diferencia entre cada uno de los niveles especificados.

2. Paralelismo: se debe utilizar el mismo tipo de términos para describir todos los niveles que sirven para valorar un desempeño específico.

3. Coherencia: la rúbrica debe mantener un solo enfoque al valorar el desempeño esperado, especificando los diferentes grados de comportamiento y habilidades manifiestas en los diferentes niveles de ejecución.

4. Descripción: el lenguaje utilizado en la descripción de los niveles de desempeño debe clarificar el nivel de ejecución esperado para cada uno de los niveles, con el propósito de ayudar a los estudiantes y profesores a reconocer las características distintivas manifiestas en los comportamientos y habilidades esperados para cada uno de ellos.

5. Validez: la rúbrica debe permitir realizar inferencias válidas sobre la apreciación de los diferentes niveles alcanzados de desempeño, con base en las características de los productos -informes, escritos, reportes, exposiciones, etcétera.

6. Confiabilidad: se establece en relación con el hecho de que diferentes evaluadores asignen el mismo nivel de desempeño en la ejecución realizada por un estudiante; incluso, en la realización de diferentes tareas o actividades, por el mismo estudiante, utilizando la misma rúbrica.

\subsubsection{DESEMPEÑO DOCENTE.}

\subsubsection{Definición.}

Miranda, R., Ragni, M. y Salas, O (2007) manifiestan que la evaluación del desempeño docente, es una herramienta fundamental para gestionar la calidad docente. Pero es más que eso, también cumple importantes funciones, en el contexto de la política de gestión de cada organización, posibilita 
establecer planificaciones, basados en el rendimiento, facilita el diseño de un sistema de promoción profesional, permite detectar necesidades de formación o capacitación no adquiridas y estimula las relaciones humanas.

Valdez, H. (2000) menciona que la evaluación del desempeño profesional del docente es un proceso sistemático de la obtención de datos válidos y fiables con el objetivo de comprobar y valorar el efecto educativo que producen en los alumnos el despliegue de sus capacidades pedagógicas, su emocionalidad, responsabilidad laboral y por ende la naturaleza de sus relaciones interpersonales con alumnos, padres, directivos, colegas y representante de las instituciones de la comunidad.

\subsubsection{La docencia y la escuela que queremos.}

En el Marco del Buen Desempeño Docente -MBDD- (2013) encontramos que para el logro de los aprendizajes fundamentales se requiere que la escuela asuma la responsabilidad social de tales aprendizajes, exhiba una gestión democrática y lidere la calidad de la enseñanza. Esto le exige movilizarse para alcanzar los aprendizajes previstos promoviendo el pensamiento crítico y creativo de sus estudiantes y la valoración positiva de la diversidad en todas sus expresiones. Este proceso se desarrolla a través de los siguientes componentes: a) La gestión escolar; b) La convivencia; c) La relación escuela-familia-comunidad y d) Los procesos pedagógicos.

\subsubsection{3. ¿Qué debe saber el buen docente?}

Willson, J. (1992) afirma que el docente debe conocer el contenido de su enseñanza y el modo como ese contenido puede tener sentido para el estudiante; el docente debe saber hablar en un lenguaje comprensible $y$ promover el diálogo con los estudiantes (es decir, debe saber comunicar y generar comunicación).

Aylwin, M. (2001) manifiesta que hoy día necesitamos a nuestros docentes apropiándose del mejor conocimiento disponible sobre la educación, con capacidad autónoma para actualizarlo y recrearlo. Tampoco se trata de un mero desafío cognitivo.

Las habilidades y los desempeños son imprescindibles tanto como los conocimientos y las aptitudes. 


\subsubsection{4. ¿Cómo debe actuar el buen docente?}

El docente es un profesional que debe poseer dominio de un saber especifico y complejo (el pedagógico), que comprende los procesos en que está inserto, que decide con niveles de autonomía sobre contenidos, métodos y técnicas, que elabora estrategias de enseñanza-aprendizaje de acuerdo a la heterogeneidad de los alumnos, organizando contextos de aprendizaje, interviniendo de distintas maneras para favorecer procesos de construcción de conocimientos desde las necesidades particulares de cada uno de sus alumnos. Los docentes son profesionales expertos en procesos de enseñanza y aprendizaje.

MBDD (2013) encontramos que en el aula, el desempeño del docente, debe permitir desarrollar las sesiones de aprendizaje según lo previsto en la unidad didáctica y en el plan de la sesión. Verifica los avances de los contenidos en función del logro de aprendizajes esperados. Demuestra flexibilidad, sensibilidad y creatividad para responder con pertinencia ante situaciones difíciles e inesperadas que se presenten durante su enseñanza, alterar sus planes iniciales y variar de estrategia y metodología, evaluando sus opciones desde una mirada amplia y creativa de las alternativas disponibles.

MBDD (2013) también reitera que el docente, conoce los principales enfoques y teorías contemporáneas de la educación y explicita su relación con la organización y desarrollo de sus prácticas de enseñanza. Sabe cómo enseñar las materias de las áreas a su cargo. Domina una variedad de estrategias de enseñanza para generar aprendizajes significativos. Reconoce cuál es la estrategia más adecuada para el tipo de aprendizaje que desea lograr. Comprende los fundamentos y estrategias que permiten que los estudiantes se acerquen a los contenidos y desarrollen habilidades teniendo en cuenta sus diferentes ritmos, estilos y características culturales.

\subsubsection{5. ¿Para qué evaluar el desempeño docente?}

Sarmiento (2010) manifiesta que permite:
a) Estimular y favorecer el interés por el desarrollo profesional.
b) Contribuir al mejoramiento de la misión pedagógica de las instituciones.
c) Favorecer la formación integral de los niños y adolescentes. 


\subsubsection{Funciones de la evaluación del desempeño docente.}

Valdez, H. (2000) manifiesta que las funciones de la evaluación del desempeño docente son: De diagnóstico, instructiva, educativa y desarrolladora.

\subsubsection{Desafíos en la formación docente.}

Cardó, P. (2010) menciona que la principal demanda es cómo responder a las diferentes necesidades de formación tanto de los maestros formadores como de los estudiantes de la formación inicial, primaria y secundaria. Necesidades que comienzan, en muchos casos, por atender a la persona en su estructura más interna que necesita ser reconstituida para garantizar un sano soporte. También, cómo conseguir que la formación docente tenga una mirada de largo plazo, donde se articule la formación inicial con la formación en servicio de tal manera que se enfoque el desarrollo profesional como un continuo. El Objetivo 3 del Proyecto Educativo Nacional (PEN) plantea Maestros bien preparados que ejercen profesionalmente la docencia, centra su intervención en el desarrollo de la Carrera Pública Magisterial y en la implementación de un sistema integral continuo de formación docente. Para responder a esto se requiere de planteamientos deliberados, consensuados y de decisiones con participación de los propios evaluados.

\subsubsection{8. ¿Cómo entender la evaluación docente?}

La evaluación docente es un proceso muy complejo y precisamente por esta razón existen muchas formas de conceptuarla, definirla y entenderla.

Mateo, J. (2000) la define a partir de lo que se hace cuando se evalúa y así afirmar que es un proceso de construcción de conocimiento a partir de la realidad, con el objetivo de provocar cambios positivos en ella. La evaluación nunca es un hecho aislado y particular, es siempre un proceso que partiendo del recojo de información se orienta a la emisión de juicios de valor respecto de algún sujeto, objeto o intervención educativos. Pero un proceso evaluativo sería absolutamente limitado y restringido si no estuviera dirigido, explícitamente, a la toma de decisiones en función de la optimización de dichos sujetos, objetos o 
intervenciones evaluadas. La evaluación por ello es que se suele afirmar que éste es un proceso cognitivo (porque en él se construyen conocimientos), instrumental (porque requiere del diseño y aplicación determinados procedimientos, instrumentos y métodos) y axiológico (porque supone siempre establecer el valor de algo). En tal perspectiva Valdez, H. (2000) afirma que la evaluación del desempeño docente es una actividad de análisis, compromiso y formación del profesorado, que valora y enjuicia la concepción, práctica, proyección y desarrollo de la actividad y de la profesionalización docente.

\subsubsection{9. ¿Qué resultados debe lograr el buen docente en su práctica profesional?}

Cardó, P. (2010) manifiesta que siendo la docencia una profesión de múltiples dimensiones, plantea que dicha evaluación permitiría al docente desarrollar:

a) Capacidades de interacción con el otro, de conocimiento del otro y de comunicación eficaz con otros diferentes a través de diversos medios.

b) Conocimientos disciplinares, didácticos y pedagógicos, así como capacidades de articulación entre estos saberes.

c) Características individuales, como sustento o refuerzo de capacidades profesionales esenciales.

d) Capacidad para desenvolverse en el escenario de la pedagogía, la gestión y la política educativa.

e) Capacidad para desenvolverse en el escenario del aula, la escuela y la comunidad.

\subsubsection{Dimensiones de la docencia propuestos por del} MBDD.

El Marco de Buen Desempeño Docente -MBDD- (2013) propone tres dimensiones: pedagógica, cultural y política que todo docente debe y tiene que desarrollar a lo largo de su formación profesional. Estas son: Dimensión pedagógica, Dimensión cultural y Dimensión política. 


\subsubsection{Propósitos de la docencia propuestos por el} MBDD

a) Establecer un lenguaje común entre los que ejercen la profesión docente y los ciudadanos para referirse a los distintos procesos de la enseñanza.

b) Promover que los docentes reflexionen sobre su práctica, se apropien de los desempeños que caracterizan la profesión y construyan, en comunidades de práctica, una visión compartida de la enseñanza.

c) Promover la revaloración social y profesional de los docentes, para fortalecer su imagen como profesionales competentes que aprenden, se desarrollan y se perfeccionan en la práctica de la enseñanza.

d) Guiar y dar coherencia al diseño e implementación de políticas de formación, evaluación, reconocimiento profesional y mejora de las condiciones de trabajo docente.

\subsubsection{Los dominios que propone el MBDD.}

EI MBDD (2013) manifiesta que se entiende por dominio un ámbito o campo del ejercicio docente que agrupa un conjunto de desempeños profesionales que inciden favorablemente en los aprendizajes de los estudiantes. En todos los dominios subyace el carácter ético de la enseñanza, centrada en la prestación de un servicio público y en el desarrollo integral de los estudiantes. En este contexto, se han identificado cuatro (4) dominios.

\section{Gráfico $N^{\circ} 05$ \\ Dominios del Marco de Buen Desempeño Docente}

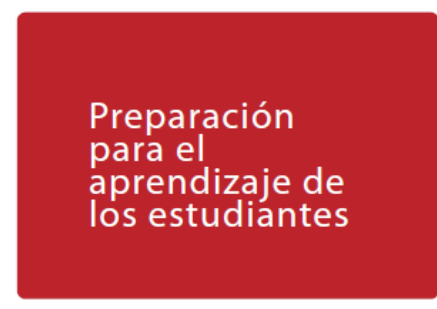

Participación en

la gestión de la

escuela articulada

a la comunidad
Enseñanza para

el aprendizaje

de los

estudiantes

Desarrollo de la

profesionalidad

y la identidad

docente

Fuente: MBDD (2013) 


\subsubsection{Las 9 competencias que propone el MBDD}

Las 9 competencias que propone el MBDD son:

\section{Dominio 1: Preparación para el aprendizaje de los estudiantes.}

a) Competencia 1: Conoce y comprende las características de todos sus estudiantes y sus contextos, los contenidos disciplinares que enseña, los enfoques y procesos pedagógicos, con el propósito de promover capacidades de alto nivel y su formación integral.

b) Competencia 2: Planifica la enseñanza de forma colegiada garantizando la coherencia entre los aprendizajes que quiere lograr en sus estudiantes, el proceso pedagógico, el uso de los recursos disponibles y la evaluación, en una programación curricular en permanente revisión.

Dominio II: Enseñanza para el aprendizaje de los estudiantes.

c) Competencia 3: Crea un clima propicio para el aprendizaje, la convivencia democrática y la vivencia de la diversidad en todas sus expresiones, con miras a formar ciudadanos críticos e interculturales.

d) Competencia 4: Conduce el proceso de enseñanza con dominio de los contenidos disciplinares y el uso de estrategias y recursos pertinentes, para que todos los estudiantes aprendan de manera reflexiva y crítica lo que concierne a la solución de problemas relacionados con sus experiencias, intereses y contextos culturales.

e) Competencia 5: Evalúa permanentemente el aprendizaje de acuerdo con los objetivos institucionales previstos, para tomar decisiones y retroalimentar a sus estudiantes y a la comunidad educativa, teniendo en cuenta las diferencias individuales y los contextos culturales.

Dominio III: Participación en la gestión de la escuela articulada a la comunidad.

f) Competencia 6: Participa activamente, con actitud democrática, crítica y colaborativa, en la gestión de la escuela, contribuyendo a la construcción y mejora continua del Proyecto Educativo Institucional y así éste pueda generar aprendizajes de calidad.

g) Competencia 7: Establece relaciones de respeto, colaboración y corresponsabilidad con las familias, la comunidad y otras instituciones del Estado y la sociedad civil; aprovecha sus saberes y recursos en los procesos educativos y da cuenta de los resultados. 
Dominio IV: Desarrollo de la profesionalidad y la identidad docente.

h) Competencia 8: Reflexiona sobre su práctica y experiencia institucional y desarrolla procesos de aprendizaje continuo de modo individual y colectivo, para construir y afirmar su identidad y responsabilidad profesional.

i) Competencia 9: Ejerce su profesión desde una ética de respeto de los derechos fundamentales de las personas, demostrando honestidad, justicia, responsabilidad y compromiso con su función social.

\subsubsection{Los desempeños que propone el MBDD.}

El MBDD (2013) manifiesta que en la definición de desempeño identificamos tres condiciones: actuación observable en correspondencia a una responsabilidad y logro de determinados resultados.

El Ministerio de Educación, mediante el MBDD, manifiesta que tenemos 40 desempeños.

\subsubsection{Dimensiones del desempeño docente en el aula}

Para el presente trabajo de investigación: Rúbrica y Desempeño Docente en la Provincia de Huancayo", se proponen las siguientes dimensiones de desempeño docente en el aula: Planificación, Metodología, Evaluación, Clima para el aprendizaje, Tiempo en el aula y Recursos y Materiales.

El puntaje mínimo de cada dimensión, es 5 puntos.

El puntaje máximo de cada dimensión, es 25 puntos.

El puntaje total de dimensiones es 150 puntos.

La escala de calificación de la rúbrica de autoevaluación del monitoreo, acompañamiento y supervisión de la sesión de clase oscila entre 00 y 150 puntos, siendo:

- De 000 a 070 puntos (Muy deficiente)

- De 071 a 090 puntos (Deficiente)

- De 091 a 110 puntos (Regular)

- De 111 a 130 puntos (Satisfactorio)

- De 131 a 150 puntos (Muy Satisfactorio) 


\subsubsection{Indicadores del desempeño docente en el aula.}

Teniendo como base la propuesta de Monitoreo al docente de PRONAFCAP (2009) se plantean los indicadores propuestos para la rúbrica de autoevaluación del monitoreo, acompañamiento y supervisión de la sesión de clase para nuestro trabajo; como supuestos que deben y pueden utilizarse en beneficio de la verificación del trabajo docente. Estos indicadores responden a las dimensiones de: Planificación, Metodología, Evaluación, Clima para el aprendizaje, Tiempo en el aula y Recursos y materiales.

El puntaje mínimo de cada indicador, es 1 punto.

El puntaje máximo de cada indicador, es 5 puntos.

Puntaje total de indicadores por dimensión es 25 puntos

Puntaje total de indicadores por instrumento es 150 puntos

La escala de calificación de la rúbrica de autoevaluación del monitoreo, acompañamiento y supervisión de la sesión de clase, respecto a cada uno de los indicadores, oscila entre 1 y 5 puntos, siendo:
- 1 punto
(Muy deficiente)
- 2 puntos
(Deficiente)
- 3 puntos
(Regular)
- 4 puntos
(Satisfactorio)
- 5 puntos
(Muy Satisfactorio)

\subsubsection{Procedimientos de evaluación del desempeño} docente.

Existen muchos procedimientos para evaluar el desempeño docente, siendo algunos: La observación de clases, La autoevaluación, Pruebas de conocimientos, El portafolio (Carpeta Didáctica), La opinión de los padres, La opinión de los alumnos, Coevaluación o evaluación de los pares, El rendimiento en el aprendizaje de los alumnos, La sesión de clase.

Mateo, J.; Escudero, T.; De Miguel, M.; Mora, J. y Rodríguez S. (1996) manifiesta que en la autoevaluación, el propio docente debe seleccionar, recoger, interpretar y juzgar la información referida a su propia práctica. Es él mismo el que establece los criterios y fija los estándares para juzgar la adecuación de sus conocimientos, habilidades y efectividad respecto de su actividad docente. 


\section{CAPÍTULO II HIPÓTESIS}

\subsection{HIPÓTESIS DE INVESTIGACIÓN.}

\subsubsection{Hipótesis general.}

La aplicación de la rúbrica tiene efecto positivo en el desarrollo del desempeño docente de los profesores de la Provincia de Huancayo.

\subsubsection{Hipótesis específicas.}

1. Las características tiene la rúbrica en el desarrollo del desempeño docente de los profesores de la Provincia de Huancayo son: a) Sirve como un proceso de auto-evaluación en donde el estudiante puede apreciar su propio desempeño, b) Proporciona información para las distintas etapas del aprendizaje del alumno; c) Se supeditan a una serie de criterios dados por el profesor o en acuerdo profesor-alumno y d) Hace más fácil el proceso de evaluación.

2. Las ventajas que tiene la rúbrica en el desarrollo del desempeño docente de los profesores de la provincia de Huancayo: a) Promueve expectativas sanas de aprendizaje pues clarifica cuáles son los objetivos del docente y de qué 
manera pueden alcanzarlos los estudiantes y b) Reduce la subjetividad en la evaluación.

3. Las desventajas que tiene la rúbrica en el desarrollo del desempeño docente de los profesores de la provincia de Huancayo: a) Hace que su práctica incorrecta no logra el desarrollo de la atención, indagación, reflejo, afirmación y disciplina en el participante y b) Requiere mucho tiempo para su elaboración.

4. Las dimensiones de desarrollo del desempeño docente en los profesores de la provincia de Huancayo al aplicar la rúbrica son: a) Planificación, b) Metodología, c) Evaluación, d) Clima para el aprendizaje, e) Tiempo en el aula y f) Recursos y Materiales.

5. El nivel de desempeño docente de los profesores de la provincia de Huancayo después de la aplicación de la rúbrica son favorables.

\subsection{VARIABLES E INDICADORES.}

\subsubsection{Variables.}

a) Variable Independiente:

Rúbrica.

b) Variable Dependiente:

Desarrollo del desempeño docente en la provincia de Huancayo.

c) Intervinientes:

Sexo, edad, especialidad y Nivel Educativo.

\subsubsection{Operacionalización de las variables.}

a) Variable Independiente: Rúbrica. 
Tabla $\mathbf{N}^{\circ} 03$

Matriz de consistencia de la variable independiente

\begin{tabular}{|c|c|c|c|c|}
\hline $\begin{array}{l}\text { Definición } \\
\text { conceptual }\end{array}$ & $\begin{array}{l}\text { Definición } \\
\text { operacional }\end{array}$ & Dimensiones & INDICADORES & $\begin{array}{c}\text { Escala } \\
\text { valorativa }\end{array}$ \\
\hline \multirow{3}{*}{$\begin{array}{l}\text { Instrumento de } \\
\text { calificación que } \\
\text { contienen los } \\
\text { criterios de } \\
\text { evaluación de } \\
\text { una actividad a } \\
\text { partir de guías, } \\
\text { matrices, escalas } \\
\text { y/o niveles } \\
\text { progresivos de } \\
\text { dominio del } \\
\text { proceso de } \\
\text { enseñanza } \\
\text { aprendizaje. }\end{array}$} & \multirow{3}{*}{$\begin{array}{l}\text { Instrumento de } \\
\text { calificación que } \\
\text { contienen los } \\
\text { criterios de } \\
\text { evaluación de } \\
\text { una actividad a } \\
\text { partir de guías, } \\
\text { matrices, } \\
\text { escalas y/o } \\
\text { niveles } \\
\text { progresivos de } \\
\text { dominio al } \\
\text { desempeño que } \\
\text { una persona } \\
\text { muestra en el } \\
\text { proceso de } \\
\text { enseñanza } \\
\text { aprendizaje } \\
\text { mediante }\end{array}$} & Metodológico & $\begin{array}{l}\text { - Es motivador e interesante. } \\
\text { - Capta el mensaje principal con } \\
\text { facilidad. } \\
\text { - Estrategia metodológica } \\
\text {.contextualizada a la realidad de los } \\
\text { alumnos. }\end{array}$ & \multirow{3}{*}{$\begin{array}{c}\text { Muy deficiente } \\
\text { (1) } \\
\text { Deficiente (2) } \\
\text { Regular (3) } \\
\text { Satisfactorio } \\
\text { (4) } \\
\text { Muy } \\
\text { satisfactorio } \\
\text { (5) }\end{array}$} \\
\hline & & Funcional & $\begin{array}{l}\text { - Facilidad de uso y/o manejo. } \\
\text { - Permite la autoafirmación. } \\
\text { - Se busca toma de decisiones. } \\
\text { - Facilita el liderazgo. }\end{array}$ & \\
\hline & & Pedagógico & $\begin{array}{l}\text { - Uso de lenguaje apropiado. } \\
\text { - Desarrolla capacidades } \\
\text { programadas. } \\
\text { - Pertinencia curricular. }\end{array}$ & \\
\hline
\end{tabular}

Fuente: Elaboración propia.

\section{b) Variable Dependiente: Desempeño docente en la provincia de Huancayo.}

Tabla $\mathrm{N}^{\circ} 04$
Matriz de consistencia de la variable dependiente

\begin{tabular}{|c|c|c|c|c|}
\hline $\begin{array}{l}\text { Definición } \\
\text { conceptual }\end{array}$ & $\begin{array}{l}\text { Definición } \\
\text { operacional }\end{array}$ & $\begin{array}{l}\text { Dimen- } \\
\text { siones }\end{array}$ & INDICADORES & $\begin{array}{l}\text { Escala } \\
\text { valorati } \\
\quad \text { va }\end{array}$ \\
\hline \multirow{7}{*}{$\begin{array}{l}\text { Es toda } \\
\text { acción } \\
\text { realizada o } \\
\text { ejecutada } \\
\text { por un } \\
\text { individuo, } \\
\text { en } \\
\text { respuesta, } \\
\text { de lo que } \\
\text { se le ha } \\
\text { designado } \\
\text { como } \\
\text { responsabil } \\
\text { idad y que } \\
\text { será } \\
\text { medido en } \\
\text { base a su } \\
\text { ejecución. }\end{array}$} & \multirow{7}{*}{$\begin{array}{l}\text { Desempeño } \\
\text { docente, es } \\
\text { evaluar, es } \\
\text { proceder a } \\
\text { identificar } \\
\text { una realidad } \\
\text { pasada en } \\
\text { su más } \\
\text { amplia } \\
\text { expresión, } \\
\text { donde } \\
\text { destacan los } \\
\text { conflictos en } \\
\text { las } \\
\text { condiciones } \\
\text { y acciones } \\
\text { realizadas }\end{array}$} & \multirow{5}{*}{ 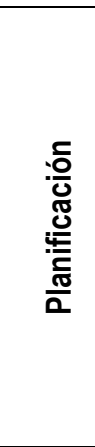 } & $\begin{array}{l}\text { Programo la unidad en relación estrecha con la programación anual } \\
\text { manifestando coherencia interna entre todos sus elementos. }\end{array}$ & \multirow{7}{*}{$\begin{array}{c}\text { Muy } \\
\text { deficiente } \\
(1) \\
\text { Deficiente } \\
(2) \\
\text { Regular } \\
(3) \\
\text { Satisfactc } \\
\text { rio (4) } \\
\text { Muy } \\
\text { satisfacto } \\
\text { rio (5) }\end{array}$} \\
\hline & & & $\begin{array}{l}\text { La Programación que presento en la unidad responde a las capacidades, } \\
\text { contenidos y actitudes seleccionados que expreso en la Sesión de clase. }\end{array}$ & \\
\hline & & & $\begin{array}{l}\text { La sesión que planifiqué atiende a las características y necesidades de los } \\
\text { estudiantes evidenciando la evaluación de los aprendizajes mediante el uso de } \\
\text { instrumentos apropiados. }\end{array}$ & \\
\hline & & & $\begin{array}{l}\text { Programé la Sesión de clase con coherencia a los propósitos de la } \\
\text { Programación en esta unidad. }\end{array}$ & \\
\hline & & & $\begin{array}{l}\text { Planifiqué actividades en la sesión de clase que desarrollan de las capacidades } \\
\text { previstas y el uso de materiales propuestos por el MED, la institución educativa } \\
\text { y/o mi área. }\end{array}$ & \\
\hline & & \multirow{2}{*}{$\begin{array}{l}\frac{\pi}{5} \\
\frac{0}{0} \\
\frac{0}{0} \\
\frac{0}{0} \\
\sum\end{array}$} & $\begin{array}{l}\text { Ejecuto actividades en concordancia con lo programado en la Sesión de clase } \\
\text { aplicando criterios de flexibilidad, manteniendo el interés del estudiante para } \\
\text { consolidar sus capacidades, destrezas y estilos de aprendizaje programados, } \\
\text { con claridad y precisión (de manera ordenada y evolutivamente). }\end{array}$ & \\
\hline & & & $\begin{array}{l}\text { Aplico estrategias que permiten recuperar saberes previos en los estudiantes } \\
\text { articulándolos con el nuevo aprendizaje, con dominio y calidad; de manera } \\
\text { amena e interesante, manteniendo la atención y motivación permanente en } \\
\text { clase. }\end{array}$ & \\
\hline
\end{tabular}




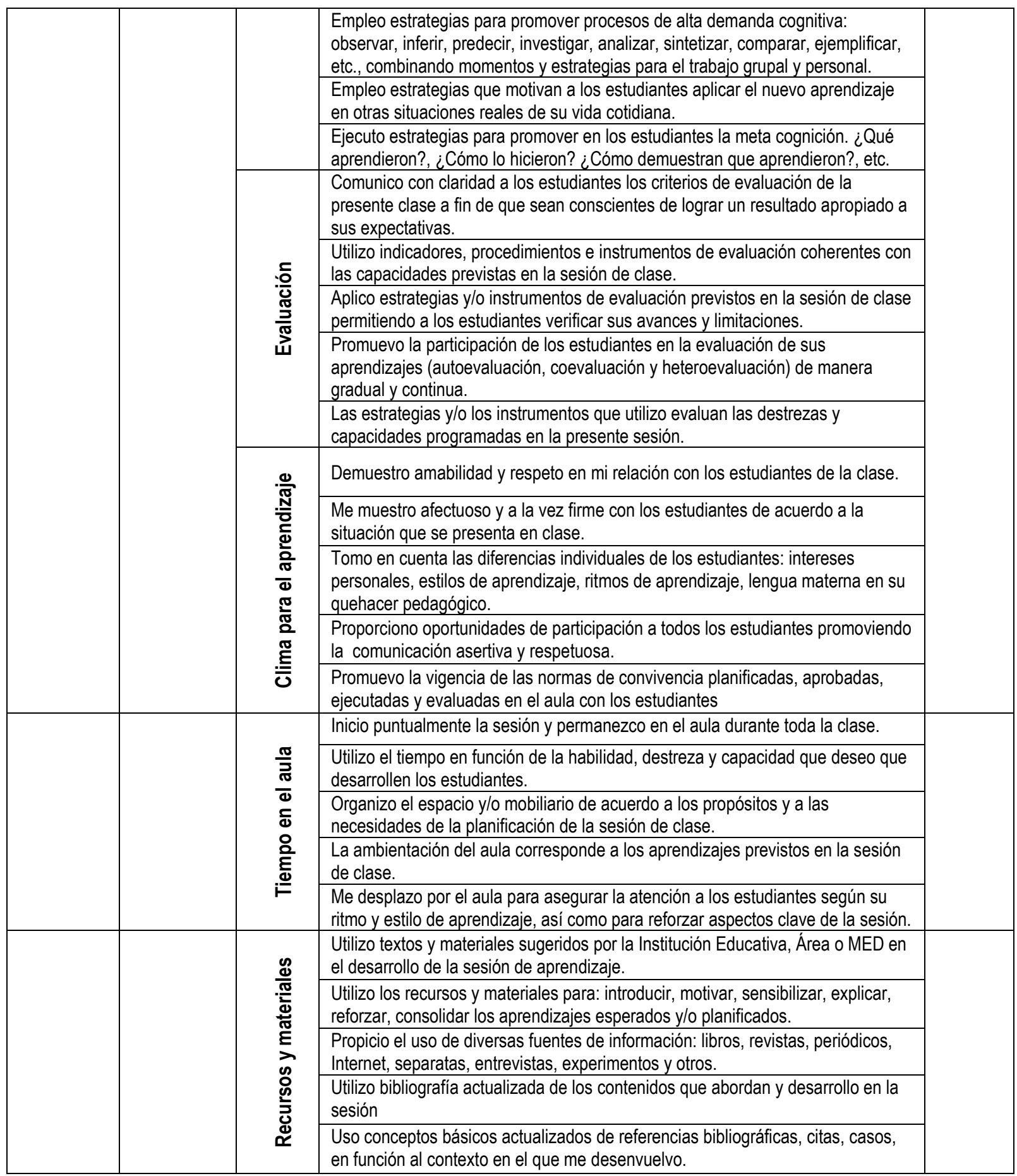

\subsubsection{Escala de medición.}

\section{Es nominal de 1 a 5 .}




\section{CAPÍTULO III MÉTODOLOGÍA}

\subsection{TIPO DE INVESTIGACIÓN.}

Es aplicativo, porque se utilizó la rúbrica en el desarrollo del desempeño docente de los profesores de la provincia de Huancayo.

\subsection{NIVEL DE INVESTIGACIÓN.}

Es de nivel explicativo, porque busca la explicación y predicción científica de la hipótesis respecto a la aplicación de la rúbrica en el desarrollo del desempeño docente de profesores de la provincia de Huancayo.

\subsection{MÉTODOS DE INVESTIGACIÓN.}

\subsubsection{Método General.}

Se utilizó el método científico como método general, porque partimos de la realidad educativa actual que nos permite formular el problema de investigación; luego se realizó la teorización y finalmente a través de ella se llegó a la generalización. Se siguieron los siguientes pasos:

- Identificación y enunciación del problema de investigación, a partir de las observaciones realizadas con los docentes de las IEP del trabajo.

- Planteamiento de hipótesis lógicas, a partir de conocimientos teóricos y los objetivos o acciones propuestas en la investigación.

- Selección de técnicas e instrumentos de recolección de datos. 
- Elección y aplicación del diseño para la contrastar la hipótesis.

- Análisis e interpretación de los resultados; y contrastación de las hipótesis de trabajo.

- Formulación de generalizaciones y conclusiones.

\subsubsection{Métodos particulares.}

El método experimental que se usó para contrastar las relaciones causa-efecto en la aplicación de la rúbrica en el desarrollo del desempeño docente; asimismo el grupo experimental fue sometido a la acción de la variable independiente.

EI método estadístico se empleó para analizar e interpretar los resultados obtenidos en la investigación (de los grupos: experimental y control)

\subsection{DISEÑO DE INVESTIGACIÓN.}

Se empleó el diseño de Un Grupo sólo después. Su esquema es:

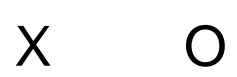

\section{Donde:}

X : Variable experimental (rúbrica)

O : Es la observación de salida.

En este diseño un tratamiento es aplicado a un grupo; luego se hace una observación o medición en los sujetos que componen el grupo, con la finalidad de evaluar los efectos del tratamiento. A este diseño también se le conoce con el nombre de estudios de casos en una dirección.

Además, la falta de un grupo control (grupo que no recibe el tratamiento experimental), y la falta de información acerca de las personas que son sometidas a la variable experimental o independiente atenta contra la mayoría de (por no decir todos), los factores de la validez interna. 


\subsection{POBLACIÓN Y MUESTRA.}

Con datos de la Dirección Regional de Educación se sabe que dentro de nuestra jurisdicción regional, laboran un total 23 mil 335 docentes repartidos en los niveles inicial, primario, secundario, centro educativo básico alternativo (CEBA), CEOS, CETPRO, Superior y Educación especial, así como la no escolarizada; esto de acuerdo al censo escolar 2012, elaborado por la dirección de gestión institucional, oficina dependiente de la DREJ.

Además se sabe que existen mayor número de docentes laborando en las instituciones educativas del sector público, puesto que suman 16 mil 519 profesionales (a nivel de la provincia de Huancayo), mientras que en los privados solo trabajan 6 mil 816. En tanto que en los centros educativos escolarizados vienen ejerciendo la docencia 23 mil 219 , cifra muy alta, a diferencia de la no escolarizada, donde trabajan solo 116 docentes.

Asimismo, en el ámbito de las 12 unidades de gestiones educativas locales (UGELES), que funcionan dentro de la región; la que más número de docentes agrupa, es la Huancayo, con un total de 9 mil 137; en tanto la UGEL que menos profesores tiene a su cargo, es la de Rio Tambo, con 499 trabajadores de la educación.

Esta cantidad está dividida en las Jurisdicciones de acuerdo a las Unidades Ejecutorias que son tres:

Unidad Ejecutoria Huancayo, Jauja, Concepción y Chupaca alberga a un total de 15,000 docentes.

Unidad Ejecutoria de Tarma, Junín y Yauli con un total de 5,000 docentes.

Unidad Ejecutoria de Chanchamayo, Pangoa, Pichanaki, Satipo, Río Tambo con 3,219 docentes.

\subsubsection{Población.}

Conforman nuestra población algunos docentes de las diferentes instituciones educativas de la provincia de Huancayo interesadas en su participación en los procesos de capacitación continua (presencial y virtual) que viene organizando el Colegio 
salesiano Santa Rosa desde el año 2008 hasta la fecha, siendo un total de 2500 docentes de las regiones Junín y Huancavelica, principalmente.

Esta población la conforman docentes en su condición de contratados y nombrados con deseos de continuar su aprendizaje permanente a través de las Comunidades de Aprendizaje Salesianos (CASA).

\subsubsection{Muestra.}

Se conformó una sola muestra integrada por 751 docentes, profesores pertenecientes a la Provincia de Huancayo.

Tabla № 05

Resumen de las características de la muestra

\begin{tabular}{|c|c|c|c|}
\hline Grupos & $\begin{array}{c}\text { Número de } \\
\text { sujetos }\end{array}$ & Género & $\begin{array}{c}\text { Edad } \\
\text { promedio }\end{array}$ \\
\hline $\begin{array}{c}\text { Docentes de las IEP de la } \\
\text { provincia de Huancayo }\end{array}$ & 751 & Femenino & 445 \\
\cline { 3 - 4 } & Masculino & 306 \\
\hline
\end{tabular}

Fuente: Elaboración propia.

b) Determinación del tamaño de muestra.

El tamaño de muestra se determinó con el muestreo aleatorio simple en poblaciones finitas para estimar la proporción de profesores con desempeño docente satisfactorio 0 muy satisfactorio, utilizando la siguiente fórmula:

$$
n=\frac{N P Q Z^{2}}{(N-1) \varepsilon^{2}+P Q Z^{2}}
$$

\section{Donde:}

n es el tamaño de la muestra (profesores a encuestar)

$\mathrm{N}$ es el tamaño de la población (profesores), 
$\mathrm{P}$ es la probabilidad de éxito (proporción de profesores don desempeño docente satisfactorio o muy satisfactorio en la población),

$\mathrm{Q}=1$ - $\mathrm{P}$ es la probabilidad de fracaso (proporción de profesores don desempeño docente regular o deficiente en la población),

$\varepsilon \quad$ Es el error de estimación máximo permisible (margen de error a tolerar),

Z Es el valor de la distribución normal estándar para una probabilidad de (1- $\alpha / 2)$, donde $\alpha$ es el nivel de significación y (1$\alpha)$ es el nivel confianza establecido.

\section{Datos:}

$\mathrm{N}=5800$ profesores de las IEPs de la Provincia de Huancayo

$\pi=0,4$ (o sea, el $40 \%$ de profesores don desempeño docente satisfactorio o muy satisfactorio)

$\alpha=0,042 ; 1-\alpha=0,958 ; Z=2,034$

$\varepsilon=0,0349($ o sea, $3,49 \%)$

El valor de $\pi=0,4$ se establece en base a la distribución estadística uniforme o rectangular con cinco niveles (muy deficiente, deficiente, regular, satisfactorio y muy satisfactorio) equiprobables para medir el desempeño docente de los profesores, cada uno con probabilidad igual a 0,2.

Reemplazando los valores en la fórmula resulta que:

$$
n=\frac{5800(0,4)(0,6)(2,034)^{2}}{5799(0,0349)^{2}+(0,4)(0,6)(2,034)^{2}}=715
$$

Esta muestra, constituida por 715 profesores, representa el $12,3 \%$ de la población total de profesores. Agregando un 5\% por previsión de pérdidas o mortalidad experimental (ausencia, negativa a responder o muerte de algún profesor seleccionado), la muestra 
definitiva es de 751 profesores, que representa el 12,9\% de la población total de profesores.

\subsubsection{Tipo demuestra.}

- El método de muestreo fue el intencional.

\subsection{TÉCNICAS E INSTRUMENTOS DE RECOLECCIÓN DE DATOS}

\subsubsection{Técnicas.}

- Técnica del fichaje. Permitió describir las características, finalidades, fundamentos y conceptos.

\subsubsection{Instrumentos.}

* Rúbrica de autoevaluación del monitoreo, acompañamiento y supervisión de la sesión de clase. Permitió evaluar el desempeño docente del docente participante

* Sesiones de Aprendizaje. Se elaboraron sesiones de clase, según la secuencia del programa propuesto para este fin.

* Fichas. Bibliográficas, de resumen, de comentario, de trascripción para la obtención del marco teórico.

\subsubsection{Validación y confiabilidad del instrumento.}

El instrumento de medición o de recolección de datos fue la Rúbrica de Autoevaluación del Monitoreo, Acompañamiento y Supervisión de la Sesión de Clase; que pasó los procesos de validación y confiabilidad; consideraba, además, una calificación para cada ítem de: 1 (Muy Deficiente), 2 (Deficiente), 3 (Regular), 4 (Satisfactorio) y 5 (Muy Satisfactorio).

\section{Evaluación de la validez}

La validez subjetiva de este instrumento fue evaluada con el juicio de 5 expertos (especialistas o jueces) con la prueba $t$ de Student para el juicio de expertos. Dichos profesionales fueron: 
- Sánchez Carlessi, Hector Hugo. Doctor en Psicología por la Universidad Nacional Mayor de San Marcos. Actual Decano de la Carrera Profesional de Psicología de La Universidad Particular Ricardo Palma.

- Martel Vidal, Victor Hugo. Doctor en Psicología. Docente Principal de La Universidad Enrique Guzmán y Valle "La Cantuta”. Docente de La Unidad de Post Grado de la UNCP.

- Moya Rojas, Nicanor. Doctor en Educación, Mención: Ciencias de la Educación por la Universidad Nacional Del Centro del Perú. Director de la Unidad de Posgrado de la Facultad de Educación de La UNCP.

- Aguado Riveros, Uldarico. Doctor en Administración de la Universidad Peruana los Andes. Actual jefe del área de planificación de la Universidad Peruana los Andes de Huancayo.

- Huaytalla Torres, Luis Orlando. Doctor en Educación por La Universidad Peruana Alas Peruanas. Actualmente DECANO de la Facultad de Educación de la Universidad Nacional del Centro del Perú.

La validez objetiva del instrumento se realizó con los resultados de la aplicación de los mismos a una muestra piloto de 50 profesores de las IEPs de la Provincia de Huancayo con el coeficiente de correlación ítem-test o ítem-total corregida de Pearson.

\section{a) Prueba t de Student.}

Dado que la muestra de expertos es pequeña $(n=5$ y $n<50)$, la media de cada criterio se evalúa con la estadística T de Student.

Las hipótesis estadísticas nula Ho y alternativa Ha a contrastar son las siguientes:

Ho: La media de las puntuaciones asignadas al ítem $X$ es igual a 4 $(\mathrm{Ho}: \mu=4)$ 
Ha: La media de las puntuaciones asignadas al ítem $X$ es mayor a 4 (Ha: $\mu>4)$

donde $\mu$ es la media poblacional de las puntuaciones asignadas al ítem X. El punto crítico o de corte de 4 se establece en base a la puntuación buena (4) o muy buena (4) asignada al ítem.

La función de prueba es la T de Student con (n-1) grados de libertad, definida como:

$$
T=\frac{\bar{x}-\mu}{\rho / \sqrt{n}}
$$

donde $\bar{x}$ y S son la media y la desviación estándar muestrales de las puntuaciones, respectivamente; $n$ es el número de expertos.

Para $\alpha=0,05, n=5$ y un contraste unilateral superior o derecha (Ha: $\mu>4$ ), el valor teórico de la T de Student con 4 grados de libertad es $\mathrm{tt}=2,132$, con el cual la hipótesis nula Ho se rechazará si su valor calculado es mayor que 2,132 y, en caso contrario se aceptará. Las regiones de rechazo y de aceptación de Ho se ven en la figura 1. En términos del valor $\mathrm{p}$, la hipótesis nula Ho será rechazada si valor $\mathrm{p}$ es menor que el nivel usual de significación de 0,05 y, en caso contrario, será aceptada.

\section{Gráfico Nº6}

Región de rechazo y aceptación de Ho

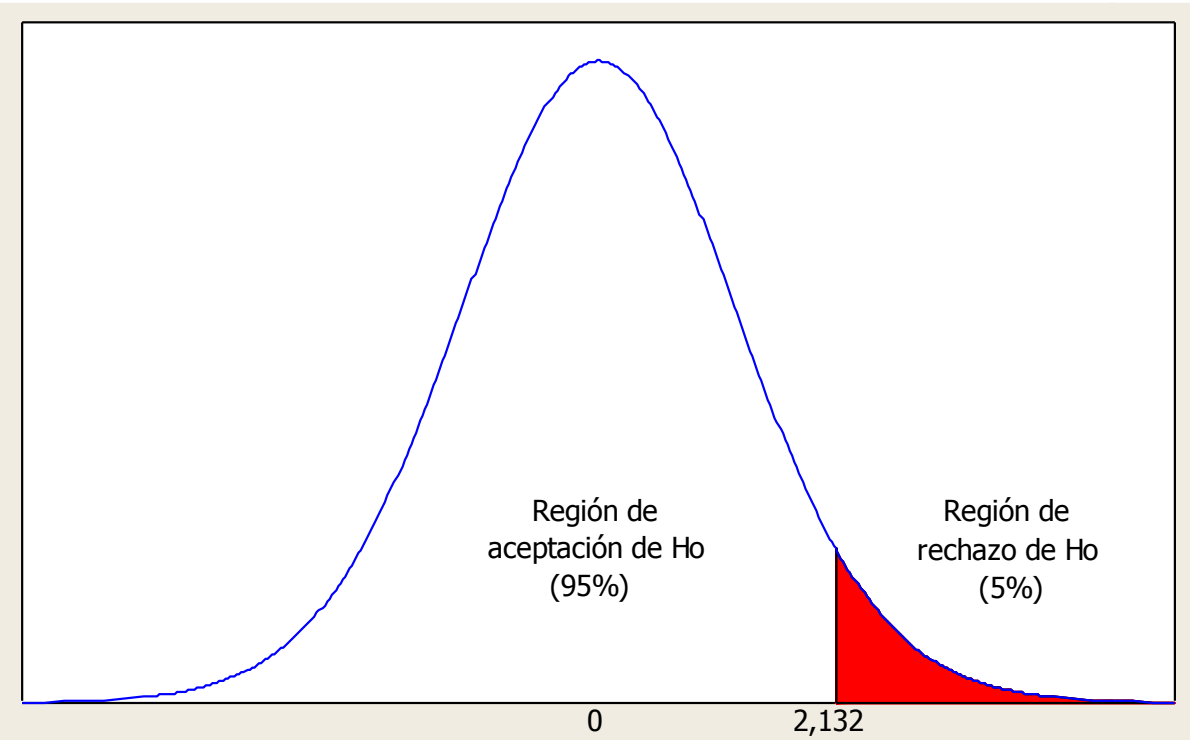

Fuente: Elaboración propia. 
b) Coeficiente de correlación $r$ de Pearson corregida

El coeficiente de correlación ítem-test corregida de Pearson se calcula con:

$$
r_{i, x-i}=\frac{r_{i x} S_{x}-S_{i}}{\sqrt{S_{x}^{2}+S_{i}^{2}-2 r_{i x} S_{x} S_{i}}}
$$

Donde:

$\mathrm{r}_{\mathrm{i}, \mathrm{x}-\mathrm{i}} \quad$ es el coeficiente de correlación ítem-test corregido,

rix es el coeficiente de correlación ítem-test,

$S_{x} \quad$ es la desviación estándar de los puntajes totales de los sujetos examinados,

$\mathrm{Si}_{\mathrm{i}} \quad$ es la desviación estándar de los puntajes del i-ésimo ítem.

Este coeficiente toma valores entre -1 y 1 , y los ítems cuyas correlaciones ítem-total arrojen valores menores a 0,2 deben ser desechados o reformulados. Los ítems con correlaciones item-total superiores a 0,2 son válidos $\mathrm{y}$, el instrumento es válido si todos sus ítems son válidos.

\subsection{Validez subjetiva}

Se presentan los datos. Veamos. 
Cuadro $\mathrm{N}^{\circ} 01$

Validez subjetiva de los ítems por juicio de expertos con la t de Student

\begin{tabular}{|c|c|c|c|c|}
\hline Item & Media & DE & tc & Valor $p$ \\
\hline 1. Item 1 & 4,6 & 0,548 & 2,45 & $0,035^{*}$ \\
\hline 2. Item2 & 4,6 & 0,548 & 2,45 & $0,035^{*}$ \\
\hline 3. Item3 & 4,6 & 0,548 & 2,45 & $0,035^{*}$ \\
\hline 4. Item4 & 4,6 & 0,548 & 2,45 & $0,035^{*}$ \\
\hline 5. Item5 & 4,6 & 0,548 & 2,45 & $0,035^{*}$ \\
\hline 6. Item6 & 4,6 & 0,548 & 2,45 & $0,035^{\star}$ \\
\hline 7. Item7 & 4,6 & 0,548 & 2,45 & $0,035^{\star}$ \\
\hline 8. Item8 & 4,8 & 0,447 & 4,00 & $0,008^{\star *}$ \\
\hline 9. Item9 & 4,8 & 0,447 & 4,00 & $0,008^{* *}$ \\
\hline 10. Item 10 & 4,8 & 0,447 & 4,00 & $0,008^{\star *}$ \\
\hline 11. Item 11 & 4,8 & 0,447 & 4,00 & $0,008^{* *}$ \\
\hline 12. Item 12 & 4,8 & 0,447 & 4,00 & $0,008^{* *}$ \\
\hline 13. Item 13 & 4,8 & 0,447 & 4,00 & $0,008^{* *}$ \\
\hline 14. Item 14 & 4,8 & 0,447 & 4,00 & $0,008^{\star *}$ \\
\hline 15. Item 15 & 4,8 & 0,447 & 4,00 & $0,008^{* *}$ \\
\hline 16. Item16 & 4,8 & 0,447 & 4,00 & $0,008^{\star *}$ \\
\hline 17. Item17 & 4,8 & 0,447 & 4,00 & $0,008^{* *}$ \\
\hline 18. Item18 & 4,8 & 0,447 & 4,00 & $0,008^{* *}$ \\
\hline 19. Item19 & 4,8 & 0,447 & 4,00 & $0,008^{* *}$ \\
\hline 20. Item20 & 4,6 & 0,548 & 2,45 & $0,035^{*}$ \\
\hline 21. Item21 & 4,8 & 0,447 & 4,00 & $0,008^{* *}$ \\
\hline 22. Item22 & 4,8 & 0,447 & 4,00 & $0,008^{* *}$ \\
\hline 23. Item23 & 4,8 & 0,447 & 4,00 & $0,008^{* *}$ \\
\hline 24. Item24 & 4,8 & 0,447 & 4,00 & $0,008^{* *}$ \\
\hline 25. Item25 & 4,8 & 0,447 & 4,00 & $0,008^{* *}$ \\
\hline 26. Item26 & 4,8 & 0,447 & 4,00 & $0,008^{* *}$ \\
\hline 27. Item27 & 4,8 & 0,447 & 4,00 & $0,008^{\star *}$ \\
\hline 28. Item28 & 4,8 & 0,447 & 4,00 & $0,008^{* *}$ \\
\hline 29. Item29 & 4,8 & 0,447 & 4,00 & $0,008^{\star \star}$ \\
\hline 30. Item30 & 4,8 & 0,447 & 4,00 & $0,008^{\star *}$ \\
\hline
\end{tabular}

Fuente: Elaboración propia.

$\mathrm{GL}=4 ; \mathrm{tt}=2,132 ; \mathrm{Ho}: \mu=4 ; \mathrm{H} 1: \mu>4$

$(* *)$ : Altamente significativa $(p<0,01)$;

$\left(^{*}\right)$ : Significativa $(p<0,05)$ 
Todos los ítems son válidos por juicio de expertos, ya que la prueba t de Student revela que sus medias superan significativamente a 4 (puntuación buena (4) o muy buena (5)), con un 95\% de confianza y, por tanto, la Rúbrica de Autoevaluación del Monitoreo, Acompañamiento y Supervisión de la Sesión de Clase es válida por juicio de expertos o subjetivamente.

\subsection{Validez objetiva.}

\section{Cuadro $\mathrm{N}^{\circ} 02$}

Correlaciones r de Pearson corregidas ítem-test (30 ítems)

\begin{tabular}{|c|c|}
\hline Item & $\begin{array}{c}\text { R corregida } \\
\text { de Pearson }\end{array}$ \\
\hline Item1 & 0,710 \\
Item2 & 0,717 \\
Item3 & 0,658 \\
Item4 & 0,770 \\
Item5 & 0,692 \\
Item6 & 0,634 \\
Item7 & 0,717 \\
Item8 & 0,750 \\
Item9 & 0,758 \\
Item10 & 0,516 \\
\hline
\end{tabular}

\begin{tabular}{|c|c|}
\hline Item & $\begin{array}{c}\text { R corregida } \\
\text { de Pearson }\end{array}$ \\
\hline Item11 & 0,752 \\
Item12 & 0,595 \\
Item13 & 0,751 \\
Item14 & 0,675 \\
Item15 & 0,642 \\
Item16 & 0,593 \\
Item17 & 0,549 \\
Item18 & 0,620 \\
Item19 & 0,590 \\
Item20 & 0,725 \\
\hline
\end{tabular}

\begin{tabular}{|c|c|}
\hline Item & $\begin{array}{c}\text { R corregida } \\
\text { de Pearson }\end{array}$ \\
\hline Item21 & 0,589 \\
Item22 & 0,693 \\
Item23 & 0,742 \\
Item24 & 0,649 \\
Item25 & 0,727 \\
Item26 & 0,626 \\
Item27 & 0,710 \\
Item28 & 0,688 \\
Item29 & 0,616 \\
Item30 & 0,661 \\
\hline
\end{tabular}

Fuente: Elaboración propia.

Todos los coeficientes de correlación $r$ corregida de Pearson son mayores que 0,2, por lo que la Rúbrica de Autoevaluación del Monitoreo, Acompañamiento y Supervisión de la Sesión de Clase es válida objetivamente.

De los resultados de la prueba t de Student para el juicio de expertos y de los valores de los coeficientes de correlación $r$ corregida de Pearson se concluye que la Rúbrica de Autoevaluación del Monitoreo, Acompañamiento y Supervisión de la Sesión de Clase es válida. 


\section{Evaluación de la confiabilidad}

La confiabilidad del instrumento se evaluó con los resultados de su aplicación a una muestra piloto de 50 profesores de las IEPs de la Provincia de Huancayo y, con el coeficiente alfa de Cronbach, cuya expresión es:

$$
\alpha=\frac{k}{k-1}\left(1-\frac{\sum S_{i}^{2}}{S^{2}}\right)
$$

donde:

a es el coeficiente alfa de Cronbach,

$S_{i}^{2} \quad$ es la varianza de los resultados del ítem,

$\mathrm{S}^{2}$ es la varianza de la puntuación total del test,

k es el número de ítems.

Estos coeficientes toman valores entre 0 y 1 , y un valor mayor a 0,7 indica que el instrumento es confiable.

El programa estadístico SPSS v.20 reporta un coeficiente alfa de Cronbach de 0,963 , con el cual se concluye que la Rúbrica de Autoevaluación del Monitoreo, Acompañamiento y Supervisión de la Sesión de Clase es confiable, porque este coeficiente es superior a 0,7 .

\section{Cuadro $\mathrm{N}^{\circ} 03$ \\ Estadísticos de Fiabilidad}

\begin{tabular}{|c|c|}
\hline $\begin{array}{c}\text { Alfa de } \\
\text { Cronbach }\end{array}$ & $\begin{array}{c}\mathrm{N} \text { de } \\
\text { elementos }\end{array}$ \\
\hline, 963 & 30 \\
\hline
\end{tabular}

Fuente: Elaboración propia.

De estos resultados se deriva que el instrumento es válido y confiable y, por tanto adecuado. 


\subsection{PROCEDIMIENTOS DE RECOLECCIÓN DE DATOS.}

Para la presente investigación se desarrollaron los siguientes pasos:

* Se realizó una invitación general (mediante el Diario Correo y virtual por la página web institucional) a los docentes y directores de las instituciones educativas de la provincia de Huancayo para participar en el ciclo de capacitaciones de Actualización Pedagógica en las Comunidades de Aprendizaje Salesianos (CASA) del Colegio Salesiano Santa Rosa de manera voluntaria y gratuita.

* Se planificó el plan de trabajo del proceso de la investigación.

* Se elaboró La rúbrica de autoevaluación del monitoreo, acompañamiento y supervisión de la sesión de clase.

* Se identificó el grupo experimental.

* Se procesaron los datos para verificar la eficacia del trabajo.

* Se redactó el borrador del informe de la investigación.

* Se presentó los ejemplares finales, luego de haber corregido los defectos y dificultades que se localizaron en la presente investigación.

\subsection{TÉCNICAS DE PROCESAMIENTO Y ANÁLISIS DE RESULTADOS.}

Se aplicó la estadística descriptiva como: la media aritmética, varianza, desviación típica o standard y coeficiente de variación, así como la estadística inferencial para la validación y comprobación de la hipótesis, Prueba Z. 


\section{CAPÍTULO IV PRESENTACIÓN Y ANÁLISIS DE RESULTADOS}

El presente capítulo describe el manejo estadístico de los datos obtenidos de la investigación: Rúbrica y desempeño docente en la Provincia de Huancayo que tuvo como finalidad el de desarrollar el desempeño docente a través de la rúbrica.

Los datos fueron procesados por el investigador con el paquete estadístico SPSS, versión 20, en español. Los datos que se muestran son producto de los resultados de la investigación.

La muestra está conformada por 751 docentes de las diferentes instituciones educativas de la provincia de Huancayo, correspondientes a las 12 Unidades de Gestión Educativa de nuestra jurisdicción.

- Ugel 1 de Concepción : 82 docentes

- Ugel 2 de Chanchamayo : 34 docentes

- Ugel 3 de Chupaca : 106 docentes

- Ugel 4 de Huancayo : 420 docentes

- Ugel 5 de Jauja : 45 docentes

- Ugel 6 de Junín : 10 docentes

- Ugel 7 de Pangoa : 03 docentes

- Ugel 8 de Pichanaki : 02 docentes

- Ugel 9 de Satipo : 02 docentes

- Ugel 10 de Tarma : 05 docentes

- Ugel 11 de Yauli : 42 docentes

- Ugel 12 de Río Tambo : 00 docentes 
Estos docentes se presentaron voluntariamente al proceso de capacitación sobre: Actualización y Capacitación Pedagógica 2011 que se organizó desde las Comunidades de Aprendizaje Salesianos de la IEP Salesiano Santa Rosa de Huancayo, en el cual se trataron diversos temas, entre ellos:

- Diversificación Curricular: Modelo T

- Estrategias de Aprendizaje Enseñanza: Actividades como Estrategias de Aprendizaje.

- Evaluación: Rúbrica de evaluación.

- Gestión Educativa: Supervisión al Desempeño Docente.

Los integrantes de la muestra pertenecen al grupo experimental de acuerdo al diseño seleccionado.

Se presentaron también docentes de las Regiones de:

- Huancavelica : 182 docentes,

- Pasco : 02 docentes

- Lima : 04 docentes

Quienes no pertenecen a la muestra por pertenecer a otra región. Presentamos los resultados pertinentes:

\subsection{PRESENTACIÓN, ANÁLISIS E INTERPRETACIÓN DE LOS DATOS.}

\subsubsection{Desempeño docente de los profesores}


Cuadro $\mathrm{N}^{\circ} 04$

Valoración de los ítems del cuestionario de desempeño docente $(n=751)$

\begin{tabular}{|c|c|c|c|c|c|c|c|c|c|c|}
\hline \multirow{3}{*}{ Item } & \multicolumn{10}{|c|}{ Valoración } \\
\hline & \multicolumn{2}{|c|}{$\begin{array}{c}\text { Muy } \\
\text { deficiente }\end{array}$} & \multicolumn{2}{|c|}{ Deficiente } & \multicolumn{2}{|c|}{ Regular } & \multicolumn{2}{|c|}{ Satisfactorio } & \multicolumn{2}{|c|}{$\begin{array}{c}\text { Muy } \\
\text { satisfactorio }\end{array}$} \\
\hline & $f$ & $\%$ & $f$ & $\%$ & $f$ & $\%$ & $\mathrm{~F}$ & $\%$ & $f$ & $\%$ \\
\hline Plan1 & 3 & 0,4 & 12 & 1,6 & 139 & 18,5 & 432 & 57,5 & 165 & 22,0 \\
\hline Plan2 & 1 & 0,1 & 10 & 1,3 & 112 & 14,9 & 440 & 58,6 & 188 & 25,0 \\
\hline Plan3 & 1 & 0,1 & 11 & 1,5 & 136 & 18,1 & 420 & 55,9 & 183 & 24,4 \\
\hline Plan4 & & & 7 & 0,9 & 115 & 15,3 & 413 & 55,0 & 216 & 28,8 \\
\hline Plan5 & 2 & 0,3 & 11 & 1,5 & 153 & 20,4 & 402 & 53,5 & 183 & 24,4 \\
\hline Met6 & & & 5 & 0,7 & 125 & 16,6 & 459 & 61,1 & 162 & 21,6 \\
\hline Met7 & & & 4 & 0,5 & 107 & 14,2 & 437 & 58,2 & 203 & 27,0 \\
\hline Met8 & & & 18 & 2,4 & 185 & 24,6 & 398 & 53,0 & 150 & 20,0 \\
\hline Met9 & & & 11 & 1,5 & 115 & 15,3 & 408 & 54,3 & 217 & 28,9 \\
\hline Met10 & 1 & 0,1 & 17 & 2,3 & 145 & 19,3 & 418 & 55,7 & 170 & 22,6 \\
\hline Eva11 & 1 & 0,1 & 11 & 1,5 & 143 & 19,0 & 386 & 51,4 & 210 & 28,0 \\
\hline Eva12 & & & 8 & 1,1 & 128 & 17,0 & 414 & 55,1 & 201 & 26,8 \\
\hline Eva13 & 2 & 0,3 & 14 & 1,9 & 158 & 21,0 & 399 & 53,1 & 178 & 23,7 \\
\hline Eva14 & 2 & 0,3 & 7 & 0,9 & 138 & 18,4 & 402 & 53,5 & 202 & 26,9 \\
\hline Eva15 & & & 13 & 1,7 & 130 & 17,3 & 411 & 54,7 & 197 & 26,2 \\
\hline Cli16 & & & 7 & 0,9 & 56 & 7,5 & 336 & 44,7 & 352 & 46,9 \\
\hline Cli17 & & & 5 & 0,7 & 59 & 7,9 & 382 & 50,9 & 305 & 40,6 \\
\hline Cli18 & & & 10 & 1,3 & 105 & 14,0 & 432 & 57,5 & 204 & 27,2 \\
\hline Cli19 & & & 5 & 0,7 & 81 & 10,8 & 388 & 51,7 & 277 & 36,9 \\
\hline Cli20 & & & 9 & 1,2 & 89 & 11,9 & 374 & 49,8 & 279 & 37,2 \\
\hline Tie21 & & & 11 & 1,5 & 97 & 12,9 & 327 & 43,5 & 316 & 42,1 \\
\hline Tie22 & & & 9 & 1,2 & 151 & 20,1 & 419 & 55,8 & 172 & 22,9 \\
\hline Tie23 & 1 & 0,1 & 8 & 1,1 & 138 & 18,4 & 403 & 53,7 & 201 & 26,8 \\
\hline Tie24 & 3 & 0,4 & 30 & 4,0 & 186 & 24,8 & 361 & 48,1 & 171 & 22,8 \\
\hline Tie25 & & & 9 & 1,2 & 76 & 10,1 & 376 & 50,1 & 290 & 38,6 \\
\hline Rec26 & 4 & 0,5 & 10 & 1,3 & 112 & 14,9 & 356 & 47,4 & 269 & 35,8 \\
\hline Rec27 & 2 & 0,3 & 5 & 0,7 & 120 & 16,0 & 414 & 55,1 & 210 & 28,0 \\
\hline Rec28 & 1 & 0,1 & 10 & 1,3 & 128 & 17,0 & 405 & 53,9 & 207 & 27,6 \\
\hline Rec29 & & & 9 & 1,2 & 102 & 13,6 & 384 & 51,1 & 256 & 34,1 \\
\hline Rec30 & & & 5 & 0,7 & 100 & 13,3 & 420 & 55,9 & 226 & 30,1 \\
\hline
\end{tabular}

Fuente: Elaboración propia. 
Gráfico № 07.

Valoración de los ítems del cuestionario de desempeño docente $(n=751)$

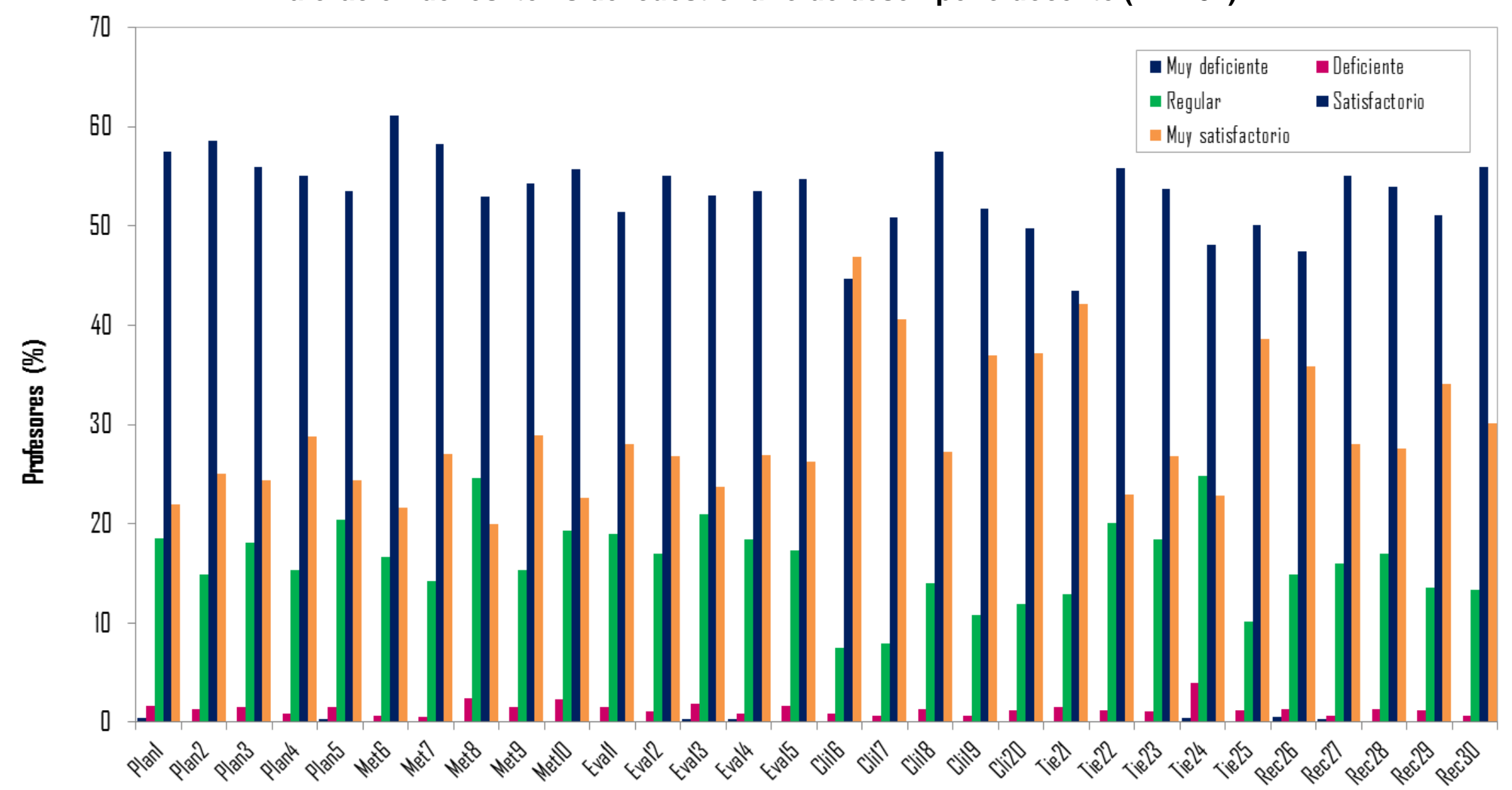

Fuente: Elaboración propia. 


\section{Interpretación:}

En el cuadro $\mathrm{N}^{\circ} 04$ y gráfico $\mathrm{N}^{\circ} 09$ se aprecia que la valoración de los ítems del desempeño docente se concentra entre regular y muy satisfactorio, con predominio de satisfactorio, seguido de muy satisfactorio y regular. La mayoría de ítems son satisfactorios $(25 / 30=83 \%)$, fluctuando entre 50,1\% (Tie25) y 61,1\% (Met6). La valoración de cinco ítems es muy cercana al 50\%: cuatro a satisfactoria (Cli210, Tie21, Tie24 y Rec26); una a muy satisfactoria (Cli26).

\section{Cuadro $N^{\circ} 05$.}

Estadísticos del desempeño docente de los profesores $(\mathbf{n}=751)$

\begin{tabular}{|c|c|c|c|c|c|c|c|}
\hline Dimensión & $\begin{array}{l}\text { Rango } \\
\text { teórico }\end{array}$ & $\begin{array}{c}\text { Rango } \\
\text { real }\end{array}$ & Media & DE & CV & CA & CC \\
\hline Planificación & 5 a 25 & 10 a 25 & 20,21 & 2,72 & $13,5 \%$ & $\overline{0}, 40$ & 0,50 \\
\hline Metodología & 5 a 25 & 10 a 25 & 20,15 & 2,63 & $13,0 \%$ & $\overline{0}, 22$ & 0,17 \\
\hline Evaluación & 5 a 25 & 10 a 25 & 20,23 & 2,79 & $13,8 \%$ & $\overline{0}, 25$ & $\overline{-}, 22$ \\
\hline Clima & 5 a 25 & 10 a 25 & 21,27 & 2,65 & $12,5 \%$ & $\overline{-}$ & 0,54 \\
\hline Tiempo & 5 a 25 & 10 a 25 & 20,47 & 2,68 & $13,1 \%$ & $\overline{0,49}$ & 0,31 \\
\hline Recursos & 5 a 25 & 10 a 25 & 20,68 & 2,70 & $13,1 \%$ & $\overline{-}$ & 0,49 \\
\hline Desempeño & 30 a 150 & $\begin{array}{l}71 a \\
150 \\
\end{array}$ & 123,01 & 13,29 & $10,8 \%$ & $\overline{0,42}$ & 0,38 \\
\hline
\end{tabular}

Fuente: Elaboración Propia.

$\mathrm{DE}=$ Desviación estándar;

$\mathrm{CV}=$ Coeficiente de variación;

$\mathrm{CA}=$ Coeficiente de asimetría;

$\mathrm{CC}=$ Coeficiente de curtosis 
Gráfico $\mathrm{N}^{\circ} 08$.

Desempeño docente de Planificación

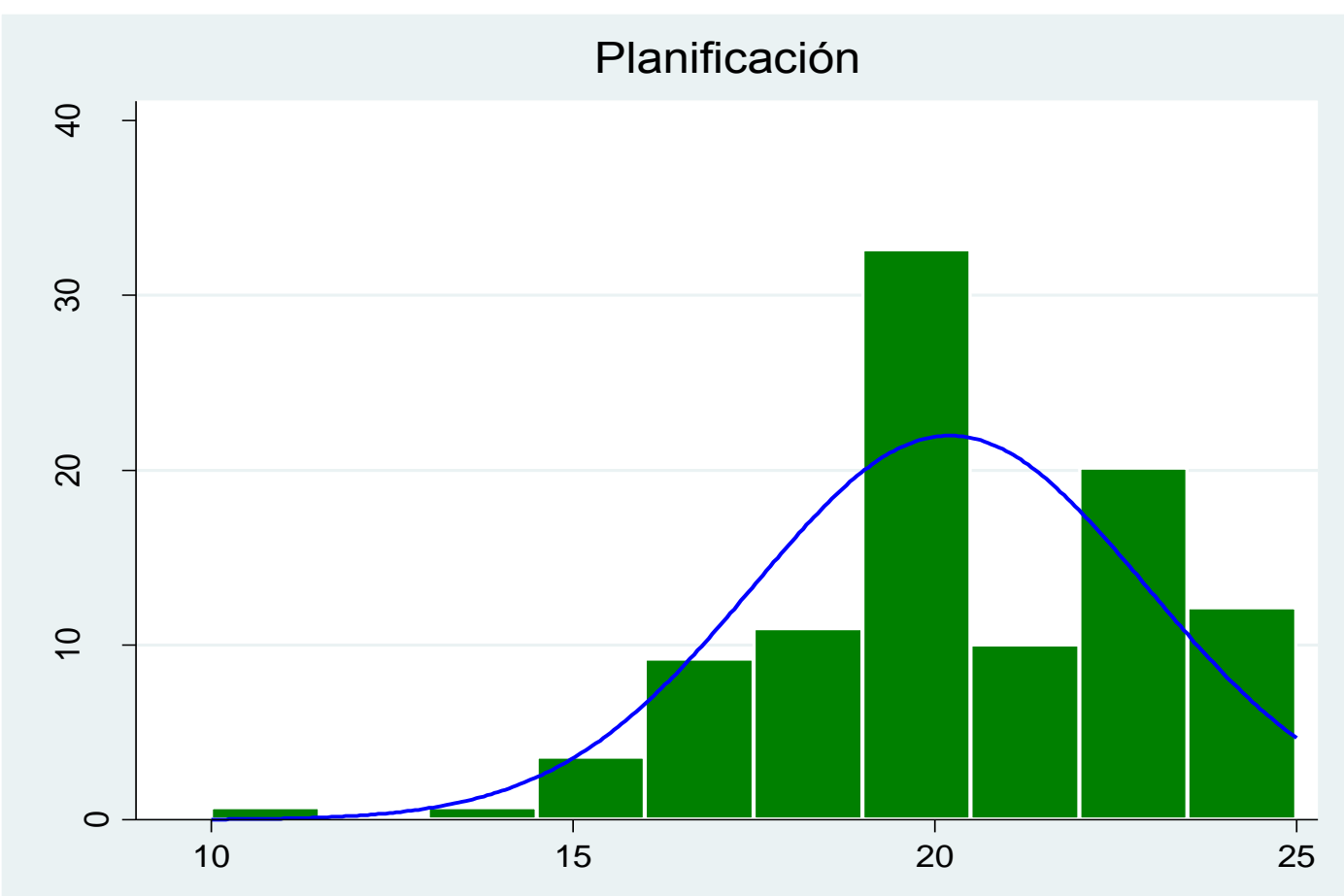

Fuente: Elaboración Propia.

Gráfico Nº9.

Desempeño docente de Metodología

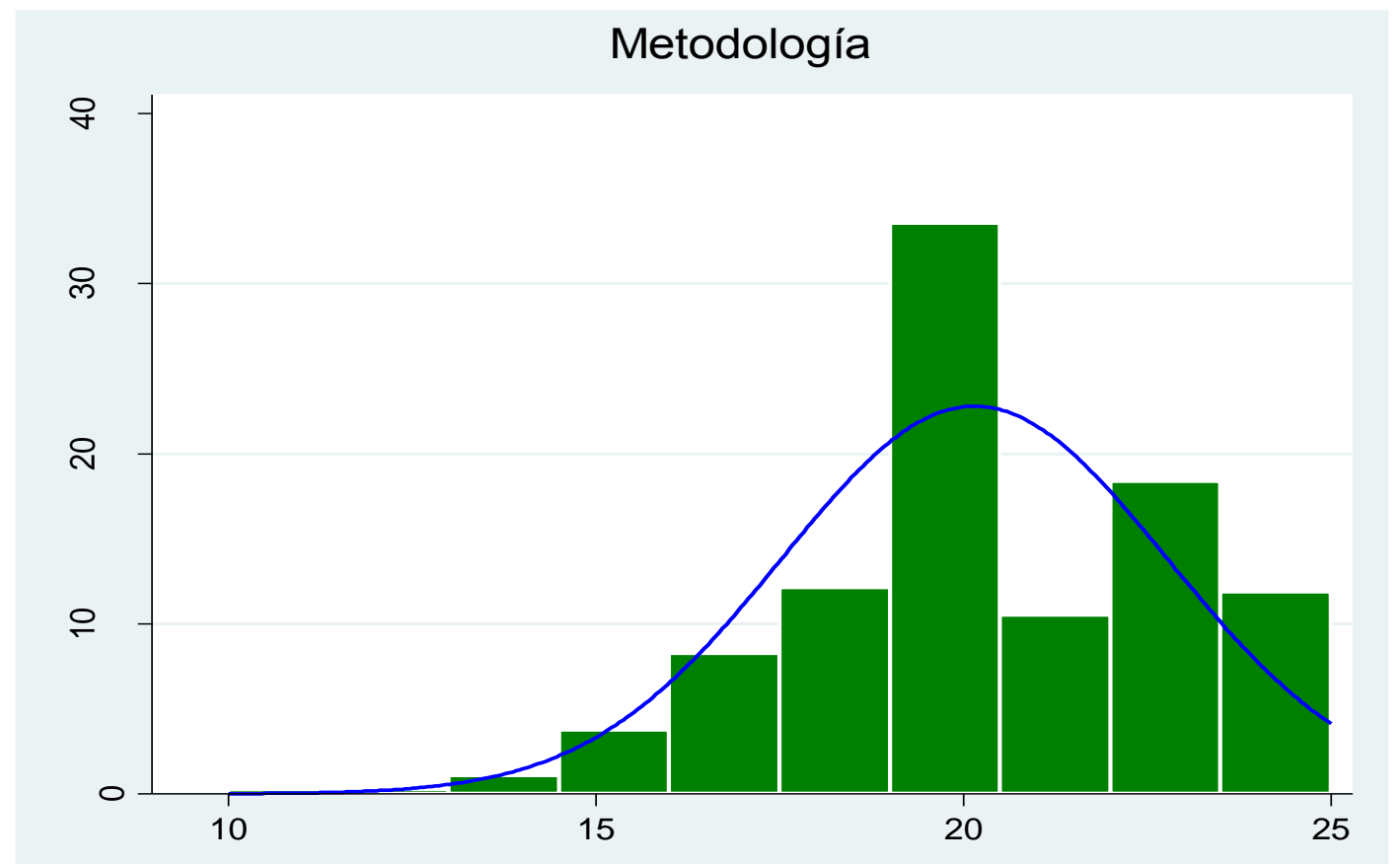

Fuente: Elaboración Propia. 
Gráfico $\mathrm{N}^{\circ} 10$.

Desempeño docente de Evaluación

Evaluación

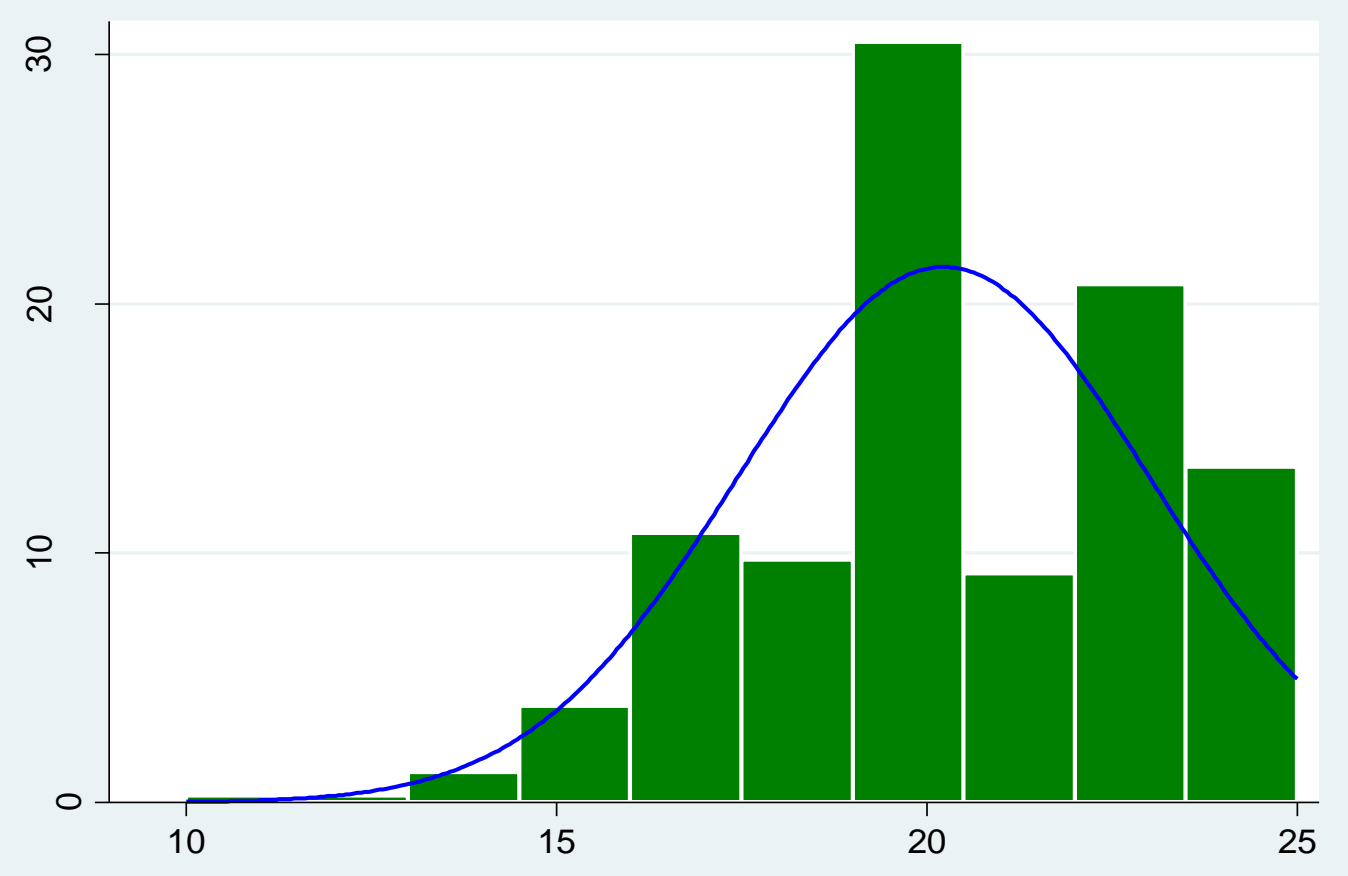

Fuente: Elaboración Propia.

Gráfico N¹1.

Desempeño docente de Clima para el Aprendizaje

Clima para el aprendizaje

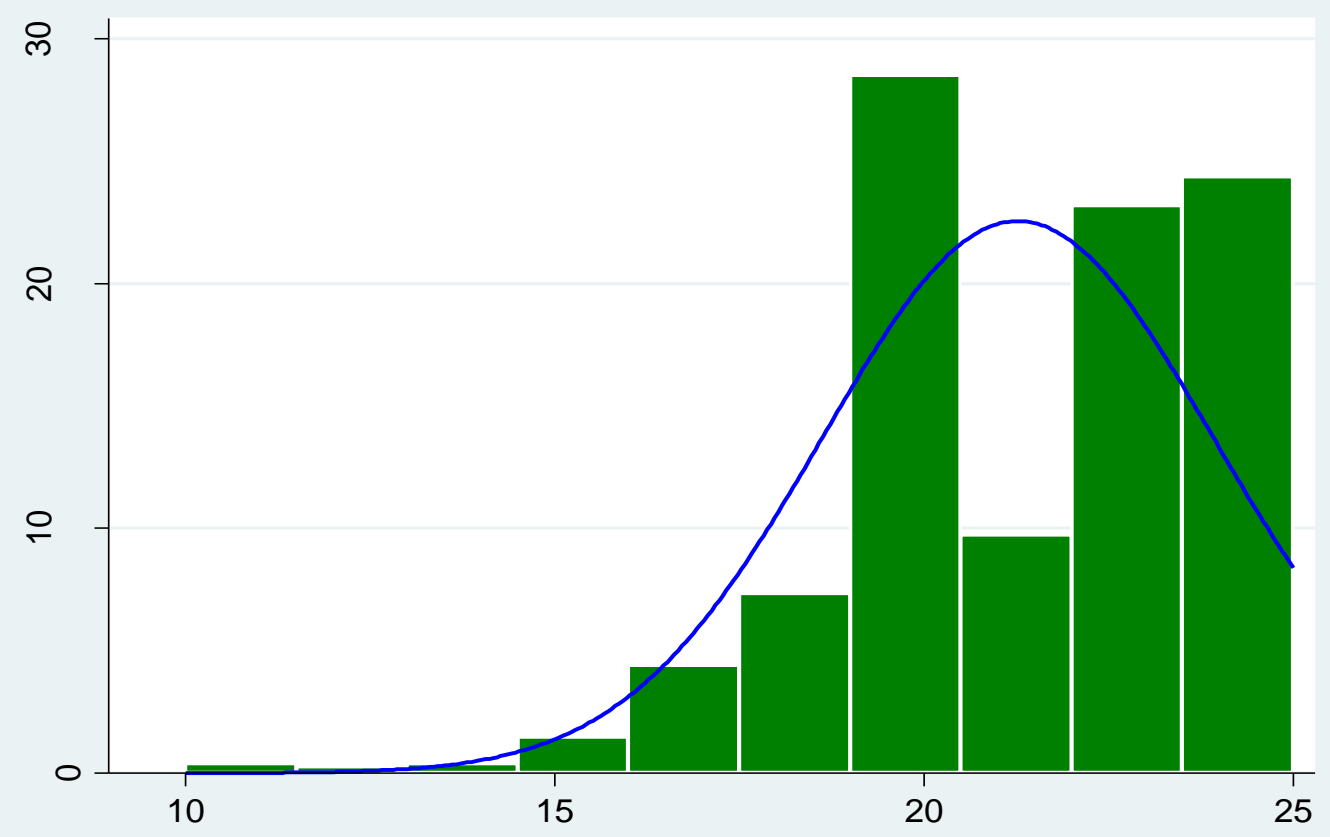

Fuente: Elaboración Propia. 
Gráfico № 12.

Desempeño docente de Tiempo en el aula

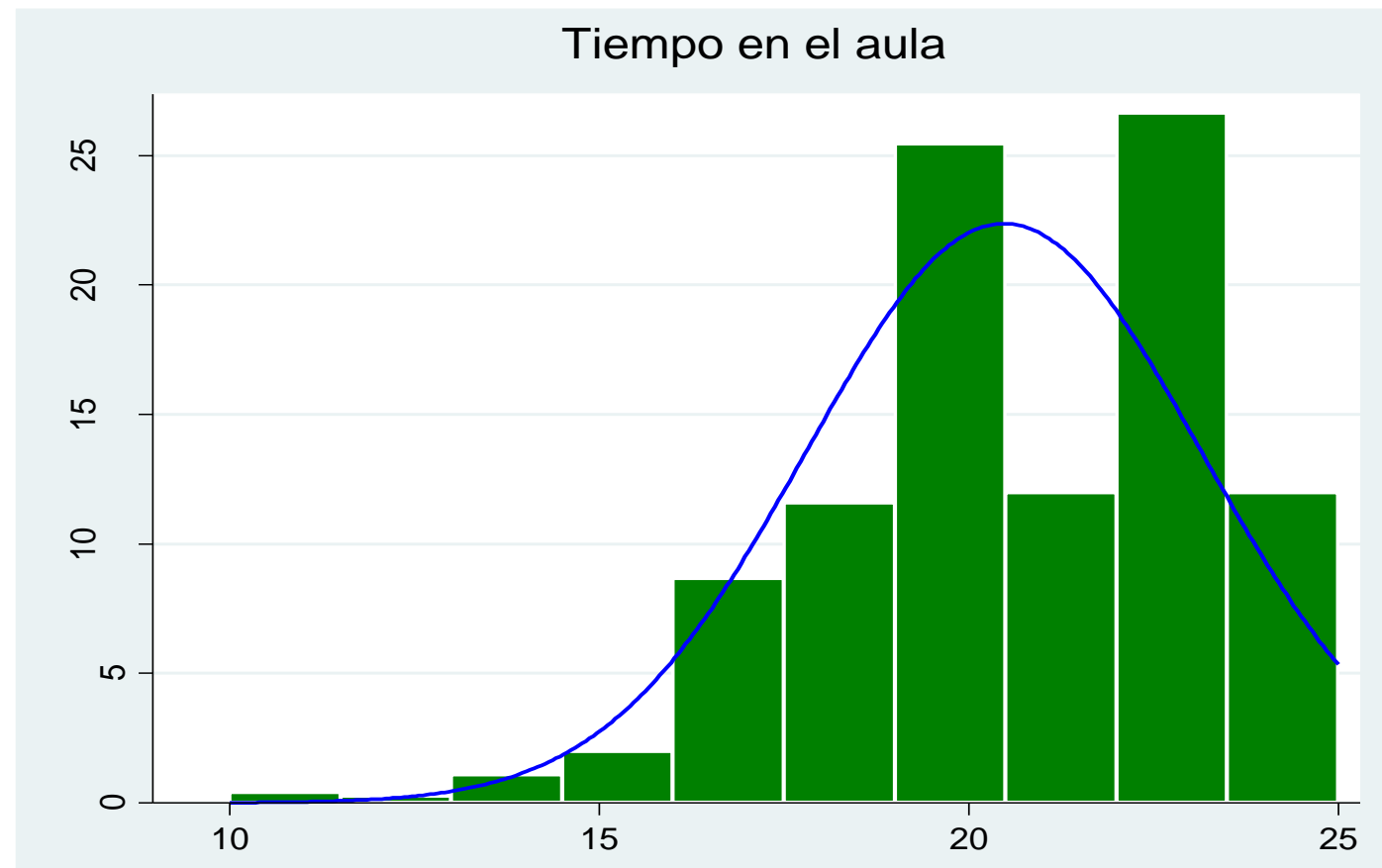

Fuente: Elaboración Propia.

Gráfico N ${ }^{\circ} 13$.

Desempeño docente de Recursos y Materiales

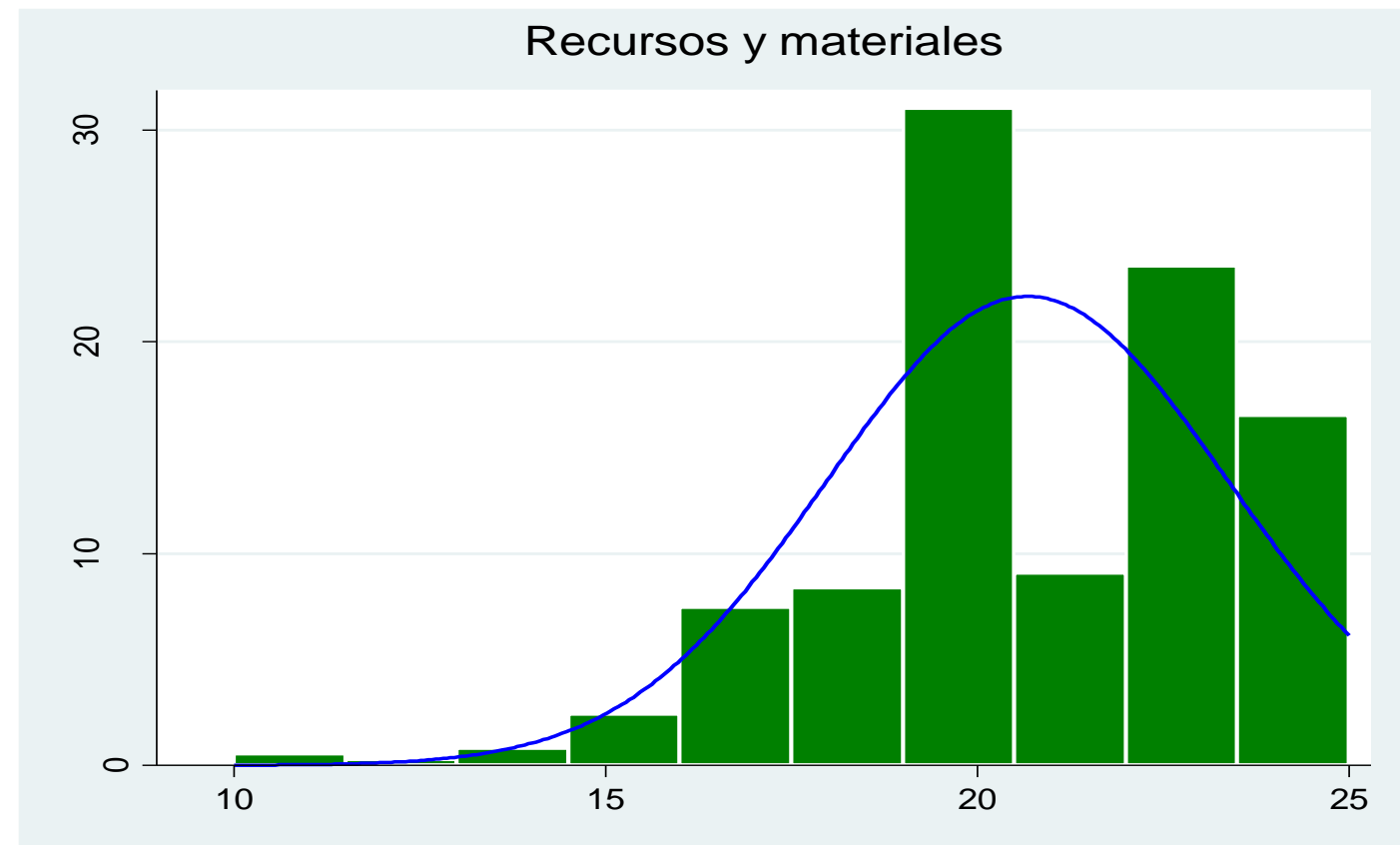

Fuente: Elaboración Propia. 
Gráfico $N^{\circ} 14$.

Resultados del Desempeño docente

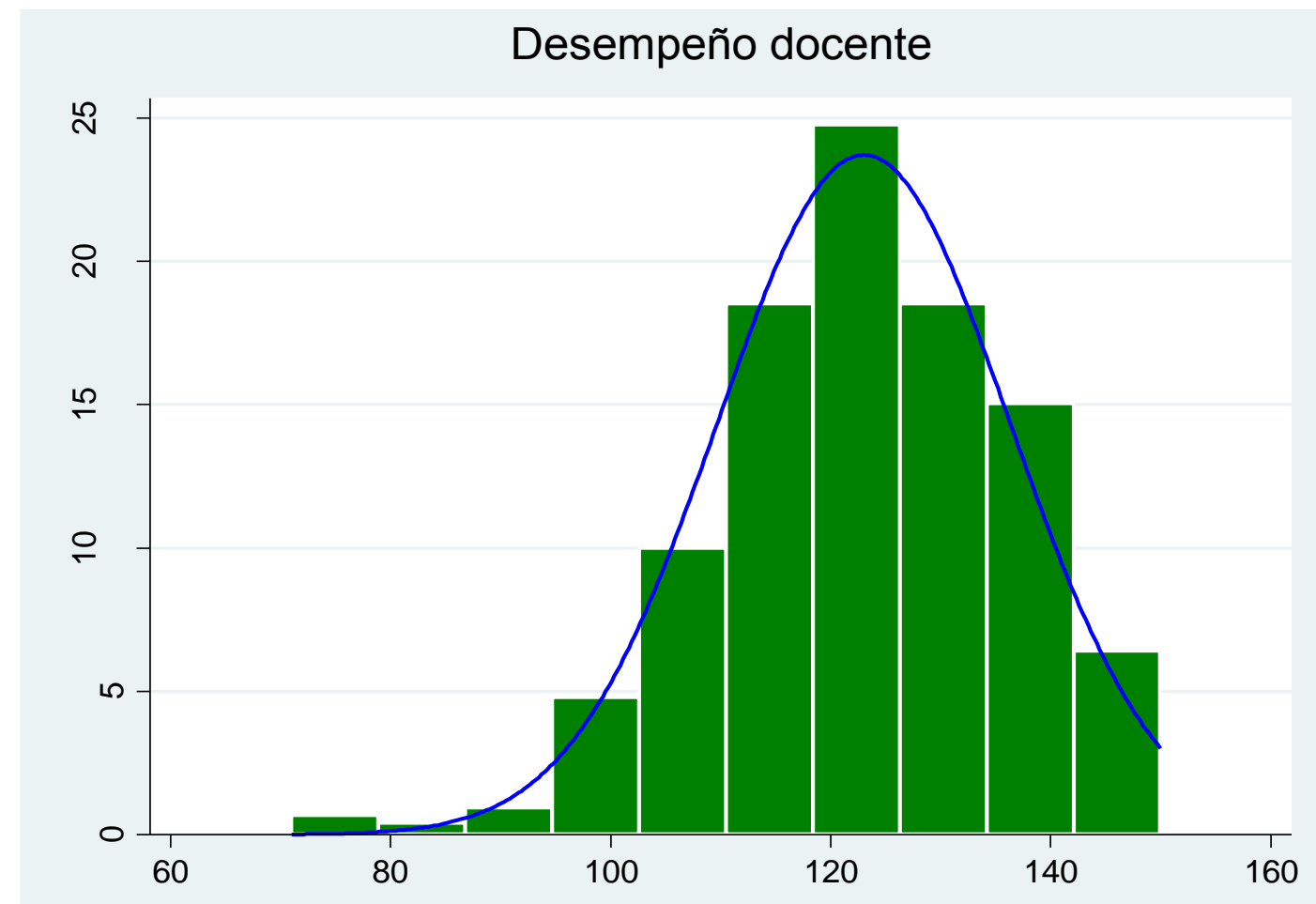

Fuente: Elaboración Propia.

Gráfico $N^{\circ} 15$

Medias teóricas y reales de las dimensiones del desempeño docente

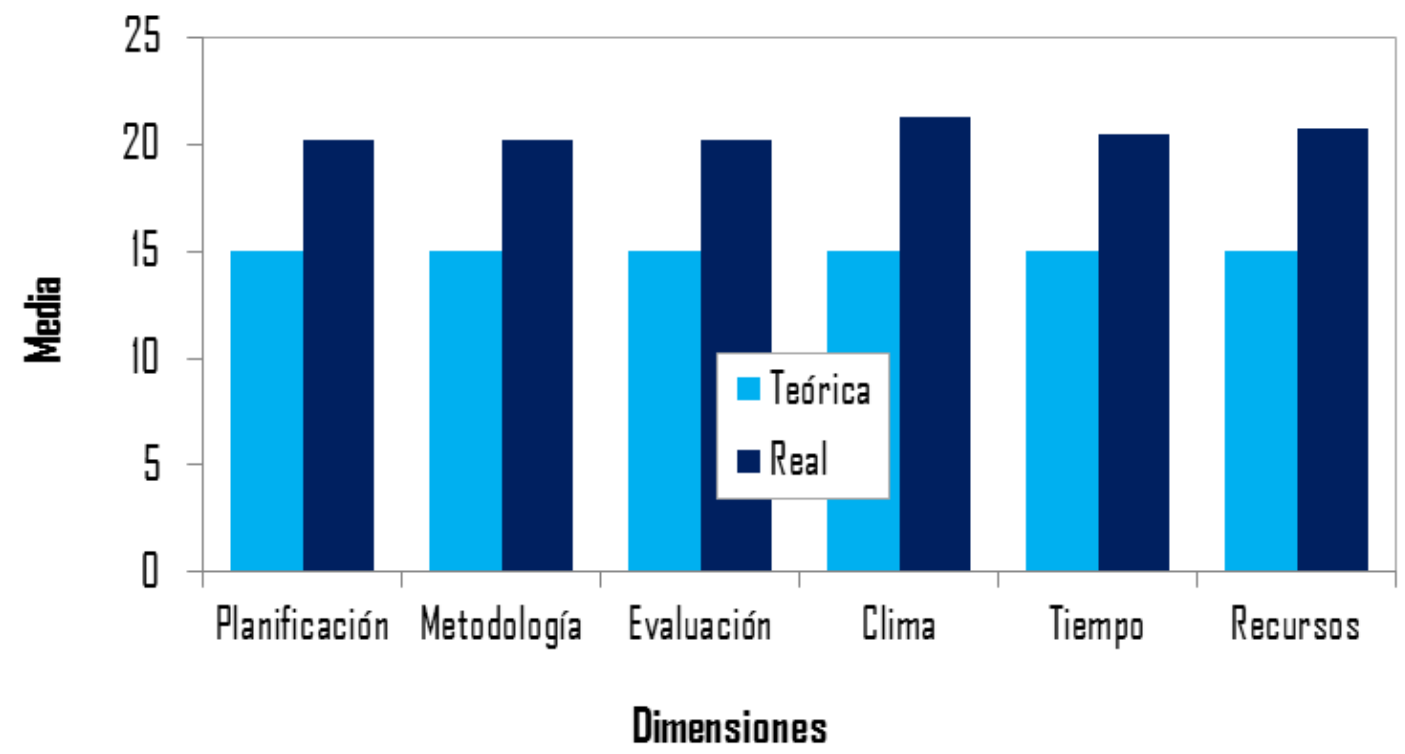

Fuente: Elaboración Propia. 


\section{Interpretación:}

En el cuadro $\mathrm{N}^{\circ} 05$ se observa que el desempeño docente de los profesores de las IEPs de la Provincia de Huancayo, después de aplicar la rúbrica, alcanza una media de 123,01 con una desviación estándar de 13,29, un coeficiente de variación de 10,8\%, un rango real de 71 a 150, un coeficiente de asimetría de -0,42 y un coeficiente de curtorsis de 0,38.

Estos estadísticos indican que la media del desempeño docente supera a la media ideal, teórica o esperada de 90(1). Los profesores constituyen un grupo homogéneo con respecto a su desempeño docente, al reportar un coeficiente de variación inferior a 15\%(2). La distribución de las puntuaciones del desempeño docente es normal (simétrica ${ }^{(3)}$ y mesocúrtica $^{(4)}$ ) (Gráficos 10, 11, 12, 13, 14, 15 y 16) al mostrar un coeficiente de asimetría y de curtosis entre $-0,5$ y 0,5.

Cada una de las dimensiones del desempeño docente logra una media superior a su media ideal respectiva (15) (Gráfico N 17). Por otro lado, los profesores conforman un grupo homogéneo con relación a cada una de las dimensiones del desempeño docente, pues sus coeficientes de variación respectivos son inferiores a 15\%.

Las distribuciones de la planificación, metodología, evaluación y tiempo en el aula son normales (simétricas y mesocúrticas) (Gráficos 10, 11, 12, $13,14,15$ y 16), ya que sus coeficientes de asimetría y de curtosis se encuentran entre $-0,5$ y 0,5 .

La distribución del clima para el aprendizaje es asimétrica negativa y leptocúrtica (más alta que la curva normal) (Gráficos 10, 11, 12, 13, 14, 15 y 16, pues su coeficiente de asimetría y de curtosis es inferior a -0,5 y superior a 0,5 , respectivamente. La distribución de recursos y materiales

(1) Rangos y medias ideales: Desempeño: 30 a 150; $(30+150) / 2$ = 90; Planificación, Metodología, Evaluación, Clima, Tiempo, Recursos: 5 a 25; $(5+25) / 2=15$

(2) Baremo del coeficiente de variación: Muy homogéneo: 0 a 5\%; homogéneo: $5,1 \%$ a $10 \%$; regularmente homogéneo: 10,1 a 15\%; regularmente heterogéneo: 15,1 a 20\%; heterogéneo: 20,1 a $25 \%$, muy heterogéneo: $25,1 \%$ a más

(3) Simetría de una distribución: Asimét. negativa: $C A<-0,5$; Simétrica: $-0,5 \leq C A \leq 0,5$; Asimét. positiva: $\mathrm{CA}>0,5$

(4) Apuntamiento de una distribución: Platicúrtica (PK): $C C<-0,5$; Mesocúrtica (MK): $-0,5 \leq \mathrm{CC} \leq 0,5$; Leptocúrtica (LK): CC > 0,5 
es asimétrica negativa y mesocúrtica, ya que su coeficiente de asimetría y de curtosis es inferior a $-0,5$ y se encuentra entre $-0,5$ y 0,5 , respectivamente.

\section{Cuadro $\mathrm{N}^{\circ} 06$}

Nivel del desempeño docente de los profesores $(n=751)$

\begin{tabular}{|c|c|c|c|c|c|c|c|c|}
\hline \multirow{3}{*}{ Dimensión } & \multicolumn{8}{|c|}{ Nivel de desempeño } \\
\hline & \multicolumn{2}{|c|}{ Deficiente } & \multicolumn{2}{|c|}{ Regular } & \multicolumn{2}{|c|}{ Satisfactorio } & \multicolumn{2}{|c|}{$\begin{array}{c}\text { Muy } \\
\text { satisfactorio }\end{array}$} \\
\hline & $f$ & $\%$ & $f$ & $\%$ & $f$ & $\%$ & $f$ & $\%$ \\
\hline Planificación & 9 & 1,20 & 98 & 13,05 & 402 & 53,53 & 242 & 32,22 \\
\hline Metodología & 5 & 0,67 & 97 & 12,92 & 422 & 56,19 & 227 & 30,23 \\
\hline Evaluación & 7 & 0,93 & 116 & 15,45 & 371 & 49,40 & 257 & 34,22 \\
\hline Clima & 8 & 1,07 & 44 & 5,86 & 342 & 45,54 & 357 & 47,54 \\
\hline Tiempo & 11 & 1,46 & 82 & 10,92 & 368 & 49,00 & 290 & 38,62 \\
\hline Recursos & 9 & 1,20 & 77 & 10,25 & 364 & 48,47 & 301 & 40,08 \\
\hline Desempeño & 5 & 0,67 & 46 & 6,13 & 400 & 53,26 & 300 & 39,95 \\
\hline
\end{tabular}

Fuente: Elaboración Propia.

Gráfico N 16.

Nivel de desempeño en: Planificación.

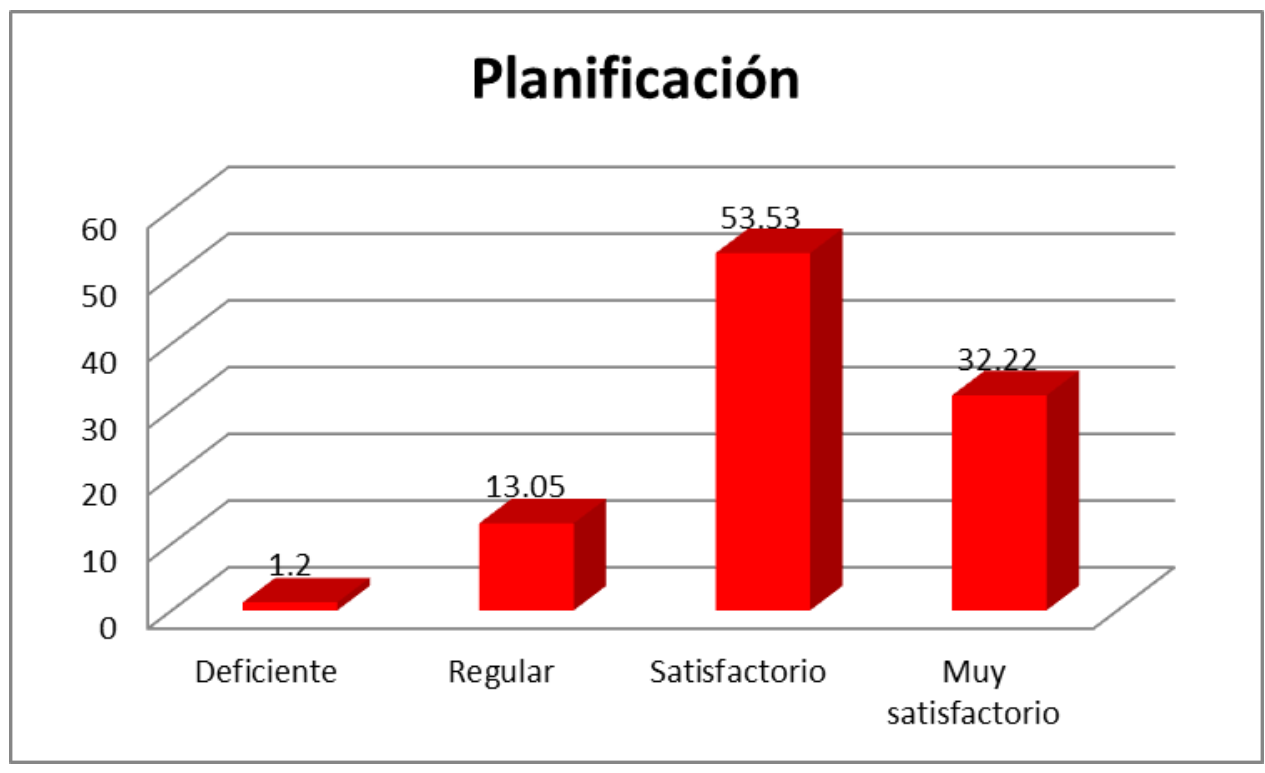

Fuente: Elaboración Propia. 
Gráfico N 17.

Nivel de desempeño en: Metodología.

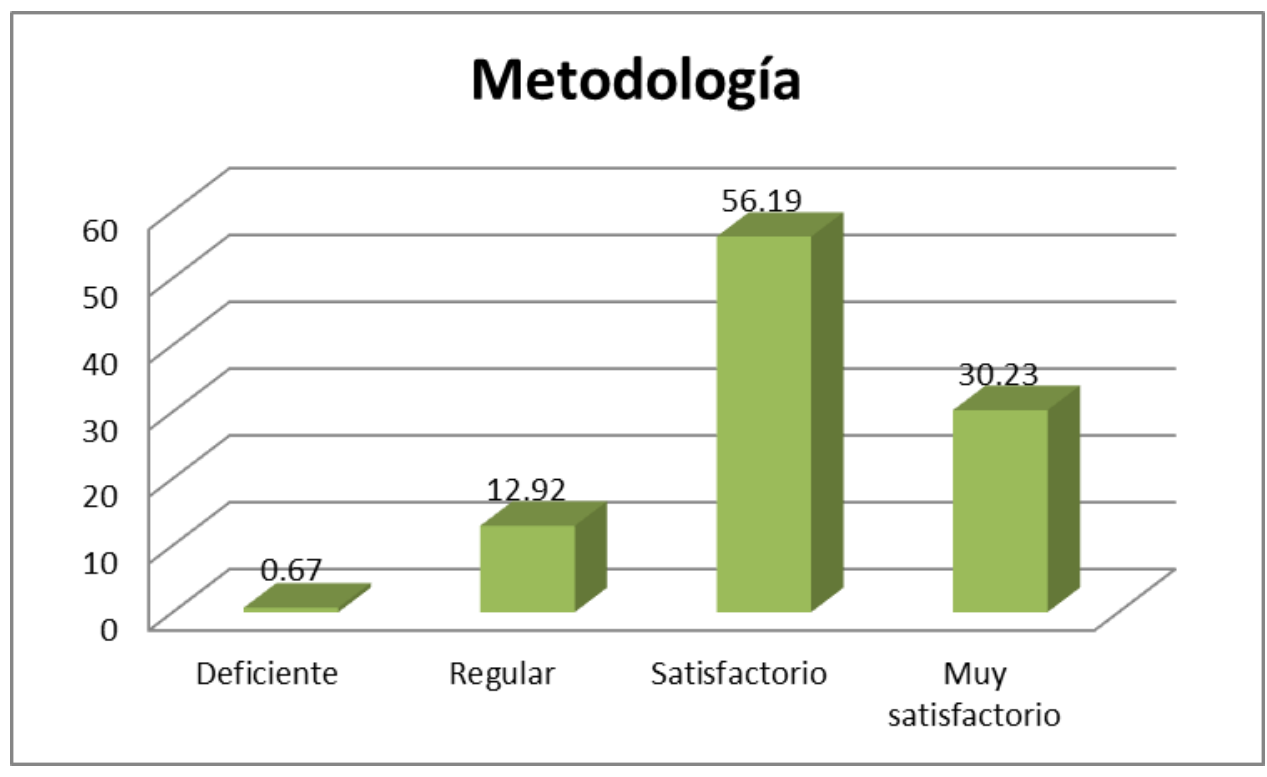

Fuente: Elaboración Propia.

Gráfico N 18.

Nivel de desempeño en: Evaluación.

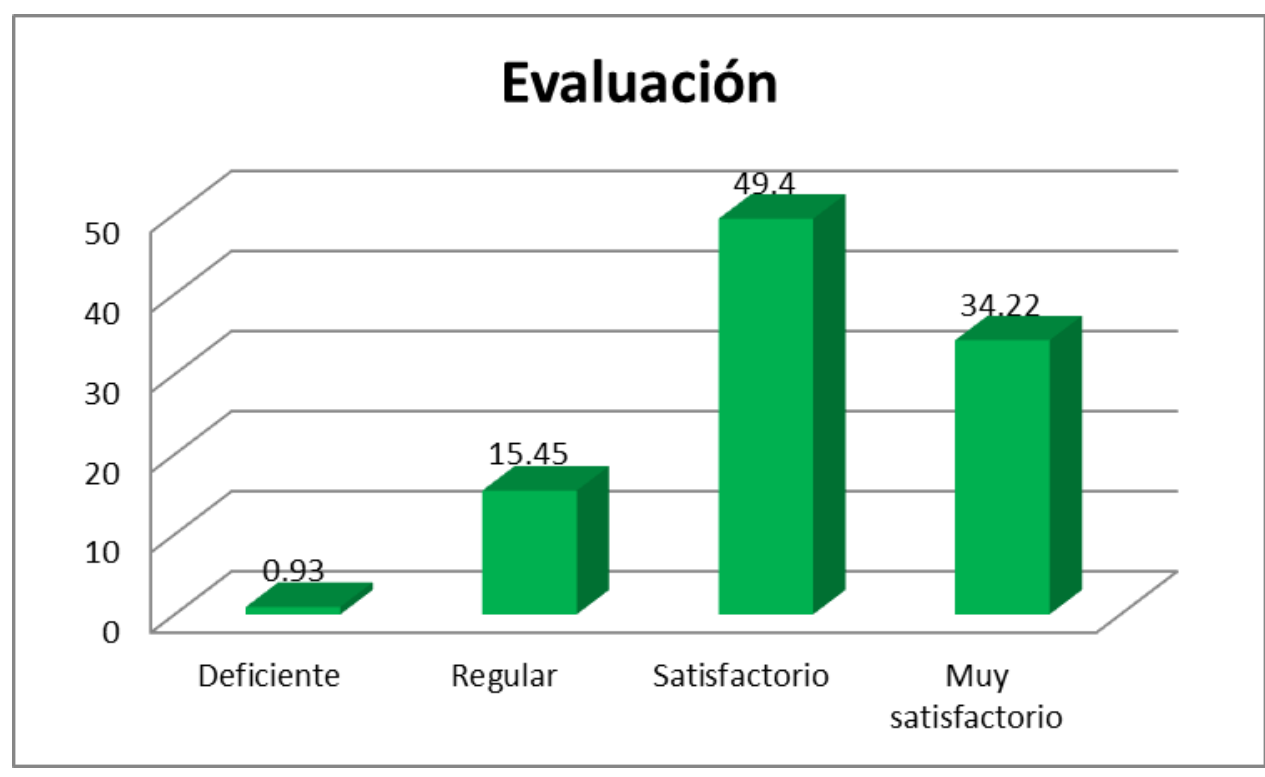

Fuente: Elaboración Propia. 
Gráfico $\mathbf{N}^{\circ} 19$.

Nivel de desempeño en: Clima para el Aprendizaje.

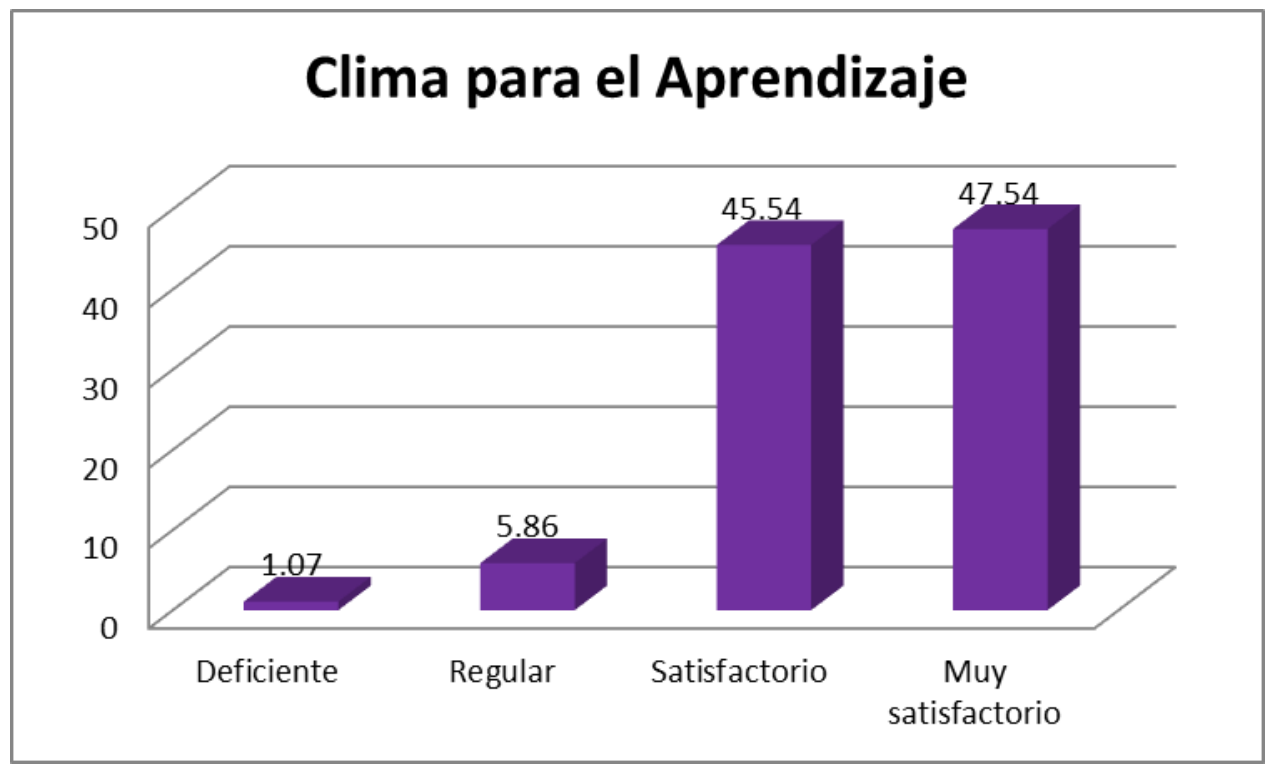

Fuente: Elaboración Propia.

Gráfico $\mathbf{N}^{\circ} 20$.

Nivel de desempeño en: Recursos y Materiales.

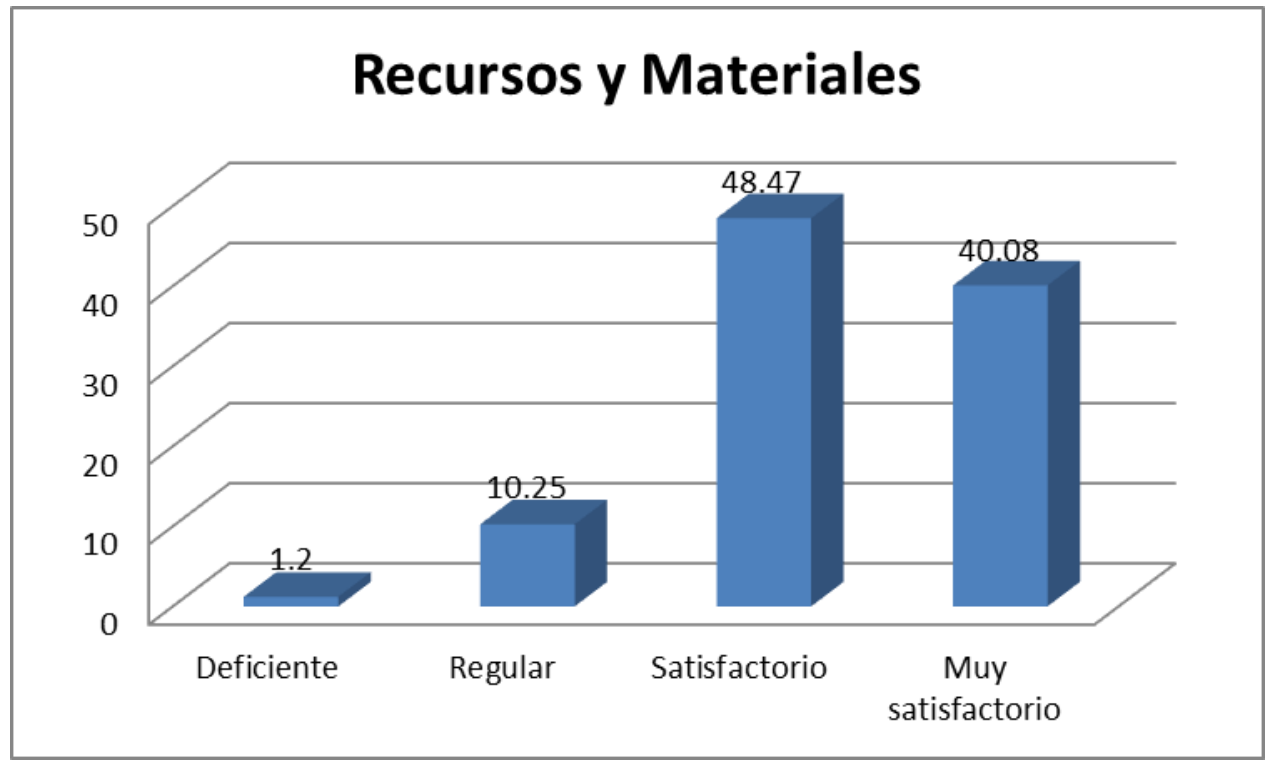

Fuente: Elaboración Propia. 
Gráfico N²1.

Nivel de desempeño en general.

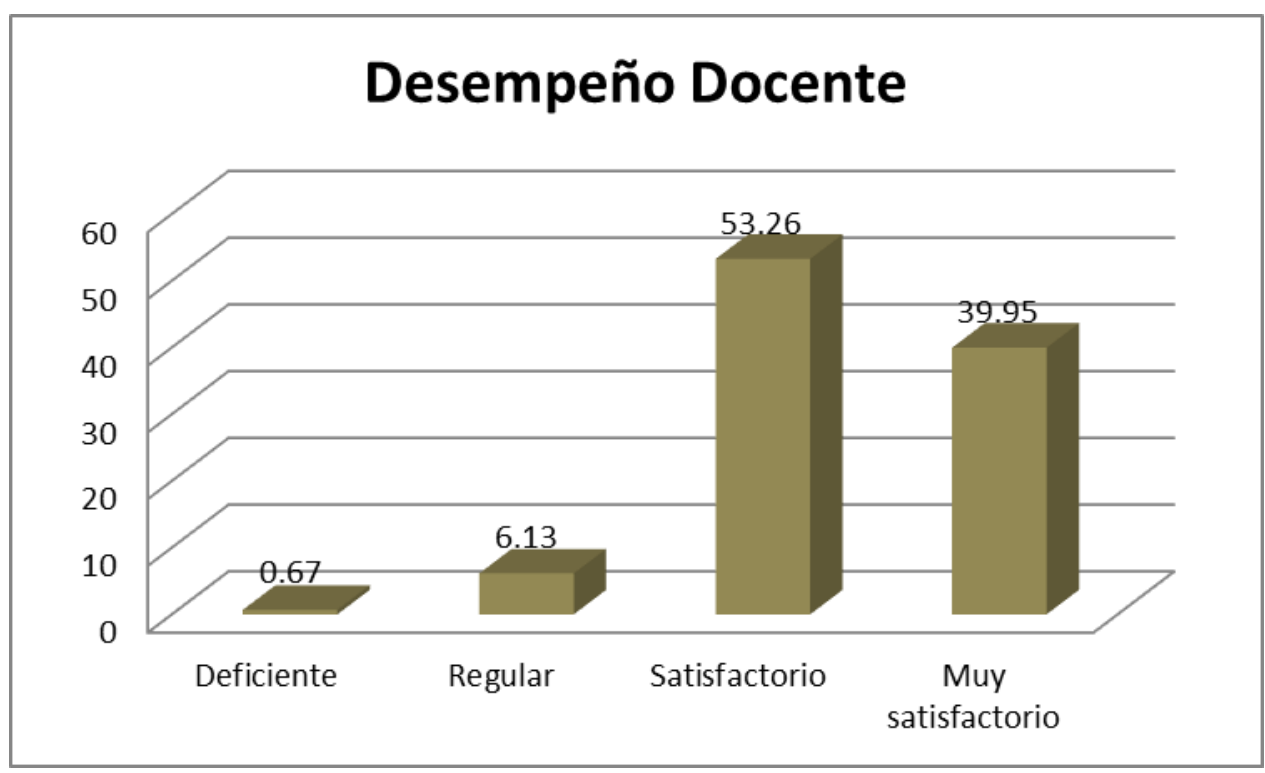

Fuente: Elaboración Propia.

\section{Interpretación:}

En el cuadro $N^{\circ} 06$ se constata que el nivel de desempeño docente de la mayoría de los profesores (53,26\%) es satisfactorio, el 39,95\% tienen un nivel muy satisfactorio, el $6,13 \%$ regular y el $0,67 \%$ deficiente (Gráficos 18, 19, 20, 21, 22, 23 y 24).

De igual modo, la mayoría de los profesores tienen un nivel satisfactorio (Gráficos 18, 19, 20, 21, 22, 23 у 24) en las dimensiones planificación $(53,53 \%)$ y metodología $(56,19 \%)$, seguido por el nivel muy satisfactorio (planificación: 32,22\%; metodología: 30,23\%).

Muy cerca del $50 \%$ de los docentes presentan un nivel satisfactorio (Gráficos 18, 19, 20, 21, 22, 23 y 24) en las dimensiones evaluación $(49,4 \%)$, clima para el aprendizaje (45,54\%), tiempo en el aula (49\%) y recursos $(48,47 \%)$, continuado por el nivel muy satisfactorio (evaluación: 34,22\%; clima para el aprendizaje: 47,54\%; tiempo en el aula: 38,62\% y; recursos: $40,08 \%)$. 


\subsubsection{Desempeño docente de los profesores, por sexo}

\section{Cuadro $\mathrm{N}^{\circ} 07$.}

Estadísticos del desempeño docente de los profesores, por sexo

\begin{tabular}{|c|c|c|c|c|c|c|}
\hline Dimensión & Sexo & $\begin{array}{c}\text { Media } \\
\text { aritmética }\end{array}$ & $\begin{array}{l}\text { Desviación } \\
\text { estándar }\end{array}$ & $\begin{array}{l}\text { Coeficiente } \\
\text { de variación }\end{array}$ & $\begin{array}{l}\text { Coeficiente } \\
\text { de asimetría }\end{array}$ & $\begin{array}{l}\text { Coeficiente } \\
\text { de curtosis }\end{array}$ \\
\hline \multirow{2}{*}{ Planificación } & $F$ & 20,15 & 2,80 & $13,9 \%$ & $-0,49$ & 0,71 \\
\hline & $M$ & 20,30 & 2,61 & $12,8 \%$ & $-0,23$ & 0,01 \\
\hline \multirow{2}{*}{ Metodología } & $\mathrm{F}$ & 20,11 & 2,75 & $13,7 \%$ & $-0,26$ & 0,24 \\
\hline & $M$ & 20,21 & 2,44 & $12,1 \%$ & $-0,10$ & $-0,14$ \\
\hline \multirow{2}{*}{ Evaluación } & $\mathrm{F}$ & 20,18 & 2,76 & $13,7 \%$ & $-0,26$ & $-0,10$ \\
\hline & $\mathrm{M}$ & 20,30 & 2,82 & $13,9 \%$ & $-0,25$ & $-0,36$ \\
\hline \multirow{2}{*}{$\begin{array}{l}\text { Clima para } \\
\text { el } \\
\text { aprendizaje }\end{array}$} & $F$ & 21,27 & 2,76 & $13,0 \%$ & $-0,61$ & 0,44 \\
\hline & $\mathrm{M}$ & 21,27 & 2,50 & $11,8 \%$ & $-0,55$ & 0,69 \\
\hline \multirow{2}{*}{$\begin{array}{l}\text { Tiempo en el } \\
\text { aula }\end{array}$} & $\mathrm{F}$ & 20,45 & 2,80 & $13,7 \%$ & $-0,61$ & 0,56 \\
\hline & $\mathrm{M}$ & 20,50 & 2,49 & $12,2 \%$ & $-0,22$ & $-0,41$ \\
\hline \multirow{2}{*}{$\begin{array}{l}\text { Recursos y } \\
\text { materiales }\end{array}$} & $\mathrm{F}$ & 20,63 & 2,77 & $13,4 \%$ & $-0,64$ & 0,93 \\
\hline & $\mathrm{M}$ & 20,74 & 2,60 & $12,5 \%$ & $-0,31$ & $-0,40$ \\
\hline \multirow{2}{*}{$\begin{array}{l}\text { Desempeño } \\
\text { docente }\end{array}$} & $\mathbf{F}$ & 122,79 & 13,83 & $11,3 \%$ & $-0,53$ & 0,72 \\
\hline & $\mathbf{M}$ & 123,31 & 12,48 & $10,1 \%$ & $-0,18$ & $-0,48$ \\
\hline
\end{tabular}

$n(F)=445 ; n(M)=306$

Fuente: Elaboración Propia.

Gráfico № 22

Media del Desempeño Docente de los profesores, por sexo

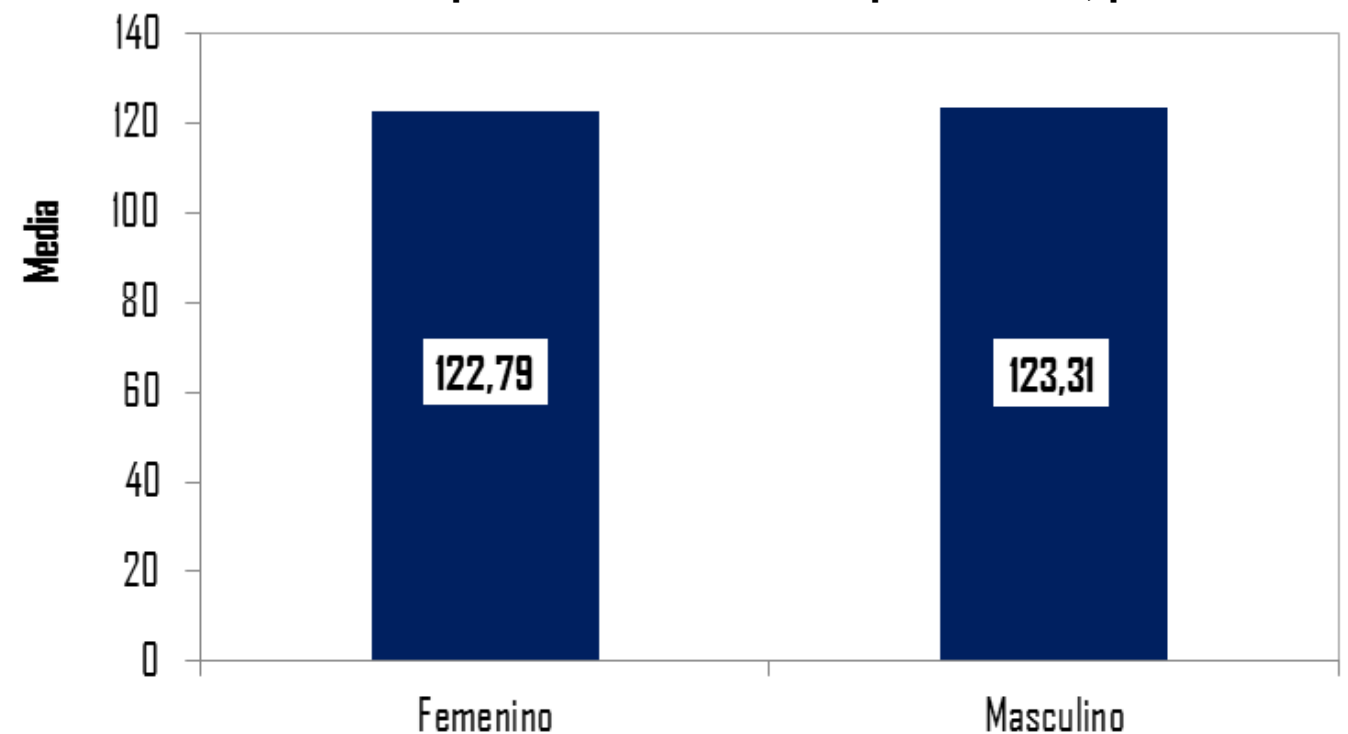

Fuente: Elaboración Propia. 


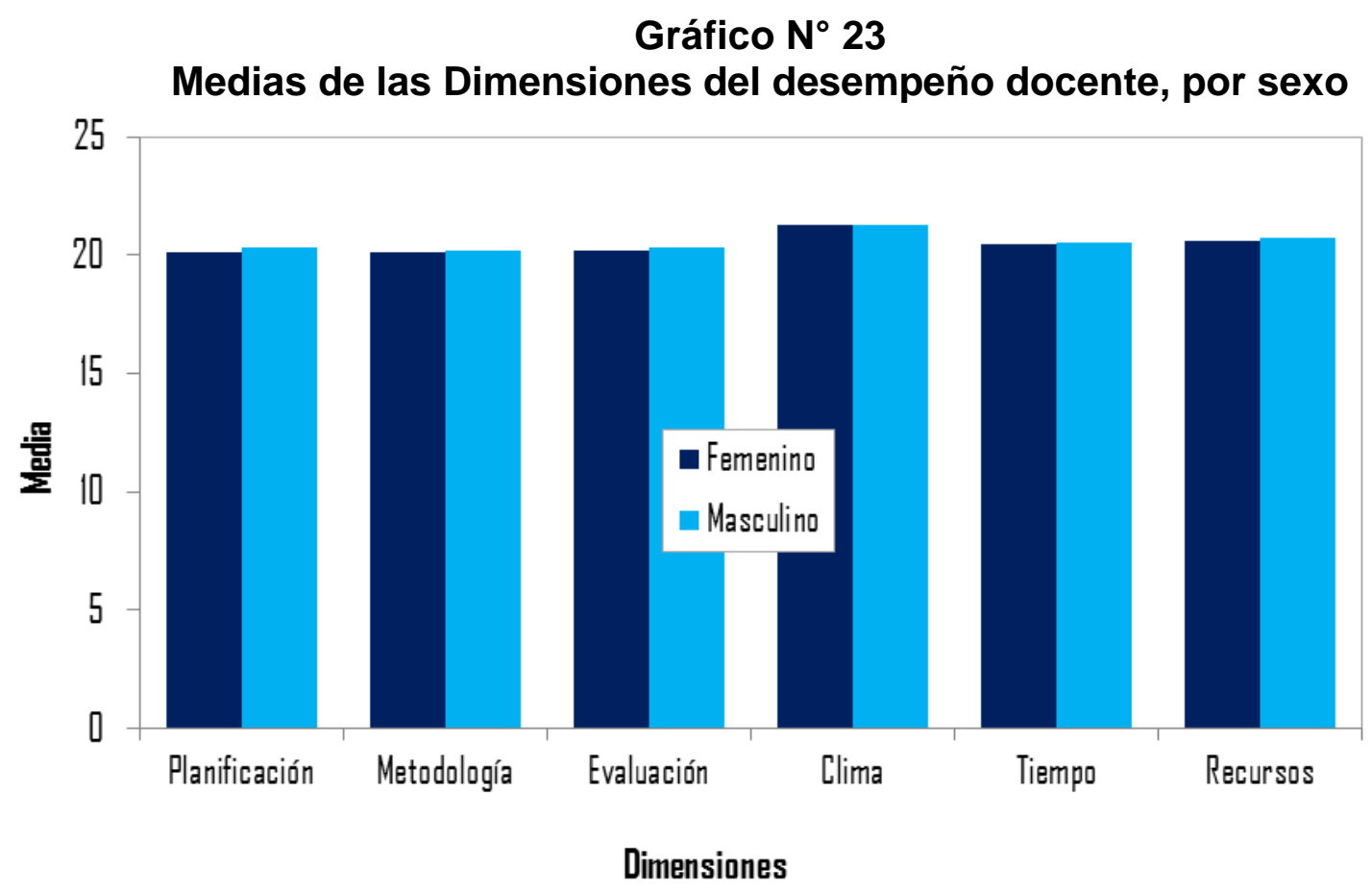

Fuente: Elaboración Propia.

\section{Interpretación:}

Los estadísticos del cuadro $\mathrm{N}^{\circ} 07$ revelan que las medias del desempeño docente (Gráfico №24) y de sus dimensiones (Gráfico $N^{\circ} 25$ ) de los profesores de sexo femenino y masculino superan la media ideal respectiva. Además, no se distinguen diferencias significativas entre las medias del desempeño docente y de sus dimensiones de las mujeres y varones.

Las mujeres y varones constituyen grupos homogéneos con respecto a su desempeño docente y a sus dimensiones. Varones y mujeres son igualmente homogéneos con relación a estas características.

Las distribuciones de las puntuaciones del desempeño docente, planificación, metodología, evaluación, tiempo en el aula y recursos de los varones son normales (simétricas y mesocúrticas). De igual modo, las distribuciones de las puntuaciones de metodología y evaluación de las mujeres son normales. Las distribuciones de las puntuaciones del tiempo en el aula, recursos y desempeño docente de las mujeres y, clima para el aprendizaje de los varones son asimétricas negativas y leptocúrticas (más altas que la curva normal). 
La distribución de los puntajes de la planificación de las mujeres es simétrica y leptocúrtica y, la distribución de las puntuaciones del clima para el aprendizaje de las mujeres es asimétrica negativa y mesocúrtica.

\section{Cuadro $\mathrm{N}^{\circ} 08$}

Nivel del desempeño docente de los profesores, por sexo

\begin{tabular}{|c|c|c|c|c|c|}
\hline \multirow[b]{2}{*}{ Dimensión } & \multirow[b]{2}{*}{ Sexo } & \multicolumn{4}{|c|}{ Nivel de desempeño } \\
\hline & & Deficiente & Regular & Satisfactorio & $\begin{array}{c}\text { Muy } \\
\text { satisfactorio }\end{array}$ \\
\hline \multirow{2}{*}{ Planificación } & $\mathrm{F}$ & $1,80 \%$ & $13,02 \%$ & $53,03 \%$ & $32,13 \%$ \\
\hline & M & $0,33 \%$ & $13,07 \%$ & $54,26 \%$ & $32,35 \%$ \\
\hline \multirow[t]{2}{*}{ Metodología } & $\mathrm{F}$ & $0,90 \%$ & $13,93 \%$ & $54,61 \%$ & $30,56 \%$ \\
\hline & M & $0,33 \%$ & $11,44 \%$ & $58,50 \%$ & $29,74 \%$ \\
\hline \multirow{2}{*}{ Evaluación } & $\mathrm{F}$ & $0,90 \%$ & $15,51 \%$ & $49,89 \%$ & $33,71 \%$ \\
\hline & $M$ & $0,98 \%$ & $15,36 \%$ & $48,69 \%$ & $34,97 \%$ \\
\hline \multirow{2}{*}{$\begin{array}{l}\text { Clima para el } \\
\text { aprendizaje }\end{array}$} & $\mathrm{F}$ & $1,35 \%$ & $6,97 \%$ & $45,17 \%$ & $46,52 \%$ \\
\hline & M & $0,65 \%$ & $4,25 \%$ & $46,08 \%$ & $49,02 \%$ \\
\hline \multirow{2}{*}{$\begin{array}{l}\text { Tiempo en el } \\
\text { aula }\end{array}$} & $\mathrm{F}$ & $2,25 \%$ & $10,56 \%$ & $48,09 \%$ & $39,10 \%$ \\
\hline & M & $0,33 \%$ & $11,44 \%$ & $50,33 \%$ & $37,91 \%$ \\
\hline \multirow{2}{*}{$\begin{array}{l}\text { Recursos y } \\
\text { materiales }\end{array}$} & $\mathrm{F}$ & $1,80 \%$ & $9,44 \%$ & $49,66 \%$ & $39,10 \%$ \\
\hline & M & $0,33 \%$ & $11,44 \%$ & $46,73 \%$ & $41,50 \%$ \\
\hline \multirow{2}{*}{$\begin{array}{l}\text { Desempeño } \\
\text { docente }\end{array}$} & $\mathbf{F}$ & $1,12 \%$ & $5,84 \%$ & $52,81 \%$ & $40,22 \%$ \\
\hline & M & & $6,54 \%$ & $53,92 \%$ & $39,54 \%$ \\
\hline
\end{tabular}

$n(F)=445 ; n(M)=306$

Fuente: Elaboración Propia.

\section{Gráfico $N^{\circ} 24$}

Nivel de desempeño docente de los profesores, por sexo

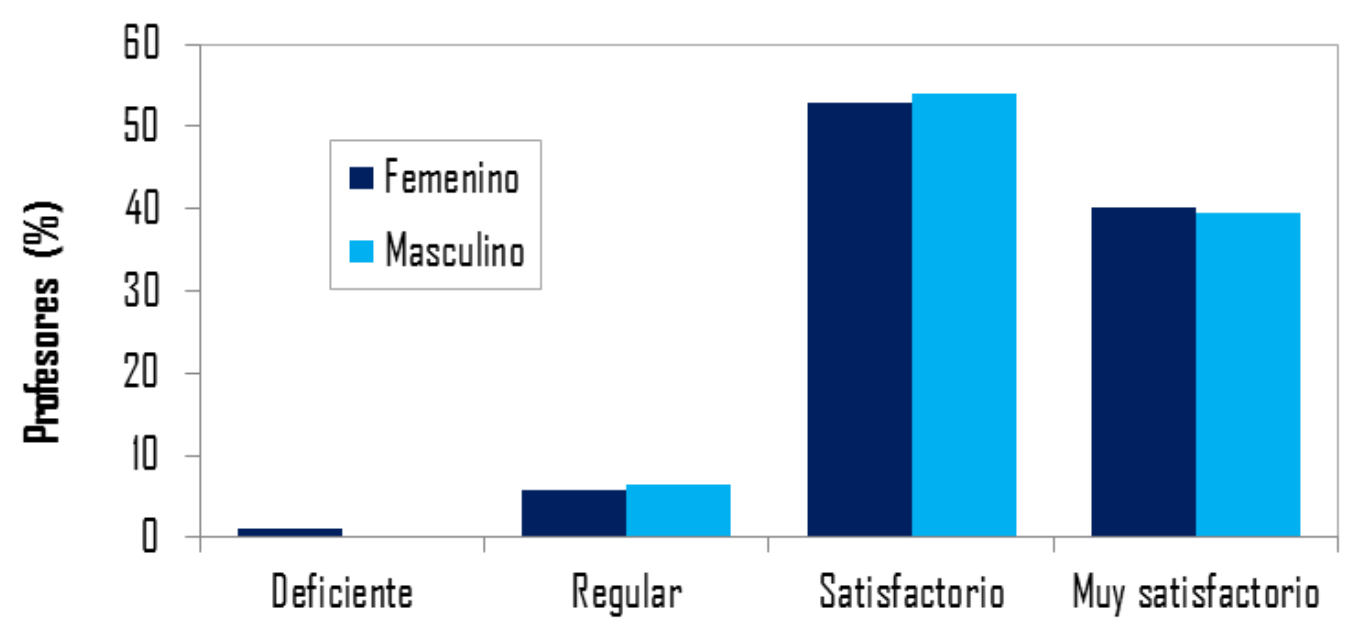

Nivel de desempeño docente

Fuente: Elaboración Propia. 


\section{Interpretación:}

En el cuadro $\mathrm{N}^{\circ} 08$ se constata que la mayoría de mujeres $(52,81 \%)$ y varones $(53,92 \%)$ tienen un desempeño docente satisfactorio, alrededor del 40\% un desempeño muy satisfactorio, cerca del 6\% un desempeño regular. El desempeño deficiente de los profesores de ambos sexos no supera el $2 \%$ (Gráfico $N^{\circ} 26$ ). No se aprecian diferencias significativas en el desempeño docente de los varones y mujeres.

En la planificación, la mayoría de mujeres (53,03\%) y varones $(54,26 \%)$ presentan un desempeño satisfactorio, algo más que el 32\% un desempeño muy satisfactorio y un poco más que el $13 \%$ un desempeño regular.

En la metodología, la mayoría de mujeres $(54,61 \%)$ y varones $(58,50 \%)$ presentan un desempeño satisfactorio, alrededor del $30 \%$ un desempeño muy satisfactorio y, el $13,93 \%$ de mujeres y el $11,44 \%$ de varones un desempeño regular.

En la evaluación, alrededor del $49 \%$ de las mujeres y varones tienen un desempeño satisfactorio, entorno al 34\% un desempeño muy satisfactorio y algo más que el $15 \%$ un desempeño regular.

En el clima para el aprendizaje, alrededor del $46 \%$ de las mujeres y varones ostentan un desempeño satisfactorio, el $46,52 \%$ de mujeres y el $49,02 \%$ de varones un desempeño muy satisfactorio y, el 6,97\% de mujeres y el 4,25\% de varones un desempeño regular.

En el tiempo en el aula, el $48,09 \%$ de mujeres y el $50,33 \%$ de varones presentan un desempeño satisfactorio, el 39,1\% de mujeres y el $37,91 \%$ de varones un desempeño muy satisfactorio y, alrededor del $11 \%$ de mujeres y varones un desempeño regular.

En recursos y materiales, el $49,66 \%$ de mujeres y el $46,73 \%$ de varones tienen un desempeño satisfactorio, el 39,1\% de mujeres y el $41,5 \%$ de varones un desempeño muy satisfactorio y, el $9,44 \%$ de mujeres y el 11,44\% varones un desempeño regular.

El desempeño deficiente de los profesores de ambos sexos en cada una de las dimensiones no alcanza el $3 \%$. 


\subsubsection{Desempeño docente de los profesores, por edad}

Cuadro $N^{\circ} 09$.

\section{Estadísticos del desempeño docente de los}

profesores, por edad

\begin{tabular}{|c|c|c|c|c|c|c|}
\hline Dimensión & Edad & $\begin{array}{c}\text { Media } \\
\text { aritmética }\end{array}$ & $\begin{array}{c}\text { Desviación } \\
\text { estándar }\end{array}$ & $\begin{array}{l}\text { Coeficiente de } \\
\text { variación }\end{array}$ & $\begin{array}{c}\text { Coeficiente de } \\
\text { asimetría }\end{array}$ & $\begin{array}{l}\text { Coeficiente } \\
\text { de curtosis }\end{array}$ \\
\hline \multirow{4}{*}{ Planificación } & $<30$ & 20,15 & 2,80 & $13,9 \%$ & $-0,49$ & 1,00 \\
\hline & 30 a 39 & 20,30 & 2,61 & $12,8 \%$ & $-0,37$ & 0,46 \\
\hline & 40 a 49 & 20,37 & 0,26 & $13,0 \%$ & $-0,26$ & $-0,14$ \\
\hline & $50 a+$ & 20,86 & 2,65 & $12,7 \%$ & $-0,69$ & 1,42 \\
\hline \multirow{4}{*}{ Metodología } & $<30$ & 20,11 & 2,75 & $13,7 \%$ & $-0,10$ & $-0,44$ \\
\hline & 30 a 39 & 20,21 & 2,44 & $12,1 \%$ & $-0,25$ & 0,51 \\
\hline & 40 a 49 & 20,15 & 2,71 & $13,5 \%$ & $-0,19$ & $-0,11$ \\
\hline & $50 a+$ & 20,20 & 2,97 & $14,7 \%$ & $-0,35$ & 0,57 \\
\hline \multirow{4}{*}{ Evaluación } & $<30$ & 20,18 & 2,76 & $13,7 \%$ & $-0,28$ & $-0,02$ \\
\hline & 30 a 39 & 20,30 & 2,82 & $13,9 \%$ & $-0,23$ & $-0,15$ \\
\hline & 40 a 49 & 20,24 & 2,73 & $13,5 \%$ & $-0,36$ & $-0,14$ \\
\hline & $50 a+$ & 20,31 & 2,80 & $13,8 \%$ & $-0,07$ & $-0,77$ \\
\hline \multirow{4}{*}{$\begin{array}{l}\text { Clima para el } \\
\text { aprendizaje }\end{array}$} & $<30$ & 21,27 & 2,76 & $13,0 \%$ & $-0,80$ & 0,97 \\
\hline & 30 a 39 & 21,27 & 2,50 & $11,8 \%$ & $-0,72$ & 1,30 \\
\hline & 40 a 49 & 21,20 & 2,69 & $12,7 \%$ & $-0,43$ & $-0,39$ \\
\hline & $50 a+$ & 21,17 & 2,57 & $12,1 \%$ & $-0,26$ & 0,20 \\
\hline \multirow{4}{*}{$\begin{array}{l}\text { Tiempo en el } \\
\text { aula }\end{array}$} & $<30$ & 20,45 & 2,80 & $13,7 \%$ & $-0,43$ & 0,39 \\
\hline & 30 a 39 & 20,50 & 2,49 & $12,2 \%$ & $-0,51$ & 0,35 \\
\hline & 40 a 49 & 20,40 & 2,68 & $13,1 \%$ & $-0,56$ & 0,24 \\
\hline & $50 a+$ & 20,56 & 2,76 & $13,4 \%$ & $-0,41$ & 0,36 \\
\hline \multirow{4}{*}{$\begin{array}{l}\text { Recursos y } \\
\text { materiales }\end{array}$} & $<30$ & 20,63 & 2,77 & $13,4 \%$ & $-0,55$ & 1,08 \\
\hline & 30 a 39 & 20,74 & 2,60 & $12,5 \%$ & $-0,60$ & 0,62 \\
\hline & 40 a 49 & 20,46 & 0,03 & $12,9 \%$ & $-0,48$ & 0,19 \\
\hline & $50 a+$ & 20,63 & 2,87 & $13,9 \%$ & $-0,47$ & 0,20 \\
\hline \multirow{4}{*}{$\begin{array}{l}\text { Desempeño } \\
\text { docente }\end{array}$} & $<30$ & 122,79 & 13,83 & $11,3 \%$ & $-0,35$ & 0,35 \\
\hline & 30 a 39 & 123,31 & 12,48 & $10,1 \%$ & $-0,45$ & 0,69 \\
\hline & 40 a 49 & 122,82 & 13,74 & $11,2 \%$ & $-0,48$ & 0,22 \\
\hline & $50 a+$ & 123,72 & 13,88 & $11,2 \%$ & $-0,34$ & 0,20 \\
\hline
\end{tabular}

Fuente: Elaboración Propia. 
Gráfico № 25

Media del desempeño docente de los profesores, por edad

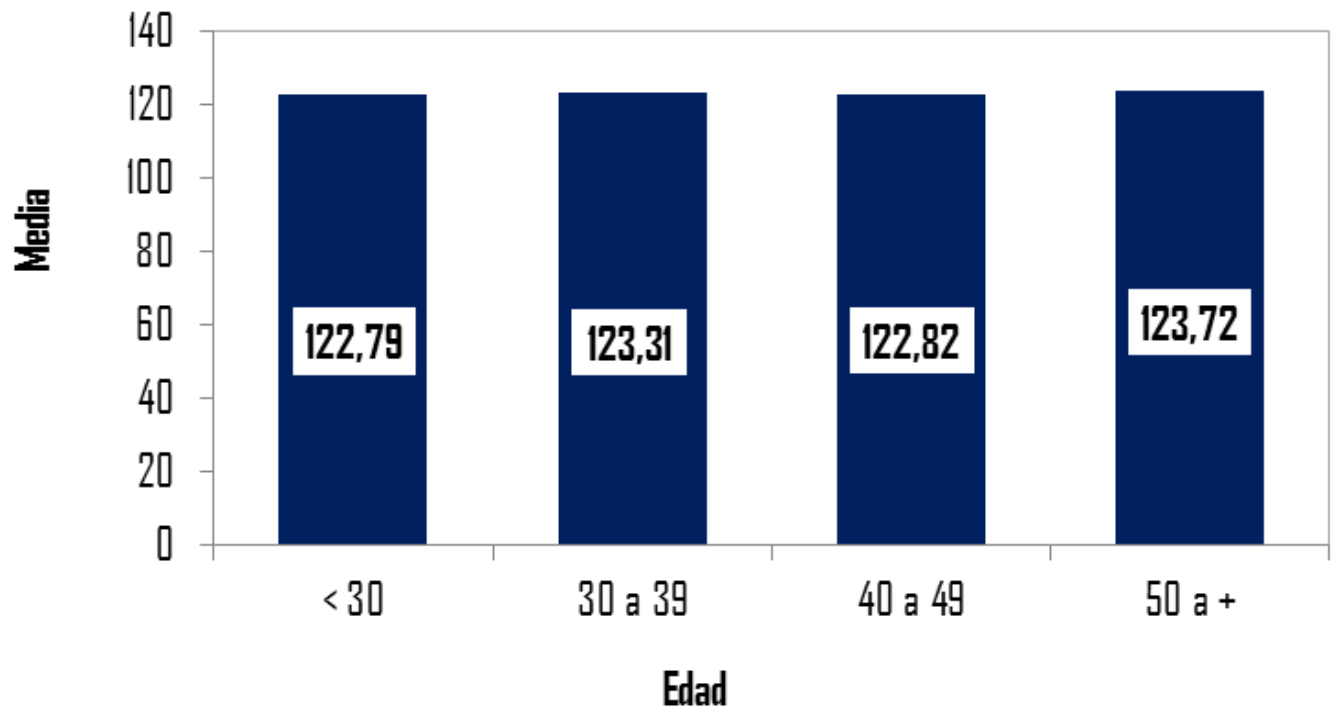

Fuente: Elaboración Propia.

Gráfico N²6

Medias de las dimensiones del desempeño docente por edad

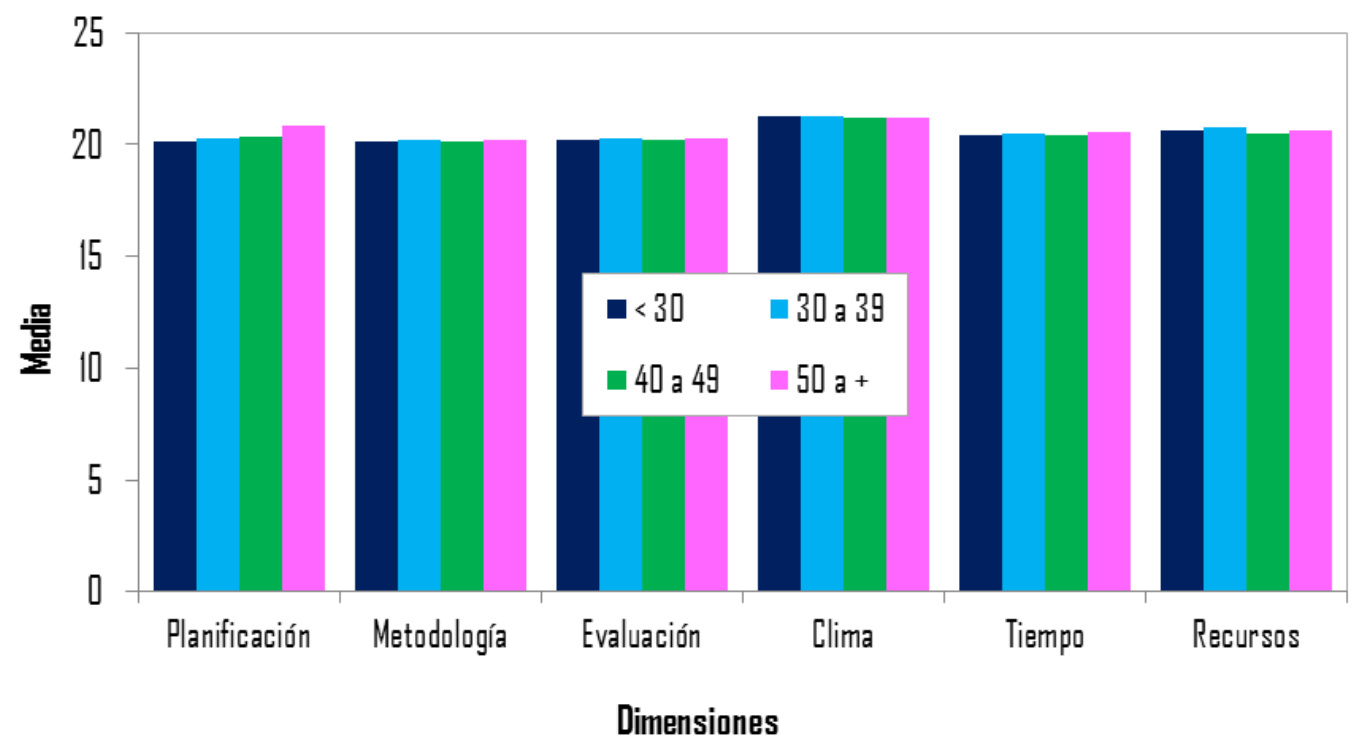

Fuente: Elaboración Propia.

Interpretación:

Los estadísticos del Cuadro $\mathrm{N}^{\circ} 09$ indican que las medias del desempeño docente (Gráfico N²7) y de sus dimensiones (Gráfico $N^{\circ} 28$ ) de los profesores de todos los grupos etáreos superan la media ideal 
respectiva. Además, no se distinguen diferencias significativas entre las medias del desempeño docente y de sus dimensiones de los profesores de todos los grupos etáreos. Los profesores de todos los grupos etáreos son homogéneos con respecto a su desempeño docente y a sus dimensiones. Los profesores de todos los grupos son igualmente homogéneos con relación a estas características.

Las distribuciones de las puntuaciones del desempeño docente, metodología, evaluación y tiempo en el aula de los profesores menos de 30 años; planificación y evaluación de los profesores de 30 a 39 años; desempeño docente, planificación, metodología, evaluación, clima para el aprendizaje y recursos de los profesores de 40 a 49 años y; desempeño docente, clima para el aprendizaje, tiempo en el aula y recursos de los profesores de 50 años a más son normales (simétricas y mesocúrticas).

Las distribuciones de los puntajes del desempeño docente y metodología de los profesores de 30 a 39 años, planificación de los profesores menores de 30 años y metodología de los profesores de 50 años a más son simétricas y leptocúrticas (más altas que la curva normal). Las distribuciones de las puntuaciones del clima para el aprendizaje y recursos de los profesores menores de 30 años y de 30 a 39 años $y$, planificación de los profesores de 50 años a más son asimétricas y leptocúrticas.

Las distribuciones de los puntajes de tiempo en el aula de los profesores de 30 a 39 años y de 40 a 49 años son asimétricas negativas y mesocúrticas $\mathrm{y}$, la distribución de los puntajes de evaluación de los profesores de 50 años a más es simétrica y platicúrtica (más baja que la curva normal). 
Cuadro $\mathbf{N}^{\circ} 10$.

Nivel del desempeño docente de los profesores, por edad

\begin{tabular}{|c|c|c|c|c|c|}
\hline \multirow[t]{2}{*}{ Dimensión } & \multirow[t]{2}{*}{ Edad } & \multicolumn{4}{|c|}{ Nivel de desempeño } \\
\hline & & Deficiente & Regular & Satisfactorio & $\begin{array}{c}\text { Muy } \\
\text { satisfactorio }\end{array}$ \\
\hline \multirow[t]{4}{*}{ Planificación } & $<30$ & $1,12 \%$ & $15,08 \%$ & $56,42 \%$ & $27,37 \%$ \\
\hline & 30 a 39 & $1,58 \%$ & $14,62 \%$ & $53,75 \%$ & $30,04 \%$ \\
\hline & 40 a 49 & $0,94 \%$ & $12,26 \%$ & $54,25 \%$ & $32,55 \%$ \\
\hline & $50 a+$ & $0,93 \%$ & $7,48 \%$ & $46,73 \%$ & $44,86 \%$ \\
\hline \multirow[t]{4}{*}{ Metodología } & $<30$ & & $12,29 \%$ & $55,31 \%$ & $32,40 \%$ \\
\hline & 30 a 39 & $0,40 \%$ & $12,65 \%$ & $60,47 \%$ & $26,48 \%$ \\
\hline & 40 a 49 & $0,94 \%$ & $13,68 \%$ & $54,25 \%$ & $31,13 \%$ \\
\hline & $50 a+$ & $1,87 \%$ & $13,08 \%$ & $51,40 \%$ & $33,64 \%$ \\
\hline \multirow[t]{4}{*}{ Evaluación } & $<30$ & $1,68 \%$ & $13,97 \%$ & $50,28 \%$ & $34,08 \%$ \\
\hline & 30 a 39 & $0,79 \%$ & $16,60 \%$ & $47,43 \%$ & $35,18 \%$ \\
\hline & 40 a 49 & $0,94 \%$ & $12,74 \%$ & $52,83 \%$ & $33,49 \%$ \\
\hline & $50 a+$ & & $20,56 \%$ & $45,79 \%$ & $33,64 \%$ \\
\hline \multirow{4}{*}{$\begin{array}{l}\text { Clima para el } \\
\text { aprendizaje }\end{array}$} & $<30$ & $1,68 \%$ & $4,47 \%$ & $42,46 \%$ & $51,40 \%$ \\
\hline & 30 a 39 & $1,19 \%$ & $5,53 \%$ & $46,64 \%$ & $46,64 \%$ \\
\hline & 40 a 49 & $0,47 \%$ & $8,96 \%$ & $41,98 \%$ & $48,58 \%$ \\
\hline & $50 a+$ & $0,93 \%$ & $2,80 \%$ & $55,14 \%$ & $41,12 \%$ \\
\hline \multirow{4}{*}{$\begin{array}{l}\text { Tiempo en el } \\
\text { aula }\end{array}$} & $<30$ & $0,56 \%$ & $11,73 \%$ & $46,37 \%$ & $41,34 \%$ \\
\hline & 30 a 39 & $1,58 \%$ & $11,46 \%$ & $50,99 \%$ & $35,97 \%$ \\
\hline & 40 a 49 & $1,42 \%$ & $11,79 \%$ & $48,11 \%$ & $38,68 \%$ \\
\hline & $50 a+$ & $2,80 \%$ & $6,54 \%$ & $50,47 \%$ & $40,19 \%$ \\
\hline \multirow{4}{*}{$\begin{array}{l}\text { Recursos y } \\
\text { materiales }\end{array}$} & $<30$ & $0,56 \%$ & $8,94 \%$ & $53,63 \%$ & $36,87 \%$ \\
\hline & 30 a 39 & $1,19 \%$ & $9,49 \%$ & $47,04 \%$ & $42,29 \%$ \\
\hline & 40 a 49 & $1,42 \%$ & $11,79 \%$ & $47,17 \%$ & $39,62 \%$ \\
\hline & $50 a+$ & $1,87 \%$ & $11,21 \%$ & $45,79 \%$ & $41,12 \%$ \\
\hline \multirow{4}{*}{$\begin{array}{l}\text { Desempeño } \\
\text { docente }\end{array}$} & $<30$ & $0,56 \%$ & $5,59 \%$ & $57,54 \%$ & $36,31 \%$ \\
\hline & 30 a 39 & $0,79 \%$ & $5,14 \%$ & $54,55 \%$ & $39,53 \%$ \\
\hline & 40 a 49 & $0,47 \%$ & $8,02 \%$ & $50,47 \%$ & $41,04 \%$ \\
\hline & $50 a+$ & $0,93 \%$ & $5,61 \%$ & $48,60 \%$ & $44,86 \%$ \\
\hline
\end{tabular}

Fuente: Elaboración Propia. 
Gráfico $N^{\circ} 27$

Nivel de desempeño docente de los profesores, por edad

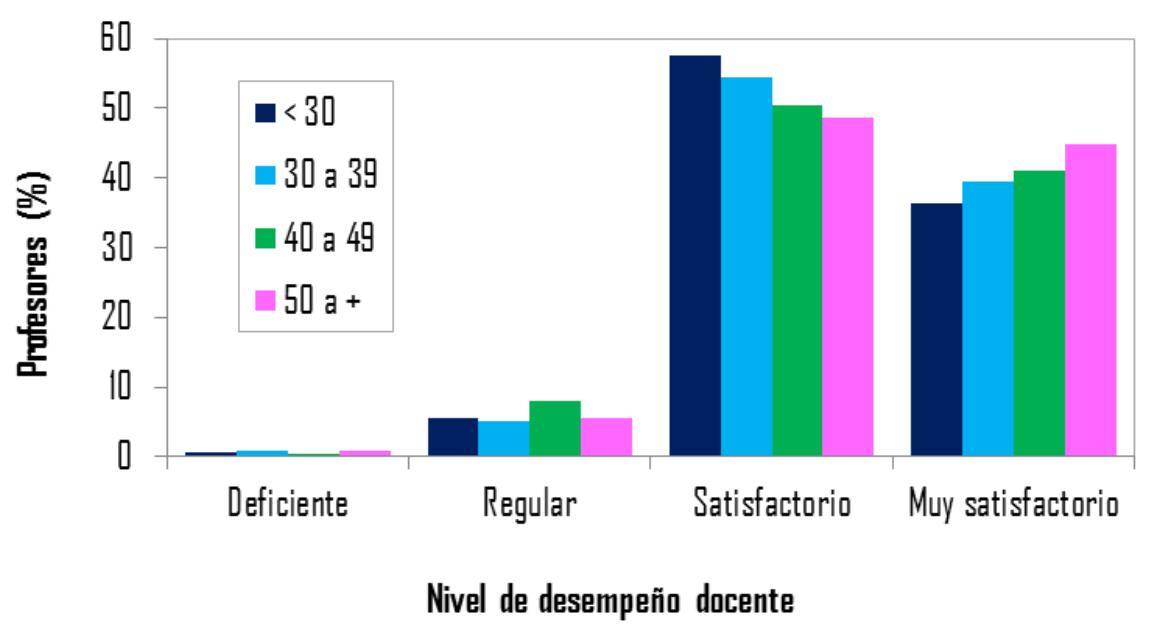

Fuente: Elaboración Propia.

\section{Interpretación:}

En el cuadro $\mathrm{N}^{\circ} 10$ se aprecia que la mayoría de los profesores de casi todos los grupos etáreos, con excepción de los de 50 años a más, tienen un desempeño docente satisfactorio, entre 50,47\% (40 a 49 años) y $57,54 \%$ (< 3 años); entre $36,31 \%$ (<30 años) y 44,86\% (50 años a más) un desempeño muy satisfactorio y; entre $5,14 \%$ (30 a 39 años) y $8,02 \%$ (40 a 49 años) un desempeño regular. El desempeño deficiente de los profesores de todos los grupos etáreos no sobrepasa el 1\% (Gráfico № 29). Se percibe que la satisfacción disminuye relativamente con la edad de los profesores, mientras que la alta satisfacción aumenta ligeramente con la edad de los mismos.

En la planificación, la mayoría de los profesores de casi todos los grupos, con excepción de los de 50 años a más, presentan un desempeño satisfactorio, entre 53,75\% (30 a 39 años) y 56,42\% (< 30 años); entre $27,37 \%$ ( $<30$ años) y 44,86\% (50 años a más) un desempeño muy satisfactorio y; entre 7,48\% (50 años a más) y 15,08\% (< 30 años) un desempeño regular.

En la metodología, la mayoría de los profesores de todos los grupos ostentan un desempeño satisfactorio, entre $51,40 \%$ (50 años a más) y 60,47\%(30 a 39 años); entre $26,48 \%$ (30 a 39 años) y 33,64\% (50 años a 
más) un desempeño muy satisfactorio y; entre 12,29\% (< 30 años) y 13,68\% (40 a 49 años) un desempeño regular.

En la evaluación, el desempeño satisfactorio de los profesores oscila entre 45,79\% (50 años a más) y 52,83\% (40 a 49 años), el desempeño muy satisfactorio entre 33,49\% (40 a 49 años) y 35,18\% (30 a 39 años) y, el desempeño regular entre 12,74\% (40 a 49 años) y 20,56\% (50 años a más).

En el clima para el aprendizaje, el desempeño satisfactorio de los profesores fluctúa entre 41,98\% (40 a 49 años) y 55,14\% (50 años a más), el desempeño muy satisfactorio entre 41,12\% (50 años a más) y $51,4 \%$ (< 30 años) y, el desempeño regular entre 2,8\% (50 años a más) y $8,96 \%$ (40 a 49 años).

En el tiempo en el aula, el desempeño satisfactorio de los profesores fluctúa entre 46,37\% (<30 años) y 50,99\% (30 a 39 años), el desempeño muy satisfactorio entre 35,97\% (30 a 39 años) y 41,34\% (< 30 años) y, el desempeño regular entre 6,54\% (50 años a más) y 11,79\% (40 a 49 años). En los recursos y materiales, el desempeño satisfactorio de los profesores varía entre 45,79\% (50 años a más) y 53,63\% (<30 años), el desempeño muy satisfactorio entre 36,87\% (<30 años) y 42,29\% (30 a 39 años) y, el desempeño regular entre 8,94\% (< 30 años) y 11,79\% (40 a 49 años).

El desempeño deficiente de los profesores de todos los grupos etáreos en cada una de las dimensiones no alcanza el 3\%. 


\subsubsection{Desempeño docente de los profesores, por nivel.}

\section{Cuadro $\mathbf{N}^{\circ} 11$}

\section{Estadísticos del desempeño docente de los}

profesores, por nivel

\begin{tabular}{|c|c|c|c|c|c|c|}
\hline Dimensión & Nivel & $\begin{array}{c}\text { Media } \\
\text { aritmética }\end{array}$ & $\begin{array}{c}\text { Desviación } \\
\text { estándar }\end{array}$ & $\begin{array}{l}\text { Coeficiente } \\
\text { de variación }\end{array}$ & $\begin{array}{l}\text { Coeficiente } \\
\text { de asimetría }\end{array}$ & $\begin{array}{l}\text { Coeficiente } \\
\text { de curtosis }\end{array}$ \\
\hline \multirow{3}{*}{ Planificación } & Inicial & 20,56 & 2,73 & $13,3 \%$ & $-0,06$ & $-0,79$ \\
\hline & Primaria & 19,96 & 2,62 & $13,1 \%$ & $-0,62$ & 1,18 \\
\hline & Secundaria & 20,38 & 2,80 & $13,7 \%$ & $-0,33$ & 0,16 \\
\hline \multirow{3}{*}{ Metodología } & Inicial & 20,77 & 2,59 & $12,5 \%$ & $-0,10$ & $-0,39$ \\
\hline & Primaria & 19,76 & 2,68 & $13,5 \%$ & $-0,36$ & 0,44 \\
\hline & Secundaria & 20,40 & 2,53 & $12,4 \%$ & $-0,05$ & 0,22 \\
\hline \multirow{3}{*}{ Evaluación } & Inicial & 20,45 & 2,77 & $13,5 \%$ & $-0,50$ & $-0,10$ \\
\hline & Primaria & 19,93 & 2,79 & $14,0 \%$ & $-0,14$ & 0,48 \\
\hline & Secundaria & 20,47 & 2,76 & $13,5 \%$ & $-0,32$ & 0,09 \\
\hline \multirow{3}{*}{$\begin{array}{l}\text { Clima para el } \\
\text { aprendizaje }\end{array}$} & Inicial & 22,00 & 2,40 & $10,9 \%$ & $-0,32$ & $-1,08$ \\
\hline & Primaria & 20,96 & 2,72 & $13,0 \%$ & $-0,60$ & 0,70 \\
\hline & Secundaria & 21,42 & 2,60 & $12,1 \%$ & $-0,60$ & 0,51 \\
\hline \multirow{3}{*}{$\begin{array}{l}\text { Tiempo en el } \\
\text { aula }\end{array}$} & Inicial & 21,30 & 2,57 & $12,1 \%$ & $-0,37$ & $-0,81$ \\
\hline & Primaria & 20,14 & 2,72 & $13,5 \%$ & $-0,48$ & 0,16 \\
\hline & Secundaria & 20,63 & 2,61 & $12,6 \%$ & $-0,52$ & 0,69 \\
\hline \multirow{3}{*}{$\begin{array}{l}\text { Recursos y } \\
\text { materiales }\end{array}$} & Inicial & 21,39 & 2,51 & $11,7 \%$ & $-0,25$ & 0,54 \\
\hline & Primaria & 20,27 & 2,83 & $14,0 \%$ & $-0,45$ & 0,10 \\
\hline & Secundaria & 20,92 & 2,55 & $12,2 \%$ & $-0,60$ & 1,14 \\
\hline \multirow{3}{*}{$\begin{array}{l}\text { Desempeño } \\
\text { docente }\end{array}$} & Inicial & 126,48 & 12,17 & $9,6 \%$ & $-0,09$ & $-0,73$ \\
\hline & Primaria & 121,01 & 13,73 & $11,3 \%$ & $-0,43$ & 0,26 \\
\hline & Secundaria & 124,22 & 12,81 & $10,3 \%$ & $-0,41$ & 0,59 \\
\hline
\end{tabular}

$\mathrm{n}($ Inicial $)=71 ; \mathrm{n}($ Primaria $)=334 ; \mathrm{n}($ Secundaria $)=346$

Fuente: Elaboración Propia. 
Gráfico $\mathbf{N}^{\circ} 28$

Media del desempeño docente delos profesores, por nivel

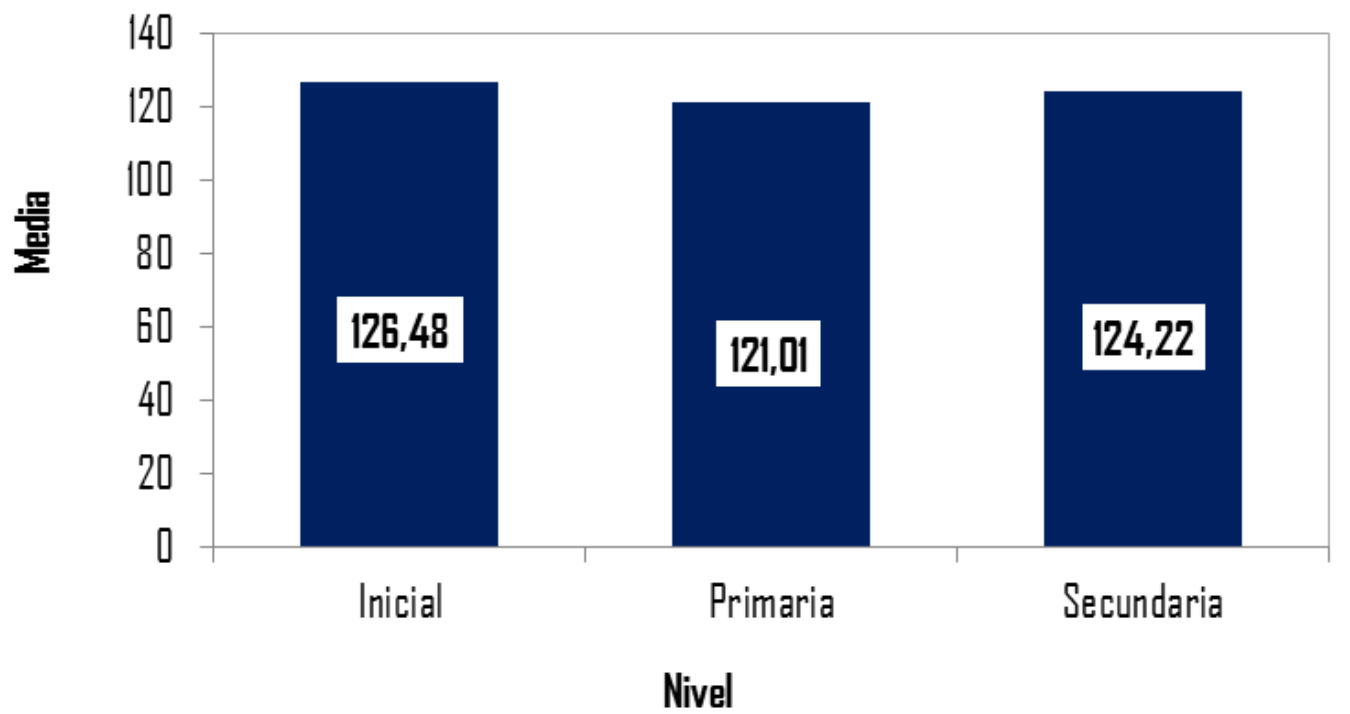

Fuente: Elaboración Propia.

Gráfico $N^{\circ} 29$

Medias de las dimensiones del desempeño docente, por nivel

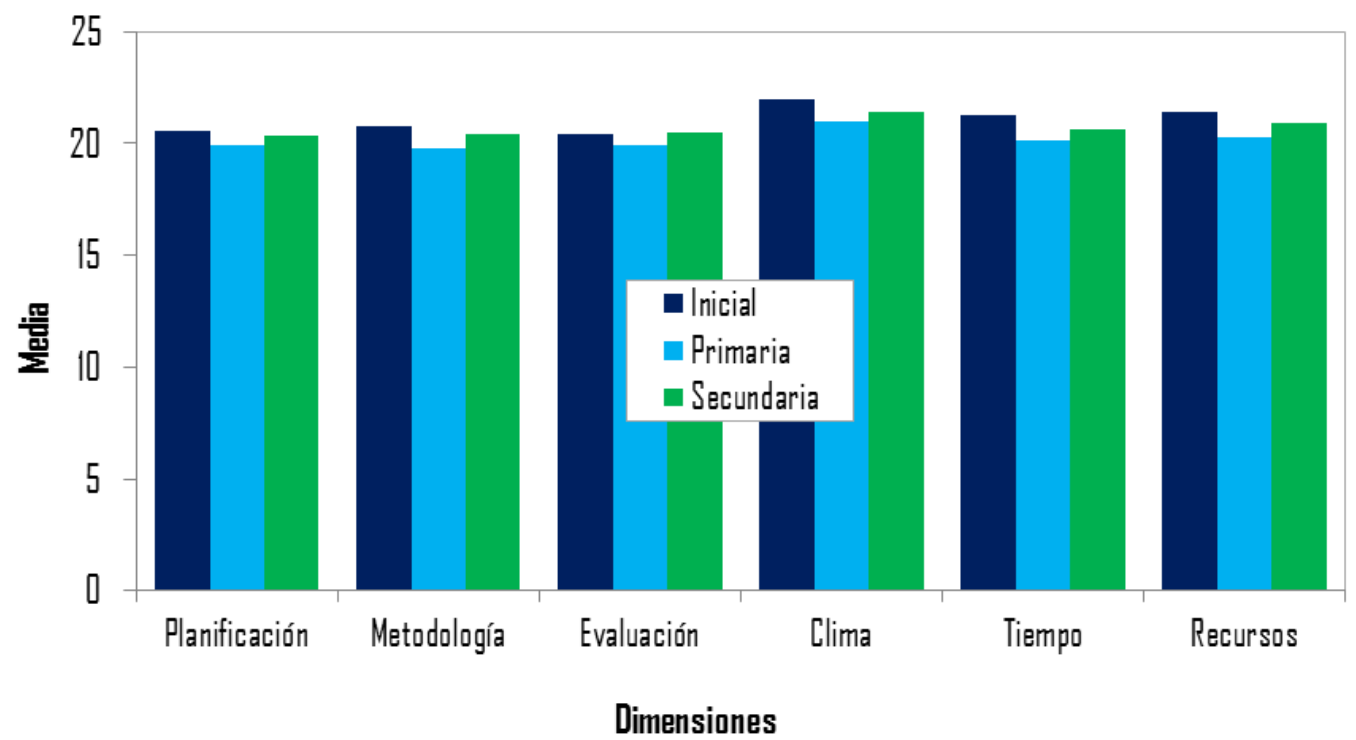

Fuente: Elaboración Propia.

Interpretación:

Los estadísticos del cuadro $\mathrm{N}^{\circ} 11$ muestran que las medias del desempeño docente (Gráfico N²9) y de sus dimensiones (Gráfico º30) de los profesores de todos los niveles superan la media ideal respectiva. Además, se aprecian diferencias significativas entre las medias del 
desempeño docente y de sus dimensiones de los profesores de todos los niveles.

Los profesores de todos los niveles son homogéneos con respecto a su desempeño docente y a sus dimensiones. Los profesores de todos los niveles son igualmente homogéneos con relación a estas características.

Las distribuciones de las puntuaciones del desempeño docente, metodología, evaluación, tiempo en el aula y recursos de los profesores del nivel primario; metodología y evaluación de los profesores del nivel inicial y secundario son normales (simétricas y mesocúrticas).

Las distribuciones de los puntajes de la planificación y clima para el aprendizaje de los profesores del nivel primario; clima para el aprendizaje, tiempo en el aula y recursos de los profesores del nivel secundario son asimétricas negativas y leptocúrticas.

Las distribuciones de las puntuaciones del desempeño docente, planificación, clima para el aprendizaje y tiempo en el aula de los profesores del nivel inicial son simétricas y platicúrticas y; la distribución de las puntuaciones del desempeño docente de los profesores del nivel secundario y recursos de los profesores del nivel inicial son simétricas y leptocúrticas. 


\section{Cuadro $\mathrm{N}^{\circ} 12$}

Nivel del desempeño docente de los profesores, por nivel

\begin{tabular}{|c|c|c|c|c|c|}
\hline \multirow[b]{2}{*}{ Dimensión } & \multirow[b]{2}{*}{ Nivel } & \multicolumn{4}{|c|}{ Nivel de desempeño } \\
\hline & & Deficiente & Regular & Satisfactorio & $\begin{array}{c}\text { Muy } \\
\text { satisfactorio }\end{array}$ \\
\hline \multirow{3}{*}{ Planificación } & Inicial & & $11,27 \%$ & $49,30 \%$ & $39,44 \%$ \\
\hline & Primaria & $1,80 \%$ & $13,77 \%$ & $57,19 \%$ & $27,25 \%$ \\
\hline & Secundaria & $0,87 \%$ & $12,72 \%$ & $50,87 \%$ & $35,55 \%$ \\
\hline \multirow{3}{*}{ Metodología } & Inicial & & $7,04 \%$ & $53,52 \%$ & $39,44 \%$ \\
\hline & Primaria & $1,20 \%$ & $16,77 \%$ & $56,89 \%$ & $25,15 \%$ \\
\hline & Secundaria & $0,29 \%$ & $10,40 \%$ & $56,07 \%$ & $33,24 \%$ \\
\hline \multirow{3}{*}{ Evaluación } & Inicial & $1,41 \%$ & $12,68 \%$ & $45,07 \%$ & $40,85 \%$ \\
\hline & Primaria & $0,90 \%$ & $19,46 \%$ & $48,50 \%$ & $31,14 \%$ \\
\hline & Secundaria & $0,87 \%$ & $12,14 \%$ & $51,16 \%$ & $35,84 \%$ \\
\hline \multirow{3}{*}{$\begin{array}{l}\text { Clima para el } \\
\text { aprendizaje }\end{array}$} & Inicial & & $4,23 \%$ & $40,85 \%$ & $54,93 \%$ \\
\hline & Primaria & $1,80 \%$ & $7,49 \%$ & $47,01 \%$ & $43,71 \%$ \\
\hline & Secundaria & $0,58 \%$ & $4,62 \%$ & $45,09 \%$ & $49,71 \%$ \\
\hline \multirow{3}{*}{$\begin{array}{l}\text { Tiempo en el } \\
\text { aula }\end{array}$} & Inicial & & $7,04 \%$ & $39,44 \%$ & $53,52 \%$ \\
\hline & Primaria & $2,40 \%$ & $12,28 \%$ & $50,60 \%$ & $34,73 \%$ \\
\hline & Secundaria & $0,87 \%$ & $10,40 \%$ & $49,42 \%$ & $39,31 \%$ \\
\hline \multirow{3}{*}{$\begin{array}{l}\text { Recursos y } \\
\text { materiales }\end{array}$} & Inicial & & $5,63 \%$ & $45,07 \%$ & $49,30 \%$ \\
\hline & Primaria & $2,10 \%$ & $14,07 \%$ & $48,50 \%$ & $35,33 \%$ \\
\hline & Secundaria & $0,58 \%$ & $7,51 \%$ & $49,13 \%$ & $42,77 \%$ \\
\hline \multirow{3}{*}{$\begin{array}{l}\text { Desempeño } \\
\text { docente }\end{array}$} & Inicial & & $1,41 \%$ & $45,07 \%$ & $53,52 \%$ \\
\hline & Primaria & $0,90 \%$ & $9,58 \%$ & $53,29 \%$ & $36,23 \%$ \\
\hline & Secundaria & $0,58 \%$ & $3,76 \%$ & $54,91 \%$ & $40,75 \%$ \\
\hline
\end{tabular}

$\mathrm{n}($ Inicial $)=71 ; \mathrm{n}($ Primaria $)=334 ; \mathrm{n}($ Secundaria $)=346$

Fuente: Elaboración Propia.

\section{Gráfico N³0}

Nivel de desempeño docente de los profesores, por nivel

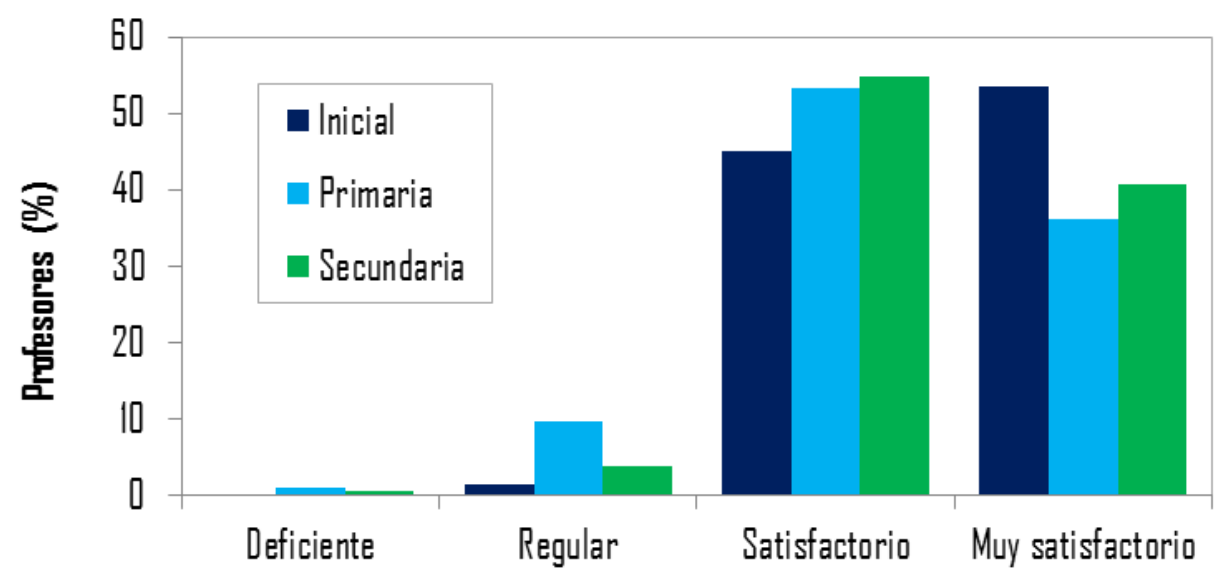

Nivel de desempeño docente

Fuente: Elaboración Propia. 


\section{Interpretación:}

En el cuadro $\mathrm{N}^{\circ} 12$ se observa que la mayoría de los profesores de casi todos los niveles, con excepción del nivel inicial, tienen un desempeño docente satisfactorio, entre 53,29\% (nivel primario) y 54,91\% (nivel secundario); entre 40,75\% (nivel secundario) y 53,52\% (nivel inicial) un desempeño muy satisfactorio y; entre 1,41\% (nivel inicial) y 9,8\% (nivel primario) un desempeño regular. El desempeño deficiente de los profesores de todos los niveles no sobrepasa el 1\% (Gráfico N³1). Se percibe que la satisfacción aumenta relativamente con el nivel de los profesores, mientras que la alta satisfacción disminuye ligeramente con el nivel de los mismos.

En la planificación, la mayoría de los profesores de casi todos los niveles, con excepción del nivel inicial, presentan un desempeño satisfactorio, entre 50,87\% (nivel secundario) y 57,19\% (nivel primario); entre $27,25 \%$ (nivel primario) y $39,44 \%$ (nivel inicial) un desempeño muy satisfactorio y; entre 11,27\% (nivel inicial) y 13,77\% (nivel primario) un desempeño regular.

En la metodología, la mayoría de los profesores de todos los niveles ostentan un desempeño satisfactorio, entre 53,52\% (nivel inicial) y $56,89 \%$ (nivel primario); entre 25,15\% (nivel primario) y 39,44\% (nivel inicial) un desempeño muy satisfactorio y; entre 7,040\% (nivel inicial) y $16,77 \%$ (nivel primario) un desempeño regular.

En la evaluación, el desempeño satisfactorio de los profesores oscila entre 45,07\% (nivel inicial) y 51,16\% (nivel secundario), el desempeño muy satisfactorio entre 31,14\% (nivel primario) y 40,85\% (nivel inicial) y, el desempeño regular entre $12,14 \%$ (nivel secundario) y $19,46 \%$ (nivel primario).

En el clima para el aprendizaje, el desempeño satisfactorio de los profesores fluctúa entre 40,85\% (nivel inicial) y 47,01\% (nivel primario), el desempeño muy satisfactorio entre 43,71\% (nivel primario) y 54,93\% (nivel inicial) y, el desempeño regular entre 4,23\% (nivel inicial) y $7,49 \%$ (nivel primario). 
En el tiempo en el aula, el desempeño satisfactorio de los profesores varía entre $39,44 \%$ (nivel inicial) y 50,60\% (nivel primario), el desempeño muy satisfactorio entre $34,73 \%$ (nivel primario) y $53,52 \%$ (nivel inicial) y, el desempeño regular entre 7,04\% (nivel inicial) y $12,28 \%$ (nivel primario).

En los recursos y materiales, el desempeño satisfactorio de los profesores oscila entre 45,07\% (nivel inicial) y 49,13\% (nivel secundario), el desempeño muy satisfactorio entre $35,33 \%$ (nivel primario) y $49,30 \%$ (nivel inicial) y, el desempeño regular entre $5,63 \%$ (nivel inicial) y $14,07 \%$ (nivel primario).

El desempeño deficiente de los profesores de todos los niveles en cada una de las dimensiones no alcanza el $3 \%$.

\subsection{CONTRASTACIÓN ESTADISTICA DE LA HIPOTESIS DE INVESTIGACION}

\section{Hipótesis:}

La aplicación de la rúbrica influye positivamente en el desempeño docente de los profesores de la Provincia de Huancayo.

Esta hipótesis es contrastada con la prueba $Z$ de Gauss para una media en muestras grandes $(n>50)$ y la prueba chi cuadrada para la bondad de ajuste de una variable cualitativa con cuatro categorías en muestras grandes ( $n>50)$, al 95\% de confianza estadística.

Las estadísticas de prueba son las siguientes:

\section{a) $Z$ de Gauss}

1) Desempeño docente:

$$
Z=\frac{\bar{x}-90}{S / \sqrt{n}}
$$




\section{2) Dimensiones:}

$$
Z=\frac{\bar{x}-15}{S / \sqrt{n}}
$$

La variable aleatoria $Z$ tiene distribución normal estándar o tipificada; esto es, $\mathrm{Z}$ es $\mathrm{N}(0,1)$.

Aquí, $\bar{x}$ y $S$ es, respectivamente, la media y desviación muestral de las puntuaciones del desempeño docente o de sus dimensiones y, $\mathrm{n}$ es el número de profesores observados (tamaño de muestra). Los valores de 90 y 15 de la estadística $Z$ son las medias ideales 0 teóricas del desempeño docente y de cada una de las dimensiones (ver llamada (1)).

b) Chi cuadrada

$$
I=\sum \frac{\left(O_{i}-e_{i}\right)^{2}}{e_{i}}
$$

La variable $\mathrm{J}$ tiene distribución chi cuadrada con 3 grados de libertad.

Aquí, O $\mathrm{O}_{\mathrm{i}}$ y ei son, respectivamente, las frecuencias observadas y esperadas de la i-ésima categoría del desempeño docente o de sus dimensiones. Las frecuencias esperadas son iguales a:

$$
e_{i}=\frac{751}{4}=187,75
$$

\subsubsection{Contrastación estadística del Desempeño docente de los profesores.}

a) Prueba $Z$ de Gauss

Las hipótesis estadísticas nula Ho y alternativa Ha contrastadas son: 
Ho: La media del desempeño docente de los profesores de las IEPs de la Provincia de Huancayo es igual a 90 (Ho: $\mu=90)$.

Ha: La media del desempeño docente de los profesores de las IEPs de la Provincia de Huancayo es superior a 90 (Ho: $\mu>90)$.

Aquí $\mu$ es la media poblacional de las puntuaciones del desempeño docente.

\section{Gráfico № 31}

Prueba Z de Gauss para una media - Desempeño Docente

\begin{tabular}{|c|c|c|c|c|}
\hline \multicolumn{5}{|c|}{ Estadísticas descriptivas: } \\
\hline Muestra & Frecuencia & Media & Desviación típica & \\
\hline Tatal & 751 & 123,015 & 13,290 & \\
\hline \multicolumn{5}{|c|}{ Prueba Z para I muestra / prueba unilateral a la derecha: } \\
\hline Z (valar observada) & 68,059 & & & \\
\hline Z (valoг сгі́ticu) & $1,645^{3}$ & & & \\
\hline p-value unilateral & $<0,000 \mid$ & & & \\
\hline Alpha & 0,05 & & & \\
\hline \multicolumn{5}{|l|}{ Conclusión: } \\
\hline & & & & \\
\hline \multicolumn{5}{|c|}{ 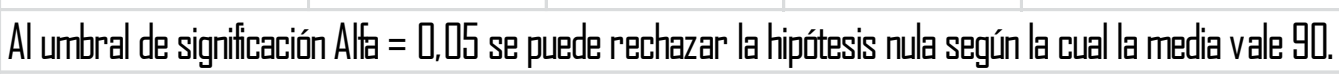 } \\
\hline \multicolumn{5}{|c|}{ 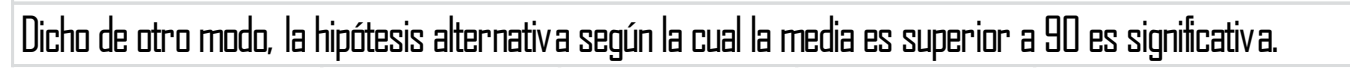 } \\
\hline
\end{tabular}

Fuente: Elaboración Propia.

El programa estadístico XIStat v.7.5.2 reporta los resultados en el gráfico 32. El valor calculado de la Z de Gauss $(68,059)$ es superior a su valor teórico $(1,64)$ y el valor $p$ ( $p$ value unilateral) $(<$ 0,0001 ) es inferior al nivel usual de significación de 0,05. Con estos resultados se rechaza la hipótesis nula Ho a favor de la hipótesis alternativa $\mathrm{Ha}$, concluyendo que la media del desempeño 
docente de los profesores de las IEPs de la Provincia de Huancayo es superior a 90 y, por tanto, la aplicación de la rúbrica influye positivamente en el desempeño docente de los profesores de la Provincia de Huancayo, con lo cual se comprueba la hipótesis de investigación.

\section{b) Prueba chi cuadrada.}

Las hipótesis estadísticas nula Ho y alternativa Ha contrastadas son:

Ho: Las proporciones de profesores de las IEPs de la Provincia de Huancayo con nivel deficiente, regular, satisfactorio y muy satisfactorio del desempeño docente son iguales $\left(\mathrm{Ho}_{\mathrm{o}} \pi_{1}=\pi_{2}=\right.$ $\pi 3=\pi 4)$

Ha: No todas las proporciones de profesores de las IEPs de la Provincia de Huancayo con nivel deficiente, regular, satisfactorio y muy satisfactorio del desempeño docente son iguales ( $\mathrm{Ha}: \pi_{\mathrm{k}} \neq \pi_{\mathrm{j}}, \forall \mathrm{i}<\mathrm{j}, \mathrm{i}=1,2,3 ; \mathrm{j}=2,3,4$ ).

Aquí, $\pi_{1}, \pi_{2}, \pi_{3}$ y $\pi_{4}$ son las proporciones poblacionales de profesores con un nivel deficiente, regular, satisfactorio y muy satisfactorio del desempeño docente, respectivamente.

El programa estadístico SPSS v.20 reporta los resultados en los cuadros 12 y 13. El valor calculado de la chi cuadrada $(591,61)$ es superior a su valor teórico $(7,815)$ y el valor $p$ ( $p$ value unilateral) $(0,000)$ es inferior al nivel usual de significación de 0,05. Con estos resultados se rechaza la hipótesis nula Ho a favor de la hipótesis alternativa $\mathrm{Ha}$, concluyendo que no todas las proporciones de profesores de las IEPs de la Provincia de Huancayo con nivel deficiente, regular, satisfactorio y muy satisfactorio del desempeño docente son iguales. Dado que la satisfacción y la alta satisfacción concentran las proporciones más altas (superiores a la cuarta parte o al $25 \%$ ), se concluye que la aplicación de la rúbrica influye positivamente en el desempeño 
docente de los profesores de la Provincia de Huancayo, con lo cual se comprueba la hipótesis de investigación.

\section{Cuadro $\mathrm{N}^{\circ} 13$}

Chi cuadrado del Desempeño Docente

\begin{tabular}{|l|r|r|r|}
\hline & N observado & N esperado & Residual \\
\hline Deficiente & 5 & 187,75 & $-182,8$ \\
Regular & 46 & 187,75 & $-141,8$ \\
Satisfactorio & 400 & 187,75 & 212,3 \\
Muy satisfactorio & 300 & 187,75 & 112,3 \\
Total & 751 & & \\
\hline
\end{tabular}

Fuente: Elaboración Propia.

\section{Cuadro $\mathrm{N}^{\circ} 14$ \\ Estadísticos de Contraste - Desempeño Docente}

\begin{tabular}{|l|r|}
\hline & Desempeño docente \\
\hline Chi-cuadrado $^{\mathrm{a}}$ & 591,961 \\
$\mathrm{gl}$ & 3 \\
Sig. asintót. &, 000 \\
\hline
\end{tabular}

a. 0 casillas $(, 0 \%)$ tienen frecuencias esperadas menores que 5 . La frecuencia de casilla esperada mínima es 187,75.

Fuente: Elaboración Propia.

\subsubsection{Contrastación estadística de las dimensiones del desempeño docente de los profesores.}

a) Prueba Z de Gauss.

Las hipótesis estadísticas nula Ho y alternativa Ha contrastadas son:

Ho: La media la dimensión $W$ del desempeño docente de los profesores de las IEPs de la Provincia de Huancayo es igual a 15 (Ho: $\mu=15)$.

Ha: La media de la dimensión $W$ del desempeño docente de los profesores de las IEPs de la Provincia de Huancayo es superior a $15(\mathrm{Ho}: \mu>15)$.

Aquí $\mu$ es la media poblacional de las puntuaciones de la dimensión W del desempeño docente. La dimensión W es: 
Planificación, metodología, evaluación, clima para el aprendizaje, tiempo en el aula y recursos.

Para la planificación, el programa estadístico XIStat v.7.5.2 reporta los resultados en el gráfico $\mathrm{N}^{\circ} 33$. El valor calculado de la $Z$ de Gauss $(52,419)$ es superior a su valor teórico $(1,64)$ y el valor p ( $p$ value unilateral) $(<0,0001)$ es inferior al nivel usual de significación de 0,05. Con estos resultados se rechaza la hipótesis nula $\mathrm{Ho}$ a favor de la hipótesis alternativa $\mathrm{Ha}$, concluyendo que la media de la dimensión planificación del desempeño docente de los profesores de las IEPs de la Provincia de Huancayo es superior a 15 y, por tanto, la aplicación de la rúbrica influye positivamente en la dimensión planificación del desempeño docente de los profesores de la Provincia de Huancayo, con lo cual se comprueba la hipótesis de investigación.

\section{Gráfico $N^{\circ} 32$}

\section{Prueba Z de Gauss para una media - Planificación}

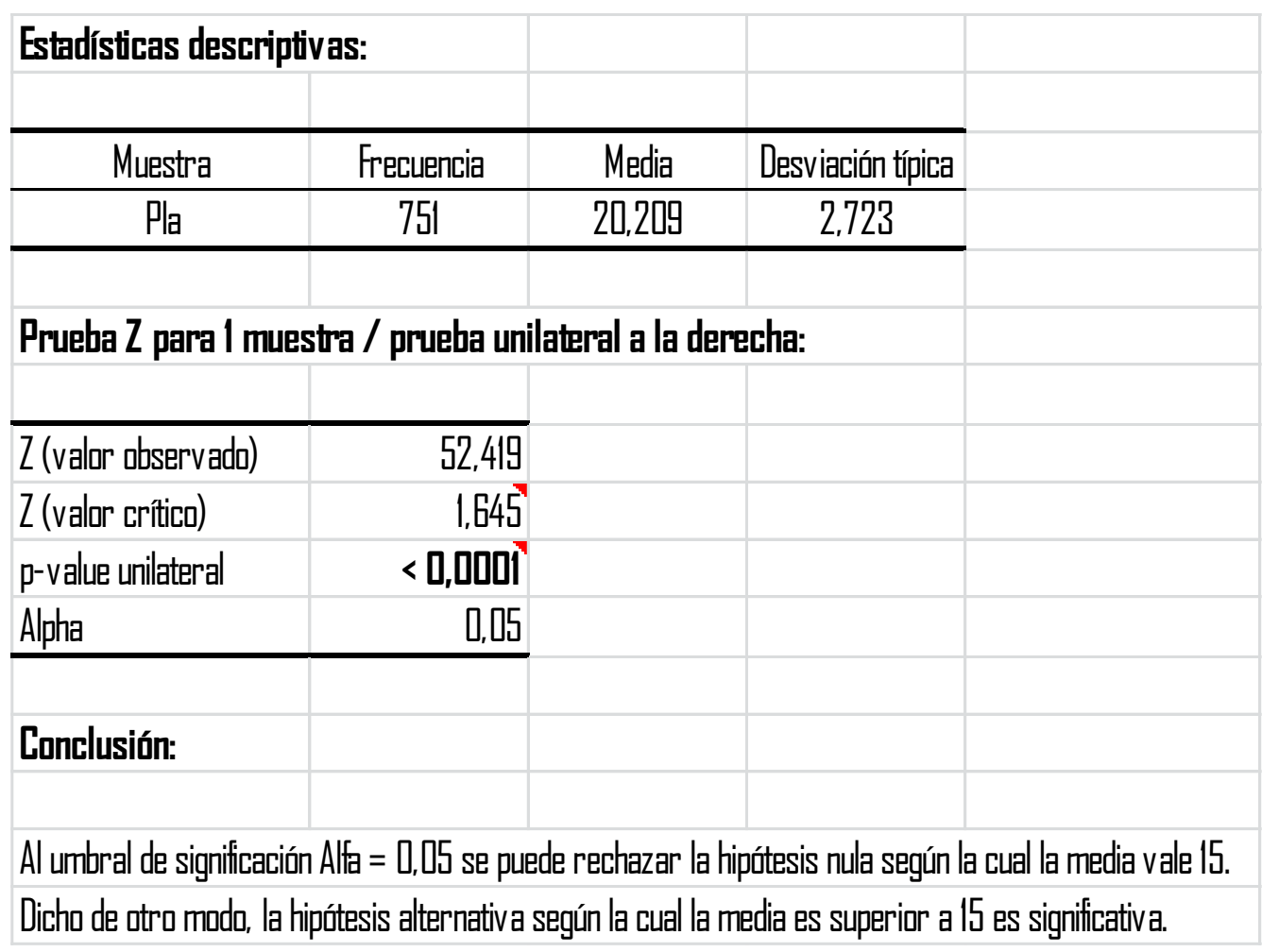


Fuente: Elaboración Propia.

Con el mismo procedimiento desarrollado para la planificación, en el cuadro $\mathrm{N}^{\circ} 15$ se presentan los valores calculados de la $Z$ de Gauss y sus valores $p$ respectivos para las otras dimensiones del desempeño docente, reportados por el XIStat.

\section{Cuadro $N^{\circ} 15$}

\section{Evaluación de la significación estadística de las medias de las dimensiones del desempeño docente}

\begin{tabular}{|l|c|c|c|}
\hline \multicolumn{1}{|c}{ Dimensión } & Z calculada & Valor $\mathbf{p}$ & Significación \\
\hline Planificación & 52,419 & 0,000 & $\mathrm{Si}$ \\
\hline Metodología & 53,738 & 0,000 & $\mathrm{Si}$ \\
\hline Evaluación & 51,417 & 0,000 & $\mathrm{Si}$ \\
\hline $\begin{array}{l}\text { Clima para el } \\
\text { aprendizaje }\end{array}$ & 64,772 & 0,000 & $\mathrm{Si}$ \\
\hline Tiempo en el aula & 56,077 & 0,000 & $\mathrm{Si}$ \\
\hline Recursos y materiales & 57,573 & 0,000 & $\mathrm{Si}$ \\
\hline
\end{tabular}

Ho: $\mu=15$; Ha: $\mu>15$

Fuente: Elaboración Propia.

En cada una de las dimensiones del desempeño docente, el valor calculado de la $Z$ de Gauss es superior a 1,64 y su valor $p$ respectivo inferior a 0,05 , con los cuales se rechazan las hipótesis nulas Ho a favor de las hipótesis alternas $\mathrm{Ha}$ respectivas, concluyendo que la media de cada una de las dimensiones del desempeño docente de los profesores de las IEPs de la Provincia de Huancayo es superior a $15 \mathrm{y}$, por tanto, la aplicación de la rúbrica influye positivamente en cada una de las dimensiones del desempeño docente de los profesores de la Provincia de Huancayo, con lo cual se comprueba la hipótesis de investigación. 


\section{b) Prueba chi cuadrada.}

Las hipótesis estadísticas nula $\mathrm{Ho}$ y alternativa $\mathrm{Ha}$ contrastadas son:

Ho: Las proporciones de profesores de las IEPs de la Provincia de Huancayo con nivel deficiente, regular, satisfactorio y muy satisfactorio de la dimensión $\mathrm{W}$ del desempeño docente son iguales (Ho: $\left.\pi_{1}=\pi_{2}=\pi_{3}=\pi 4\right)$.

Ha: No todas las proporciones de profesores de las IEPs de la Provincia de Huancayo con nivel deficiente, regular, satisfactorio y muy satisfactorio de la dimensión $W$ del desempeño docente son iguales (Ha: $\pi_{\mathrm{k}} \neq \pi_{\mathrm{j}}, \forall \mathrm{i}<\mathrm{j}, \mathrm{i}=1,2,3$; $j=2,3,4)$.

Aquí, $\pi_{1}, \pi_{2}, \pi_{3}$ y $\pi_{4}$ son las proporciones poblacionales de profesores con nivel deficiente, regular, satisfactorio y muy satisfactorio del desempeño docente, respectivamente. La dimensión W es: Planificación, metodología, evaluación, clima para el aprendizaje, tiempo en el aula y recursos.

Para la planificación, el programa estadístico SPSS v.20 reporta los resultados en los cuadros $N^{\circ} 16$ y 17 . El valor calculado de la chi cuadrada $(473,250)$ es superior a su valor teórico $(7,815)$ y el valor $p$ ( $p$ value unilateral) $(0,000)$ es inferior al nivel usual de significación de 0,05.

Con estos resultados se rechaza la hipótesis nula $\mathrm{Ho}$ a favor de la hipótesis alternativa $\mathrm{Ha}$, concluyendo que no todas las proporciones de profesores de las IEPs de la Provincia de Huancayo con nivel deficiente, regular, satisfactorio y muy satisfactorio de la dimensión planificación del desempeño docente son iguales.

Dado que la satisfacción y la alta satisfacción concentran las proporciones más altas (superiores a la cuarta parte o al 25\%), se concluye que la aplicación de la rúbrica influye positivamente en la dimensión planificación del desempeño docente de los 
profesores de la Provincia de Huancayo, con lo cual se comprueba la hipótesis de investigación.

\section{Cuadro $\mathrm{N}^{\circ} 16$}

\section{Prueba chi cuadrada para la igualdad de proporciones - Planificación}

\begin{tabular}{|l|r|r|r|}
\hline & Nobservado & N esperado & Residual \\
\hline Deficiente & 9 & 187,8 & $-178,8$ \\
Regular & 98 & 187,8 & $-89,8$ \\
Satisfactorio & 402 & 187,8 & 214,3 \\
Muy satisfactorio & 242 & 187,8 & 54,3 \\
Total & 751 & & \\
\hline
\end{tabular}

Fuente: Elaboración Propia.

\section{Cuadro $\mathrm{N}^{\circ} 17$}

\section{Estadísticos de contraste - Planificación}

\begin{tabular}{|l|r|}
\hline & Planif icación \\
\hline Chi-cuadrado $^{a}$ & 473,250 \\
gl & 3 \\
Sig. asintót. &, 000 \\
\hline
\end{tabular}

a. 0 casillas $(, 0 \%)$ tienen frecuencias esperadas menores que 5. La frecuencia de casilla esperada mínima es 187,8.

Fuente: Elaboración Propia.

Con el mismo procedimiento desarrollado para la planificación, en el cuadro $\mathrm{N}^{\circ} 18$, se presentan los valores calculados de la chi cuadrada y sus valores $p$ respectivos para las otras dimensiones del desempeño docente, reportados por el SPSS. 


\section{Cuadro $\mathrm{N}^{\circ} 18$}

\section{Evaluación de la significación estadística de las proporciones}

de las dimensiones del desempeño docente

\begin{tabular}{|l|c|c|c|}
\hline \multicolumn{1}{|c|}{ Dimensión } & $\begin{array}{c}\text { Chi cuadrada } \\
\text { calculada }\end{array}$ & Valor p & Significación \\
\hline Planificación & 473,250 & 0,000 & $\mathrm{Si}$ \\
\hline Metodología & 522,220 & 0,000 & $\mathrm{Si}$ \\
\hline Evaluación & 405,831 & 0,000 & $\mathrm{Si}$ \\
\hline $\begin{array}{l}\text { Clima para el } \\
\text { aprendizaje }\end{array}$ & 561,453 & 0,000 & $\mathrm{Si}$ \\
\hline Tiempo en el aula & 454,694 & 0,000 & $\mathrm{Si}$ \\
\hline $\begin{array}{l}\text { Recursos y } \\
\text { materiales }\end{array}$ & 469,277 & 0,000 & \\
\hline
\end{tabular}

SiHo: $\pi_{1}=\pi_{2}=\pi_{3}=\pi_{4} ; \mathrm{Ha}: \pi_{\mathrm{k}} \neq \pi_{\mathrm{j}}, \forall \mathrm{i}<\mathrm{j}, \mathrm{i}=1,2,3 ; \mathrm{j}=2,3,4$

Fuente: Elaboración Propia.

En cada una de las dimensiones del desempeño docente, el valor calculado de la chi cuadrada es superior a 1,64 y su valor $p$ respectivo inferior a 0,05 , con los cuales se rechazan las hipótesis nulas Ho a favor de las hipótesis alternas $\mathrm{Ha}$ respectivas, concluyendo que no todas las proporciones de profesores de las IEPs de la Provincia de Huancayo con nivel deficiente, regular, satisfactorio y muy satisfactorio de cada una de las dimensiones del desempeño docente son iguales. Dado que la satisfacción y la alta satisfacción concentran las proporciones más altas (superiores a la cuarta parte o al 25\%), se concluye que la aplicación de la rúbrica influye positivamente en cada una de las dimensiones del desempeño docente de los profesores de la Provincia de Huancayo, con lo cual se comprueba la hipótesis de investigación.

Con los resultados de las secciones 4.2 .1 y 4.2 .2 se comprueba la hipótesis de investigación, tanto a nivel cuantitativo (medias) y como a nivel cualitativo (proporciones de niveles). 


\section{CAPÍTULO V DISCUSIÓN}

\subsection{DISCUSIÓN DE RESULTADOS.}

Los resultados nos muestran que la rúbrica permite el desarrollo del desempeño docente en los profesores de la provincia de Huancayo de manera positiva.

La rúbrica está fundamentada en la teoría de la evaluación ya que logra el desempeño docente de los participantes de la provincia de Huancayo.

Además de acuerdo con los resultados obtenidos podemos decir que La rúbrica tiene influencia positiva en el desarrollo del desempeño docente de los profesores de la provincia de Huancayo, a su vez manifestamos que el trabajo de investigación coinciden con:

Torres, J. (2010) En la tesis de la Universidad de Sevilla-España podemos encontrar que la rúbrica supone -para el docente que la utiliza- una nueva forma de entender y de llevar a cabo los procesos de evaluación, a la vez que un mayor acercamiento por parte del estudiante a la función tutorial que éste desempeña.

Domínguez, M; Sánchez, L. y Aguilar, M, (2010) manifiestan en su tesis para la Universidad de del Estado de Morelos-México que: Se presenta una rúbrica para evaluar mapas conceptuales cuyo propósito es guiar la interpretación del docente en la evaluación de mapas conceptuales elaborados por alumnos universitarios a partir de la lectura de texto. 
Flores, F. (2009) En la Tesis doctoral de la Universidad Complutense de Madrid-España manifiesta que: Las competencias que los profesores de educación básica movilizan en su desempeño profesional docente. Universidad Complutense de Madrid, Facultad de Educación, Departamento de Psicología Evolutiva y de la Educación.

Cedeño, l. y otro (2008) mencionan que su trabajo de tesis, estuvo orientada a determinar el coaching como herramienta gerencial para optimizar el desempeño laboral del docente de la UNEFA, Núcleo Barquisimeto. Venezuela Este estudio se enmarcó en una investigación de campo, de modalidad descriptiva, cuyo objetivo se basó en determinar la situación actual del desempeño de los docentes y su conocimiento sobre las estrategias del coaching que pueden ser aplicables en el ámbito educativo. Para el análisis de resultados, se utilizó la estadística descriptiva.

Martínez, J. (2008) en la tesis de la Universidad Nacional de Colombia menciona que las rúbricas como instrumento de evaluación son perfectibles en tanto que las mismas constituyen una herramienta que se puede ir ajustando con la práctica hasta encontrar el valor justo de las metas de la evaluación a las cuales se espera llegar o se quiere que los estudiantes lleguen.

Alan, A. (2014) en la tesis: Desarrollo de un sistema de gestión de evaluaciones basadas en rúbricas en cursos de proyectos universitarios de una carrera acreditada. Facultad de Ciencias e Ingeniería de la Pontificia Universidad Católica del Perú, concluye: 1) Se ha logrado construir un sistema para la planificación y consolidación de las evaluaciones basadas en rúbricas para la especialidad de Ingeniería Informática.

Romero, A. (2014) en la tesis: Evaluación del desempeño docente en una red de colegios particulares de Lima. Escuela de Posgrado de la Pontificia Universidad Católica del Perú, concluye: 1) En todas las Sub - variables, tanto los directores como los alumnos expresaron que el desempeño de sus docentes es "Alto" (superior a 89). 
Esto indica que cuentan con docentes bien preparados y comprometidos con su labor pedagógica.

Flores, L. (2009) en la tesis: Rubrica para la evaluación de proyectos de tesis en Ingeniería Informática. Pontificia Universidad Católica del Perú. Facultad de Ciencias e Ingeniería. Especialidad de Ingeniería Informática. Concluye: La rúbrica abarca dos partes: la evaluación del informe escrito por el estudiante y su defensa oral del contenido del mismo ante un jurado designado. La rúbrica contiene una colección de indicadores de calidad asignados a cada aspecto relevante del proyecto para su evaluación, una escala numérica de valorización asociada a cada indicador, y una descripción de lo que implica cada número para cada indicador.

Mendoza, R. (2009) en la tesis: El coaching y su aplicación en la Institución Educativa № 14344 Silahua-Frias-Ayabaca-Piura. Concluye que: a) Las organizaciones e instituciones educativas necesitan gente que pueda pensar por sí misma, que sea responsable de todo lo que ocurre en su centro educativo porque así lo sienten, porque así lo desean. A su vez el coaching, ayuda a los docentes a mejorar sus destrezas de trabajo a través de elogios y retroalimentación positiva basado en observación.

Adriano, A. (2007) en la investigación "Clima organizacional y satisfacción laboral en las instituciones educativas del distrito de Satipo", concluye que: a) El clima organizacional y la satisfacción laboral en las instituciones educativas privadas es estable y persistente en las actividades y acciones que realizan los docentes en coordinación con los directivos a diferencia de las Instituciones Educativas públicas, el clima organizacional y la satisfacción es parcialmente estable; es decir, que la participación de los docentes en las diferentes actividades y acciones planificadas por la institución no es constante.

Cárdenas, J. (2011) en la tesis: Coaching y desempeño docente en la Provincia de Huancayo, de la Unidad de posgrado de la Facultad de Educación de la Universidad Nacional del Centro del Perú. Concluye: 
1) La aplicación del coaching tiene influencia positiva en el desarrollo del desempeño docente de los profesores de la Provincia de Huancayo.

Montalvo, M. (2008) en la tesis: Motivación y Desempeño Docente. Manifiesta que la motivación es el factor más importante del desempeño docente; lo que significa que el docente debe estar motivado psicológica, moral, económica, política, social y anímicamente para demostrar un desempeño docente pertinente y adecuado; esto se demuestra a partir de la experiencia de mejora de salarios de los docentes pertenecientes a la carrera pública magisterial que el Ministerio de Educación viene implementando con el proceso de nombramiento.

Salomé, R. (2008), en la tesis: El liderazgo estratégico del director y su relación entre el desempeño docente en instituciones educativas del distrito de San Agustín de Cajas.

Por lo mencionado manifestamos que la rúbrica tiene influencia positiva en el desarrollo del desempeño docente de los profesores de la Provincia de Huancayo.

\subsection{APORTES TEÓRICOS O METODOLÓGICOS.}

El trabajo de investigación da alcances significativos respecto a la rúbrica como la definición, aplicación, características, uso, ventajas y desventajas.

Además se proporciona información referente al desempeño docente en el contexto en el que nos ubicamos.

La metodología ha sido activa y muy productiva, ya que en el planteamiento que se ha realizado se ha aplicado y ejecutado de manera adecuada.

Además la aplicación de la rúbrica en el desarrollo del desempeño docente de los profesores de la Provincia de Huancayo es apl:- ${ }^{-h}$ 'e en nuestro medio.

Las características tiene la rúbrica en el desarrollo del desempeño docente de los profesores de la Provincia de Huancayo son: a) Sirve como un proceso de auto-evaluación en donde el estudiante puede apreciar su propio desempeño, b) Proporciona información para las distintas etapas del aprendizaje del alumno; c) Se supeditan a una serie 
de criterios dados por el profesor o en acuerdo profesor-alumno y d) Hace más fácil el proceso de evaluación.

Las ventajas que tiene la rúbrica en el desarrollo del desempeño docente de los profesores de la provincia de Huancayo: a) Promueve expectativas sanas de aprendizaje pues clarifica cuáles son los objetivos del docente y de qué manera pueden alcanzarlos los estudiantes y b) Reduce la subjetividad en la evaluación.

Las desventajas que tiene la rúbrica en el desarrollo del desempeño docente de los profesores de la provincia de Huancayo: a) Hace que su práctica incorrecta no logra el desarrollo de la atención, indagación, reflejo, afirmación y disciplina en el participante y b) Requiere mucho tiempo para su elaboración.

Las dimensiones de desarrollo del desempeño docente en los profesores de la provincia de Huancayo al aplicar la rúbrica son: a) Planificación, b) Metodología, c) Evaluación, d) Clima para el aprendizaje, e) Tiempo en el aula y f) Recursos y Materiales.

El nivel de desempeño docente de los profesores de la provincia de Huancayo después de la aplicación de la rúbrica son favorab'-

\subsection{APORTES INSTITUCIONALES O ADOPCIÓN DE DECISIONES.}

El uso de la rúbrica en las instituciones educativas tiene influencia positiva.

Se propone una rúbrica de autoevaluación del monitoreo, acompañamiento y supervisión de la sesión de clase como aporte institucional como aporte a la investigación científica, en especial a la educación. (Ver anexo). 


\section{CONCLUSIONES}

1. La aplicación de la rúbrica tiene influencia positiva en el desarrollo del desempeño docente de los profesores de la provincia de Huancayo.

2. Las características tiene la rúbrica en el desarrollo del desempeño docente de los profesores de la Provincia de Huancayo son: a) Sirve como un proceso de auto-evaluación en donde el estudiante puede apreciar su propio desempeño, b) Proporciona información para las distintas etapas del aprendizaje del alumno; c) Se supeditan a una serie de criterios dados por el profesor o en acuerdo profesor-alumno y d) Hace más fácil el proceso de evaluación.

3. Las ventajas que tiene la rúbrica en el desarrollo del desempeño docente de los profesores de la provincia de Huancayo: a) Promueve expectativas sanas de aprendizaje pues clarifica cuáles son los objetivos del docente y de qué manera pueden alcanzarlos los estudiantes y b) Rodine la subjetividad en la evaluación.

4. Las desventajas que tiene la rúbrica en el desarrollo del desempeño docente de los profesores de la provincia de Huancayo: a) Hace que su práctica incorrecta no logra el desarrollo de la atención, indagación, reflejo, afirmación y disciplina en el participante y b) Requiere mucho tiempo para su elaboración.

5. Las dimensiones de desarrollo del desempeño docente en los profesores de la provincia de Huancayo al aplicar la rúbrica son: a) Planificación, b) Metodología, c) Evaluación, d) Clima para el aprendizaje, e) Tiempo en el aula y f) Recursos y Materiales.

6. El nivel de desempeño docente de los profesores de la provincia de Huancayo después de la aplicación de la rúbrica son favorables. 


\section{RECOMENDACIONES}

1. Debe aplicarse la rúbrica en todos los centros educativos de nuestra región y así poder asumir actitudes distintas frente al desarrollo del desempeño docente.

2. A los docentes de las diferentes instituciones educativas se les sugiere que puedan aplicar la rúbrica en su aprendizaje, inclusive de sus materias como estrategia de aprendizaje.

3. A los docentes e interesados se sugiere la aplicación y utilización de metodología moderna y actualizada a los docentes debido a que si lo docentes se actualizan y están a la altura de la modernidad su trabajo será de manera más sencilla y útil para los alumnos.

4. A los investigadores en temas educativos y de evaluación, se les insta a aplicar el instrumento como heteroevaluación, para verificar si se : ' izan los mismos resultados.

5. A los directores de los centros educativos, sugerimos perfeccionar la supervisión educativa, mediante la evaluación del desempeño de sus docente en las dimensiones: a) Planificación, b) Metodología, c) Evaluación, d) Clima para el aprendizaje, e) Tiempo en el aula y f) Recursos y Materiales.

6. A los investigadores le sugerimos utilizar las ventajas que tiene la rúbrica en el desarrollo del desempeño docente de los profesores de la provincia de Huancayo: a) Promueve expectativas sanas de aprendizaje pues clarifica cuáles son los objetivos del docente y de qué manera pueden alcanzarlos los estudiantes y b) Reduce la subjetividad en la evaluación. 


\section{REFERENCIAS BIBLIOGRAFICAS}

Abrile, M. (1994) Nuevas demandas a la educación y a la institución escolar, y la profesionalización de los docentes. Revista Iberoamericana de Educación Número 5 Calidad de la Educación. Argentina.

Adriano, A. (2007) Clima organizacional y satisfacción laboral en las Instituciones Educativas del distrito de Satipo. Universidad Nacional del Centro del Perú.

Andrade, H. (2005) Teaching with rubrics. College Teaching. 53 pp.27.30.

Aylwin, M. (2001) Profesionalización docente y calidad de la educación. Santiago de Chile, 8 y 9 de mayo de 2001.

Blanco, A. (2008) Las rúbricas un instrumento útil en la evaluación de competencias. En la revista Tendencias actuales de la investigación educativa. Universidad de Barcelona.

Brewer, R. (1996) Ejemplares: Solución de un profesor. Underhill, VT: Ejemplares.

Brophy, J. (1986) En motivar a los estudiantes. Occasional Paper No. 101. East Lansing, Michigan: Instituto para la Investigación sobre la Enseñanza, Universidad Estatal de Michigan, octubre de 1986. .

Bujan, K., Rekalde, I., y Aramendi, P. (2011). Las rúbricas de evaluación en formación por competencias. Universidad del País Vasco.

Capote, S. y Sosa A. (2006) Evaluación, rúbrica y listas de control. s/e.

Cárdenas (2011) Coaching y desempeño docente en la Provincia de Huancayo, de la Unidad de posgrado de la Facultad de Educación de la Universidad Nacional del Centro del Perú.

Cárdenas y otros (2013) El Proyecto de Investigación. Para optar el título profesionales o los grados de Magíster y/o Doctor. Más Ciencia Editores. Huancayo. Perú.

Cardó, A. (2010) Buen desempeño profesional docente: Lineamientos preliminares. Presidente del Consejo Nacional de Educación. Mejores 
aprendizajes con buen desempeño docente en nuevas escuelas. Del Primer Congreso Pedagógico Nacional organizado por el Consejo Nacional de Educación.

Cedeño, I. y otro (2008) El coaching como herramienta gerencial para optimizar el desempeño laboral del docente de la Universidad Nacional Experimental de las Fuerzas Armadas (UNEFA) Nucleo Barquisimeto, Estado Lara. Venezuela

Conteras, W. (2008) Sistema de rúbricas para la evaluación de habilidades y actitudes en la enseñanza del diseño. Facultad de Educación y Humanidades. Universidad del Bío Bío.

Contreras, W. (2001). Experiencias en evaluación, auto-evaluación y coevaluación en la enseñanza de una asignatura de Diseño. IX Encuentro Nacional de Informática y Computación en Educación, 1 al 3 de agosto. Santiago: Universidad de las Américas.

Damián, L. (2007) Evaluación de capacidades y valores en la sociedad del conocimiento. Editorial Norma. Perú. 2007.

Díaz, F. (2005). Enseñanza situada: Vínculo entre la escuela y la vida. México: McGraw Hill.

Díaz, F., y De la Cruz, G. (2011). Rúbricas en la evaluación de competencias y aprendizaje complejo. Alcances y restricciones en educación superior. Universidad Nacional Autónoma de México.

Domínguez, M; Sánchez, L., Aguilar, M, (2010) Rúbrica con sistema de puntaje para evaluar mapas conceptuales de lectura de comprensión. Universidad Autónoma del Estado de Morelos, México.

Flores, F. (2009) Las competencias que los profesores de educación básica movilizan en su desempeño profesional docente. Universidad Complutense de Madrid, Facultad de Educación, Departamento de Psicología Evolutiva y de la Educación.

Flores, L. (2009) Rubrica para la evaluación de proyectos de tesis en Ingeniería Informática. Tesis. Pontificia Universidad Católica del Perú. Facultad de Ciencias e Ingeniería. Especialidad de Ingeniería Informática.

Frola, P. y Velasquez, J. (2011) Competencias docentes para la evaluación cualitativa del aprendizaje. Centro de Investigación Educativa y Capacitación Institucional S.C. México D.F. 
Fuchs, R. (1997) Psicología y la actividad física: una base para las intervenciones basadas en teoría. Universidad de Friburgo. Suiza.

Gallardo, C. (2010) Los buenos desempeños docentes desde el colegio de profesores del Perú. CPP.

Hernández, C. (2009) Aproximaciones a la Discusión sobre el Perfil del Docente. II Seminario Taller sobre perfil docente y estrategias de formación. Países de Centroamérica, El Caribe, México, España y Portugal. San Salvador, El Salvador.

Hernández, R. y otros (2013) Metodología de la investigación. Editorial Mc Graw Hill. Interamericana. Editores S.A. de C.V. Segunda Edición. México.

Jonsson, A., y Svingby, G. (2007) The use of rubrics: realibility, validity and educational consequences. Educational Research Review, 2. Pp. 130.140.

López, B, e Hinojosa E. (2000). Evaluación del aprendizaje. Alternativas y nuevos desarrollos. Editorial Trillas, México.

López, M. (2007) Innovación educativa. Guía básica para la elaboración de rúbricas. Universidad Iberoamericana Puebla. México.

Marcelo, C. (2006). La formación docente en la sociedad del conocimiento y la información: avances y temas pendientes. Ponencia presentada al IV Encuentro Internacional de KIPUS. Políticas públicas y formación docente (Venezuela, 4-6 de octubre, 2006

Martínez, J. (2008) Las rúbricas en la evaluación escolar: su construcción y su uso. Universidad Nacional de Colombia. Avances en Medición. Didáctica.

Marzano, R., Pickering D., y J. Mctighe (1993). Evaluación de Resultados de los Alumnos:. Evaluación del Desempeño de Uso de las Dimensiones del aprendizaje Modelo Alexandria.

Mateo, J. (2000) La evaluación educativa, su práctica y otras metáforas. Barcelona. Ed. Horsori.

Mateo, J.; Escudero, T.; De Miguel, M.; Mora, J. y Rodríguez S. (1996). "La Evaluación del profesorado. Un tema a debate". Revista de Investigación Educativa. 14, 2, 73-94. 
Mendoza, R. (2009) El coaching y su aplicación en la Institución Educativa № 14344 Silahua-Frias-Ayabaca-Piura. Tesis.

Messina, G. (2001) "La formación docente para la educación de jóvenes y adultos". Perspectivas y debate". Panel de especialistas. Buenos Aires. Noviembre.

Ministerio de Educación de Chile. MED-CHILE (2001) Estándares de desempeño para la formación inicial de docentes. División de Educación Superior. Programa de Fortalecimiento de la Formación Inicial docente.

Ministerio de Educación del Perú MED-PERU (2011) Sistematización del Plan Piloto de Evaluación del Desempeño Docente. USAID - PERU - SIMA.

Miranda, R; Ragni, M, Salas, O (2007) La Evaluación del Desempeño Docente y su Impacto en el Mejoramiento de la Calidad de la Educación.

Montalvo, M. (2008) Motivación y Desempeño Docente. Unidad de posgrado de la Facultad de Educación. Universidad Nacional del Centro del Perú.

OREALC-UNESCO. (2007). Educación de calidad para todos: un asunto de derechos humanos. Santiago de Chile: OREALC-Unesco. Documento de discusión sobre políticas educativas en el marco de la II Reunión Intergubernamental del Proyecto Regional de Educación para América Latina y el Caribe (EPT/ PRELAC) 29 y 30 de marzo de 2007; Buenos Aires, Argentina

PRONAFCAP (Programa de formación y capacitación permanente) (2009). Ministerio de Educación. Ficha de monitoreo al docente.

Proyecto Educativo Nacional (2009) al 2021. La educación que queremos para el Perú. Consejo Nacional de Educación.

Rimari, W. (2008). La rúbrica un innovador y eficaz instrumento de evaluación. Revista pedagógica del maestro peruano San Jerónimo.

Rolf, A (2006). Desarrollo de la Calidad Pedagógica y Profesionalidad del Docente Modulo I. Tegucigalpa, Honduras: Lopez (UPNFM), Virna, Carcamo (UMH), Carmen, Naira, Martha, Pineda (UNITEC), Irma.

Romero, A. (2014) Evaluación del desempeño docente en una Red de Colegios Particulares de Lima. Escuela de posgrado. Pontificia Universidad Católica del Perú. 
Rowe, A. (2010) Inteligencia Creativa: Descubrir el potencial innovador en nosotros mismos y otros Rústica: 192 páginas. Editorial: FT Press, una edición (28 de noviembre de 2008)

Salomé, R (2008), El liderazgo estratégico del director y su relación entre el desempeño docente en instituciones educativas del distrito de San Agustín de Cajas. Universidad Nacional del Centro del Perú. Unidad de posgrado de la Facultad de Educación.

Sánchez, H. y Reyes, C. (2009) Metodología y diseños en la investigación científica. Universidad Ricardo Palma. Lima Perú.

Sarmiento (2010) Supervisión Educativa y Desempeño Docente en educación media técnica del Municipio Escolar de San Francisco II del Estado de Zulia. Universidad Rafael Urdaneta. Maracaibo. Venezuela.

Simon, M. y Forgette, R. (2001) A rubric for scoring postsecondary academic skills. Practical Assessment, Research \& Evaluation, 7.

Stevens, D. y Levi, A. (2012) Introducción a las rúbricas: Una herramienta de evaluación para ahorrar tiempo de clasificación, transmitir efectiva retroalimentación, y promover el aprendizaje de los estudiantes. Sterling, VA: Stylus Publishers.

Stufflebeam, D. y Shinkfield, A. (1995). Evaluación sistemática - Guía teórica y práctica. España: Centro de Publicaciones del Ministerio de Educación y Ciencia, Ediciones Paidós Ibérica.

Torres, J. (2010) La rúbrica como instrumento pedagógico para la tutorización y evaluación de los aprendizajes en el foro online en educación superior Universidad de Sevilla. España.

Vilcatoma, A. (1998). Estadística Aplicada a la Pedagogía. Fondo Edito-rial F.P.H. Huancayo-Perú.

Wilson, J. (1992) Cómo valorar la calidad de la enseñanza, Barcelona: Paidós/MEC.

Woolfolk, A (1999). Psicología Educativa (7 Edición). México: Prentice Hall.

Zabalza, M. (1991); Técnicas para la evaluación del desempeño: Mapas Mentales. Solución de problemas. Método de casos. Proyecto Diario. Debate. Ensayos. Técnica de la Pregunta. Portafolios.

Zazueta, M. y Herrera, L (2008) Rúbrica o matriz de valoración, herramienta de evaluación formativa y sumativa. Universidad de Campeche - México. 
Zazueta, M. y Herrera, L (2008) Rúbrica o matriz de valoración, herramienta de evaluación formativa y sumativa. Universidad de Campeche - México.

\section{DIRECCIONES EN INTERNET}

Anónimo (2009). El Rol Del Maestro 2. Consultado en Marzo, 18,2009 en http://www.scribd.com/doc/12802559/el-rol-delmaestro-2.

Fernández, J. (s/f/) Matriz de competencias del docente de Educación Básica. Caracas: Universidad Politécnica Antonio José de Sucre. Recuperado el 13-04-2015

de: <http://www.rieoei.org/investigacion/939Fernandez.PDF>.

Goodrich, H. (2008) Categorías comprensión. http://learnweb.harvard.edu/alps/thinking/docs/rubricar.htm.

Rodríguez, B (2008) Las rúbricas, matrices de evaluación. Recuperado el 11 04-2015 de http://rubricasrodriguez.blogspot.com/2012/07/las-rubricasmatrices-de-evaluacion.html

Valdez, H. (2000) Desarrollo escolar: Evaluación del desempeño docente en (documento en línea). Disponible: http://www.oei.es/de/rifad/o.htm.(consulta.2007,abril)

Vera L. (2008). La rúbrica y la lista de cotejo. Departamento de educación y Ciencias Sociales., Universidad Interamericana de Puerto Rico., Recinto de Ponce. Recuperado de http://www.tecnoedu.net/lecturas/materiales/lectura10.pdf

Wikipedia (s/a) La rúbrica. Recuperado el día 29 de octubre de 2013 de: http://es.wikipedia.org/wiki/R\%C3\%BAbrica

¿Qué es una rúbrica?: http://platea.pntic.mec.es/ erodri1/TALLER.htm\#Rúbricas

EDUTEKA. Matriz de Valoración. Rúbricas. http://www.eduteka.org/MatrizValoracion.php3.

Ejemplos de Rúbricas para evaluar Arte: http://www.fm.coe.uh.edu/resources_span/furniture/furniture_rubric.html http://platea.pntic.mec.es/ erodri1/TALLER.htm\#Rúbricas

http://www.pucpr.edu/facultad/ejaviles/ED\%20630\%20PDF\%20Files/R\%C3\%B Abrica\%20Evaluar\%20Modelo\%20de\%20Evaluaci\%C3\%B3n\%20Curricu lar.doc

RubiStar es una herramienta gratuita que ayuda a los educadores a crear rúbricas de calidad:

http://rubistar.4teachers.org/index.php?skin=es\&lang=es

Rubrica para evaluar modelo de evaluación curricular: http://rubistar.4teachers.org/index.php?skin=es\&lang=es

www.upsp.edu.pe/descargas/Docentes/Antonio/archivos/tempo/apuntevaluacio n.doc - 
ANEXOS 
MATRIZ DE CONSISTENCIA

\begin{tabular}{|c|c|c|c|}
\hline \multicolumn{2}{|l|}{ TíTULO } & \multicolumn{2}{|c|}{$\begin{array}{l}\text { RÚBRICA Y DESEMPEÑO DOCENTE } \\
\text { EN LA PROVINCIA DE HUANCAYO }\end{array}$} \\
\hline \multicolumn{2}{|l|}{ PROBLEMA } & \multirow{2}{*}{\multicolumn{2}{|c|}{$\begin{array}{c}\text { ¿Cuál es la influencia de la aplicación de la rúbrica en el desarrollo del } \\
\text { desempeño docente de los profesores de la provincia de Huancayo? } \\
\text { Determinar la influencia de la aplicación de la rúbrica en el desarrollo } \\
\text { del desempeño docente de los profesores de la provincia de } \\
\text { Huancayo. }\end{array}$}} \\
\hline & & & \\
\hline OBJETIVOS & & \multicolumn{2}{|c|}{$\begin{array}{l}\text { 1. Identificar las características que tiene la rúbrica en el desarrollo } \\
\text { del desempeño docente de los profesores de la provincia de } \\
\text { Huancayo. } \\
\text { 2. Establecer ventajas y desventajas que tiene la rúbrica en el } \\
\text { desarrollo del desempeño docente de los profesores de la provincia } \\
\text { de Huancayo. } \\
\text { 3. Establecer el nivel de desempeño docente de los profesores de la } \\
\text { provincia de Huancayo después de la aplicación de la rúbrica. } \\
\text { 4. Establecer indicadores de desarrollo del desempeño docente de los } \\
\text { profesores de la provincia de Huancayo al aplicar la rúbrica. } \\
\text { 5. Conocer los resultados al analizar e interpretar los datos obtenidos } \\
\text { del desempeño docente en después del experimento. }\end{array}$} \\
\hline \multicolumn{2}{|l|}{ HIPÓTESIS } & \multicolumn{2}{|c|}{$\begin{array}{l}\text { La aplicación de la rúbrica tiene influencia positiva en el desarrollo del } \\
\text { desempeño docente de los profesores de la Provincia de Huancayo. }\end{array}$} \\
\hline \multicolumn{2}{|l|}{$m$} & \multicolumn{2}{|l|}{ Aplicativo. } \\
\hline \multirow{2}{*}{\multicolumn{2}{|c|}{$\begin{array}{l}\text { MÉTODO Y } \\
\text { DISEÑO }\end{array}$}} & & Diseño de un solo grupo solo después \\
\hline & & $\begin{array}{l}\text { Científico, como método } \\
\text { general. Descriptivo, } \\
\text { experimental y estadístico } \\
\text { como métodos } \\
\text { específicos. }\end{array}$ & $\begin{array}{l}\text { Donde: } \\
X \quad \text { Es el experimento. (rúbrica) } \\
0 \quad \text { Observación }\end{array}$ \\
\hline \multicolumn{2}{|l|}{ VARIABLES } & \multicolumn{2}{|c|}{$\begin{array}{l}\text { - Variable independiente: Rúbrica. } \\
\text { - Variable dependiente: Desarrollo del desempeño docente. }\end{array}$} \\
\hline \multirow{2}{*}{\multicolumn{2}{|c|}{$\begin{array}{l}\text { POBLACIÓN } \\
\text { MUESTRA }\end{array}$}} & & \\
\hline & & \multicolumn{2}{|r|}{ de la provincia de Huanc } \\
\hline \multirow{2}{*}{\multicolumn{2}{|c|}{$\begin{array}{l}\text { TÉCNICAS E } \\
\text { INSTRMENTOS DE } \\
\text { RECOLECCIÓN } \\
\text { DE DATOS }\end{array}$}} & \\
\hline & & $\begin{array}{l}\text { Fichas bibliográficas } \\
\text { Observación } \\
\text { Evaluación educativa }\end{array}$ & $\begin{array}{l}\text { Fichas: resumen, trascripción } \\
\text { y bibliográficas } \\
\text { Pruebas pedagógicas }\end{array}$ \\
\hline \multicolumn{2}{|l|}{$\begin{array}{l}\text { PROCESAMIENTC } \\
\text { DE DATOS }\end{array}$} & \multicolumn{2}{|c|}{$\begin{array}{l}\text { Medidas de tendencia central (Media aritmética, moda, } \\
\text { mediana, desviación típica y desviación Standard) Estadística } \\
\text { inferencial. }\end{array}$} \\
\hline
\end{tabular}

